\title{
THE CLARINET AS EXTENSION OF THE VOICE AND EXPRESSIVE CONDUIT OF \\ MUSICAL STYLES IN DIVERSE
}

\section{ENSEMBLES}

\author{
by \\ Lucy Rainey
}

\author{
A thesis \\ Submitted for the Victoria University of Wellington \\ in fulfilment of the requirements for the degree of \\ Master of Musicology \\ 2011
}

New Zealand School of Music

Wellington

New Zealand 


\section{TABLE OF CONTENTS}

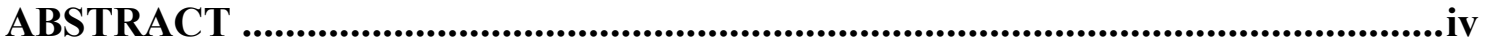

ACKNOWLEDGEMENTS .......................................................................................v

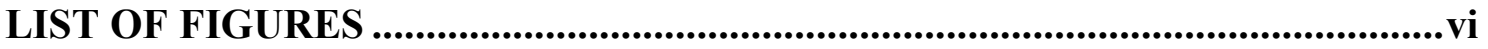

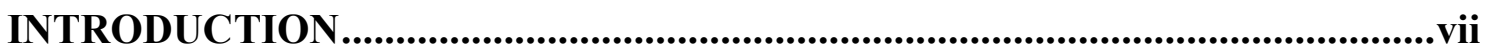

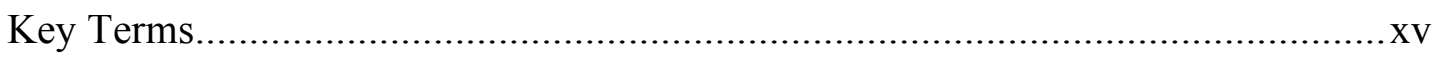

CHAPTER ONE: The Clarinet as Extension of the Voice........................................1

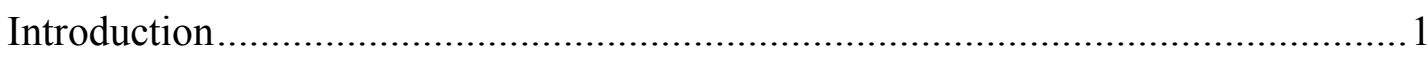

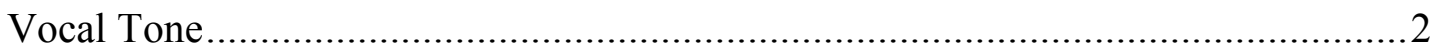

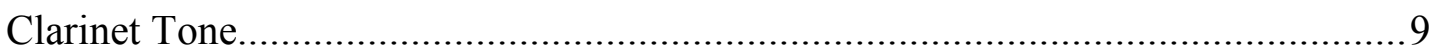

Vocal and Clarinet Tone Comparisons............................................................. 16

Clarinet Construction and Historical Development .............................................24

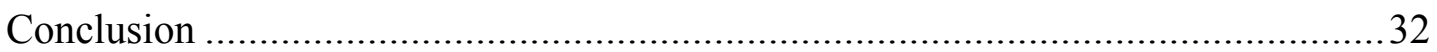

CHAPTER TWO: Case Studies of Four Clarinettists in Wellington .....................34

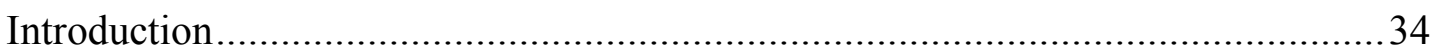

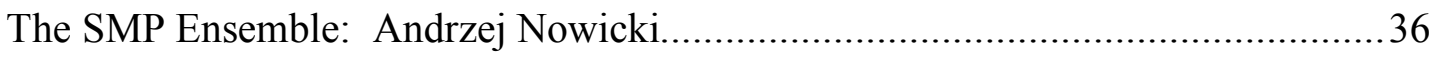

The New Zealand Clarinet Quartet: Debbie Rawson ..........................................4 46

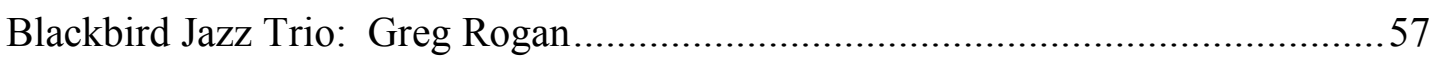

The Klezmer Rebs: Urs Signer ..................................................................6 67

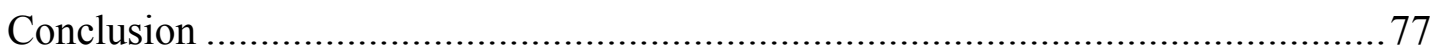

CHAPTER THREE: Voice and Clarinet Identity ............................................8

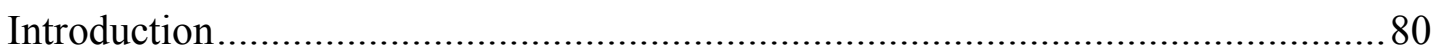

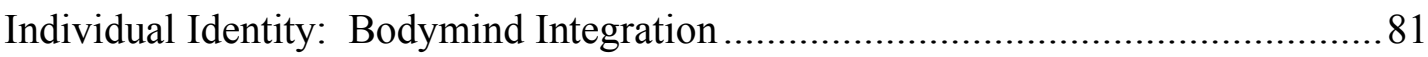

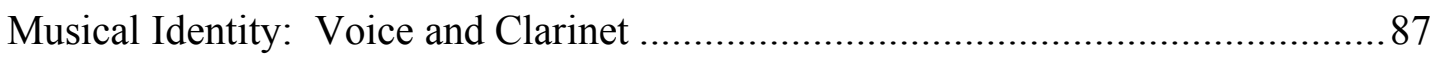

Ensemble Identity: The 'Vocal' Clarinettist ......................................................... 94

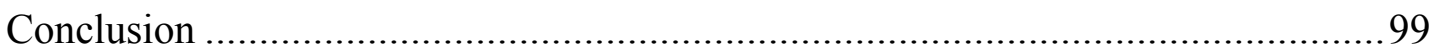

CHAPTER FOUR: Clarinettists as Conduits of Musical Styles ..........................101

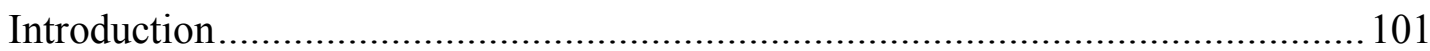

Clarinettists Transcend Boundaries: Gender, Ethnicity, Ensemble ...................... 102

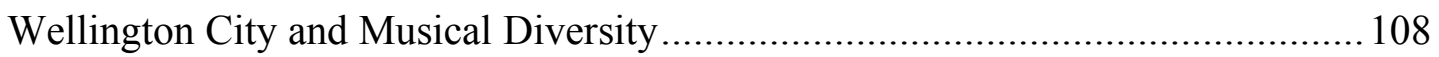

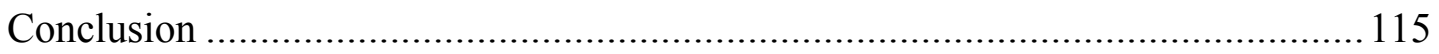




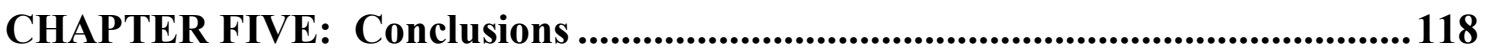

Appendix A..................................................................................................................... 124

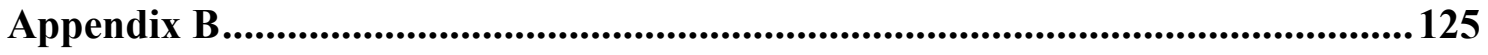

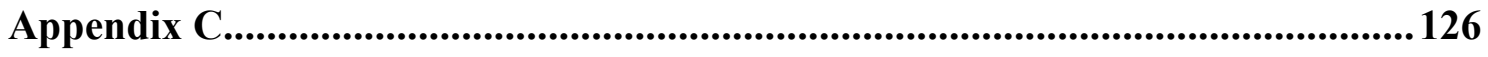

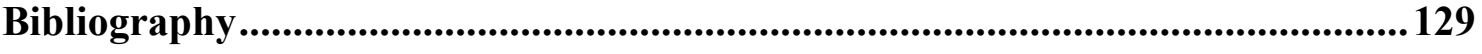




\begin{abstract}
Original research into the links between vocal and clarinet tone reveals how clarinettists act as expressive conduits of musical styles in diverse ensembles. This research is relevant to musicologists and anthropologists as well as clarinettists and composers, who wish to gain an understanding of the vocal links in clarinet playing, and how clarinettists function in socio-musical contexts. Research is mainly based on Musicology and Music Education (vocal-clarinet links), and also refers to sources in Anthropology (musical identity), and Ethnomusicology (music in ensembles) in order to find some insightful connections. Ethnographic fieldwork is based on four professional freelance clarinettists in four different ensembles in Wellington, New Zealand. Their function in western art and contemporary art music, jazz and klezmer music is explored, to discover how these clarinettists extend, mirror, partner, or replace the voice in these musical contexts. Additional work undertaken on bodymind integration is designed to complement the musical identity work in the thesis and to enhance the musicianship and physical wellbeing of clarinettists. The section on clarinet design illustrates how different combinations of instruments and mouthpieces can vary the tone quality of the clarinet and enhance individual playing styles. The research shows that due to the versatility and flexibility of the instrument, clarinettists are able to transcend gender, ethnic, and ensemble boundaries, to take on leadership roles and to act as expressive conduits of musical styles in and between diverse ensembles. The outcome of the research highlights the intersection between the physiological relationship between the voice and the clarinet and scholarship on musical identity.
\end{abstract}




\section{ACKNOWLEDGEMENTS}

I would like to warmly thank the four professional clarinettists in the case studies: Andrzej Nowicki, Deborah Rawson, Greg Rogan and Urs Signer, and the members of their various ensembles. I appreciate them advising me of their rehearsal and performance dates, for giving me insightful interviews and for answering many detailed questions as the thesis developed.

Special thanks go to my main supervisor Brian Diettrich who spent many hours discussing my thesis concepts, advising me on reference material, and editing my work in a thoughtful and encouraging way. My thanks also go to Donald Maurice for his initial encouragement to embark on this research, and his helpful feedback in a cosupervisory role. Thanks also to members of the New Zealand School of Music academic and administrative music staff for their ongoing support in my research.

Finally love and thanks to my husband Bill, and my adult children Daniel and Genevieve, who have challenged and supported me in my research, and who provide my musical inspiration. 


\section{LIST OF FIGURES}

Figure 1: Vocal Subsystems: Air Pressure, Vibratory and Resonating Systems.............3

Figure 2: Neocortex Messages to Larynx via Laryngeal Nerves ................................ 4

Figure 3: Larynx Cartilage and Muscles ..................................................................

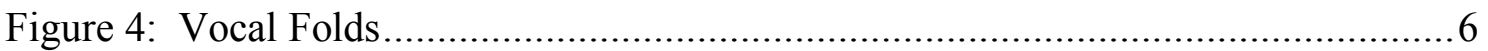

Figure 5: Head and Neck Resonators and Articulators in Vocal Production..................7

Figure 6: Concertina $5 b$ by Andrzej Nowicki and Richard Robertshawe ....................38

Figure 7: The SMP Ensemble in Waipoua Forest by Gareth Farr ............................. 41

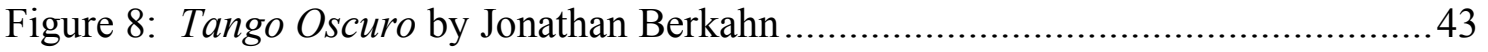

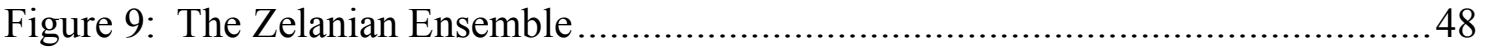

Figure 10: The New Zealand Clarinet Quartet ......................................................51

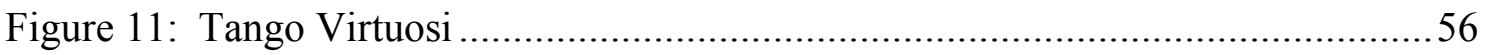

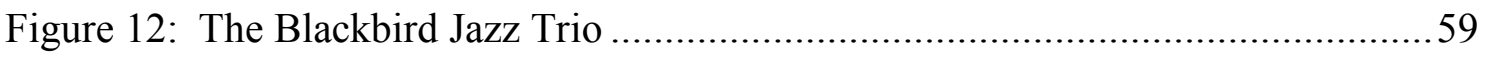

Figure 13: The Blackbird Jazz Trio at the Old Government Buildings, 2008 ..............62

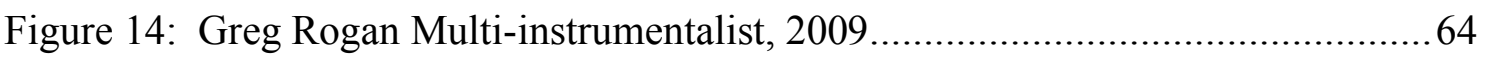

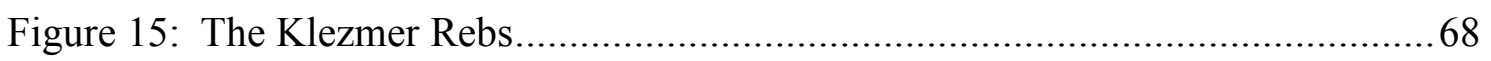

Figure 16: The Klezmer Rebs at the Palmerston North City Library, 2010 .................71

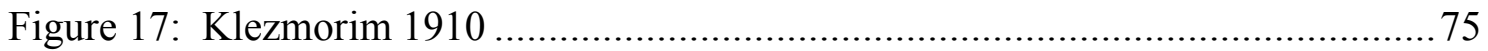




\section{INTRODUCTION}

For as long as I can remember I have been listening to the sound of the clarinet, first hearing the velvet tones of Antoine de Bavier playing Mozart's Clarinet Quintet with the Quartetto Italiano as an infant, then playing my first clarinet as a child. As well as gaining experience in orchestral, chamber music, and jazz clarinet styles, I became fascinated with singing, taking lessons and singing in choral and jazz ensembles. It became clear to me that the clarinet acts as an extension of the voice in a myriad of contexts from classical and contemporary art music, to klezmer, tango, folk and jazz musical styles. My most recent experience of this vocal-clarinet link was earlier this year, as I accompanied my daughter Genevieve who sang a Schubert Romanze (Die Verschworenen), in which the clarinet partnered and extended the vocal line throughout the piece.

The research aim of this thesis is to discover whether the links between vocal and clarinet tone reveal that clarinettists act as expressive conduits of musical styles in diverse ensembles. My methodology includes researching four case studies: clarinettists who perform in four stylistically different ensembles, western art and contemporary art music, klezmer and jazz, as discussed in Chapter Two.

Interdisciplinary research in physiology, musicology, music education, anthropology and ethnomusicology is undertaken to establish the existence of vocal-clarinet links and how they might affect the clarinettists' roles. In researching physiological and psychological integration (bodymind) my aim is to establish that the voice is an individual autobiography of the body and the primal sound of an individual's musical identity. My intention is to prove that clarinettists are able to extend their own voices by playing the clarinet and also by choosing specific clarinets and mouthpieces to highlight their preferred individual sound quality. Further to this I hope to establish that 
the clarinettist has the ability to play in a myriad of different musical styles so that they meld their personal sound with the ensemble style. For example, Urs Signer a clarinettist in the case studies, sounds like an expressive klezmer clarinettist, and yet to other clarinettists musicians in his ensemble and his audience, he still sounds like Urs and not like the well-known klezmer player Giora Feidman, because of his individual tone and phrasing nuances.

Although a discussion based on cultural vocality belongs in future research and not within the scope of this thesis based on the clarinet, I will briefly mention some of the relevant issues here. By researching the voice as 'vocality' it becomes a cultural construct reflecting the attributes of the culture it functions in. The voice, says Middleton, is 'the profoundest mark of the human...this is because vocalising is the most intimate, flexible and complex mode of articulation of the body [and] is fundamental to the creation of human societies' (Middleton 1990: 262). It can be observed that infants and children in all cultures learn to use their voices in individually unique but also culturally grounded ways. In order to appreciate the complexity of vocality in different cultures and ensembles we need to consider vocal attributes such as: timbre, inflection, resonance, nasality, pitch and micro-pitch intonation, pitch range, vibrato, language, accents, vowel sounds, interjections, percussive and guttural effects, melisma, falsetto, improvisation, ornamentation rhythmisation, laughing, sighing, wailing, sobbing, whispering, use of head and chest registers and declamatory and legato styles of voice production. Each culture chooses particular vocal attributes, language and specific phrasing for expressive purpose within that culture. Choral ensembles within each culture also have their own clear performance expectations for part division, harmony, volume and tone colour. Clayton Parr comments that the root of the word "culture" is the Greek word kultus, meaning "belief", and that in 
multicultural musical contexts these beliefs influence things such as what constitutes good singing technique and a good musical arrangement, the proper time and place to perform a certain piece, who should sing a certain piece, and other issues of performance practice, language and even religious beliefs' (Parr 2006:34). In this thesis the four singers in the case studies perform the appropriate vocality in western art and contemporary music, klezmer and jazz ensembles as discussed in Chapter Two. From this brief discussion it is evident that extensive future research into specific aspects of cultural and cross-cultural vocality including the concepts of fusion, appropriation, representation and hybridity would yield fascinating results.

As the vehicle for language and song, the human voice has enormous potential for natural expression. Song operates at a 'pre-linguistic' level, with the ability to connect at a deep and powerful level with people and to influence their emotions and attitudes. The acoustic properties of the clarinet allow it to replicate many aspects of the human voice, which as Jack Brymer comments are 'acoustic differences which have always set it apart and made its voice unique' (Brymer 1976: 8). As a versatile, resonant and 'multi-voiced' instrument, the clarinet has the ability to act as an extension of the voice and conduit for expression in orchestral, operatic, klezmer, jazz, folk, and contemporary styles in many different countries.

It could be argued that many other musical instruments are also capable of imitating the voice, in particular the other members of the woodwind family. These instruments however, tend to have a homogenous tone quality across their entire range, and as they have either no mouthpiece or very little in the mouth, the effects of the vocal tract, the pharynx and the shape of the oral cavities are far more limited than they are in clarinet playing. The clarinet has an heterogeneous tone quality which embodies three distinct 'voices' and a register break similar to the soprano voice, and the position 
of the clarinet mouthpiece between the bottom lip and top teeth means that the player feels the vibrations in the soft tissues and bones of their heads, in the same way that singers do. I support the view that woodwind, string and brass instruments are all capable of producing particular vocal qualities, but in this thesis I explain why the clarinet has the closest links to the voice, why composers and instrument makers have always recognised this quality, and how this vocal-clarinet link affects the life of the professional clarinettist in their various ensembles.

Before embarking on this thesis I had read about the theoretical links between the voice and the clarinet as discussed by various virtuoso clarinet authors, but there had been no specific research into this topic to substantiate the theory. My initial aim was to understand the specific physiological processes of both vocal and clarinet tone production to find a connection between the two (vocal-clarinet links). The next step was to combine these physiological vocal-clarinet links with the psychological aspects of musical identity to assess the ways in which clarinettists express themselves in ensembles. I based the majority of my research on Musicology and Music Education (vocal-clarinet links), later referring to sources in Anthropology (musical identity), and Ethnomusicology (music in ensembles) in order to find some insightful connections.

The impetus for the research came from reading several books by respected clarinet virtuoso performers and teachers on the connections between the voice and the clarinet. These included Jack Brymer, Eric Hoeprich, Keith Stein, Anthony Pay, Nicolas Cox, Roger and Chris Heaton, and Stephen Cottrell and Evangelina Mantzourani. In Jack Brymer's book Clarinet, one of the celebrated Yehudi Menuhin Teaching Guides, he discusses the clarinet's history and development, acoustic characteristics, design aspects, artistic approach, pedagogy and repertoire from a personal and vastly experienced musical perspective. Throughout the book Brymer 
makes many comments about the close relationship between the voice and the clarinet in its inherent design, and its practical use in orchestral or chamber music ensembles, (Brymer 1976:148). As I also had first-hand experience as a singer and clarinettist I decided to quantify these proposed vocal-clarinet links by studying the physiological aspects of vocal production and clarinet tone production to find comparisons between them. In order to start with a controlled study I referred to vocal and clarinet resources in western art music education to clearly illustrate the similar bio-mechanics of tone production.

I researched the physiological processes of vocal production by referring to the Anatomy and Physiology of Voice Production web-site (2004) and articles such as The Physiology of Voice Production in Journal of Singing (2005:176) by Yolanda HemanAckah. For an overview of ideas on successful voice production from a past and a present perspective I researched Vocal Success (1935:19) by Roland Foster, Voice Power (2002:23) by Renee Grant-Williams, and articles by Valerie Trollinger (2005:45) and Christopher D. and Dona K. White (2001:39) in The Music Educator's Journal. I also referred to an article by David Burrows entitled Singing and Saying in the Journal of Musicology in which he discusses the differences between the two modes of expression and suggests that singing is 'pre-linguistic vocalising' (Burrows 1989:396) and that the 'speech centres of the brain are recent evolutionary developments' (Burrows 1989:395). These comments resonated with me as they clarified why music has the ability to transcend other forms of communication as it operates at such a deep place in an individual's identity.

In order to uncover the foundation stones of musical identity I started to research physiological and psychological identity links in the book Bodymind by Ken Dychtwald in which he discusses in detail the benefits of bodymind integration (1978:24). I also 
referred to the Feldenkrais web-site (2007) as it is a movement method which is relevant to musicians, and which encourages the freedom and expressiveness of bodymind integration. I found the chapter 'Music and the Body' in Music and Cultural Theory (1997:179) by Shepherd and Wicke very useful in its description of the relationship between the body and the mind as it relates to music. Richard Middleton's ideas in his book Studying Popular Music (1990:189) on the way in which different music can have an effect on class, gender and ethnic identity were thought provoking, as was the Introduction to the book Ethnicity Identity and Music (1994:24) by Martin Stokes, in which he discusses the way that music defines distinctive groups and establishes social and political systems thereby creating boundaries. A chapter entitled 'On the Sapphonic Voice" by Elizabeth Wood in the book Music, Culture and Society (2002:86) shed some light on the gender identity of a coloratura voice, enabling it to be compared closely with a clarinet.

After establishing the connection between vocal-clarinet links and musical identity at its deepest level, the next step was to assess how this musical combination affects the role of the case studies' clarinettists in their ensembles. I was influenced by Bonne Wade's comment in the chapter 'Thinking About Instruments' in her book Thinking Musically: Experiencing Music Expressing Culture, that musical instruments are items of expressive and material culture as works of art, symbols, technological inventions and professional tools (2004:28). This view was endorsed by Kevin Dawe in his chapter entitled the 'Cultural Study of Musical Instruments' in The Cultural Study of Music (2003:276), where he states that musical instruments are physical, metaphorical and social constructions as well as material objects and he suggests that we can understand much about culture by studying their function. From a sociological perspective I also referred to a very recent book entitled Developing Change Leaders 
(2010:51 and 54) by Aitken and Higgs in which they contend that the best leaders are expressive, persuasive and open, qualities which are demonstrated by all of the clarinettists in the case studies.

This thesis includes an abstract, introduction, and five chapters. The first chapter gives the reasons why the clarinet is able to act as an extension of the voice. In it I discuss specific methods of tone production in voice and clarinet, the physiological comparisons between singing and playing the clarinet, and the historical development of various clarinet designs as they relate to the resonance and vocality of the clarinet.

The second chapter discusses the case studies of four clarinettists in Wellington from four separate musical ensembles to examine ways in which they act as expressive conduits of music in their various ensembles. The four clarinettists are freelance professional clarinettists working in Wellington, New Zealand: Andrzej Nowicki plays contemporary art music in the SMP Ensemble, Debbie Rawson plays western art music in the New Zealand Clarinet Quartet, Greg Rogan plays jazz in the Blackbird Jazz Trio and Urs Signer plays klezmer music in the Klezmer Rebs. As these ensembles are a representative sample of four distinct musical styles, they provided a rich resource to describe the ways in which clarinettists extend the voice in these ensembles, and how they relate to the other musicians in a socio-musical context. This chapter contains the background of each ensemble, the profile of the particular clarinettist, descriptions of various performances, the cultural heritage of each clarinettist, their leadership role, and it concludes with specific ways in which the clarinettist acts as an expressive conduit of music in their specific musical ensemble. Clarinet repertoire performed by each ensemble is included to highlight the musical flavour of the ensemble, and to illustrate how in their leadership roles, the cultural background of the clarinettists influences their repertoire choices for their ensembles. 
The third chapter discusses voice and clarinet identity from three different perspectives: individual identity, musical identity in voice and clarinet, and ensemble identity. The individual identity section includes reference to bodymind integration to reveal how integrated and balanced posture and musculature enhances musical performance in both voice and clarinet playing. The musical identity section discusses the ways in which singers can influence clarinettists, giving specific examples from the case studies where clarinettists extend, imitate, partner, or replace the vocal part. The ensemble identity section discusses the 'vocal' clarinettist: the three clarinet voices, clarinet-voice links in the ensemble, 'blender-soloist' personality traits in clarinettists and ways in which they operate in socio-musical contexts.

Leading on from these socio-musical concepts the fourth and final chapter discusses ways in which clarinettists are able to transcend gender, ethnicity and ensemble boundaries and therefore act as expressive conduits of musical styles in and between diverse ensembles. In the course of researching these cross-ensemble exchanges it became clear that the city of Wellington also contributes to this eclecticism by supporting musical and cultural diversity in a variety of ways.

My intention is for this research to suggest new ways of approaching clarinet repertoire for clarinettists and scholars, and an awareness of how the clarinettist functions in different socio-musical contexts. The bodymind integration section is intended to assist players to develop an ease of playing and a freedom of tonal expression. An excellent outcome would be for composers to use the details of the voice-clarinet comparisons, to help inform new 'vocal' compositions for the instrument. 


\section{Key Terms}

\section{Blender-soloist}

This term is used by Deborah Rawson in an interview about the clarinettist's two-fold role in an ensemble: as a 'blender' due to the breadth of tone and central orchestral seating, and as a 'soloist' due to the virtuoso aspects of clarinet playing (Rawson, 4 August 2010, pers.comm).

\section{Bodymind integration}

Physiological and psychological links between the body and mind which facilitate individual expression and musical identity (Dychtwald 1978: 24-25).

\section{Clarinet as an extension of the voice}

The similarities between the bio-mechanics of vocal and clarinet tone production allows members of the clarinet family to imitate and extend a variety of vocal attributes (Shepherd and Wicke 1997:179). These include vocal timbre, resonance, pitch and micro-pitch legato gliding, head and chest voice qualities, percussive and guttural effects, wailing, growling, sighing, laughing, and whispering.

\section{Expressive conduit}

Due to its ability to act as an extension of the voice and its inherent versatility and flexibility, the clarinet is an exceptional vehicle of musical expression in and between diverse ensembles.

\section{Diverse ensembles}

Musical groups with different cultural heritage and styles: for example jazz, western art and klezmer, which were initially diverse in geographical location as well as in their cultural heritage. The case studies are a representative sample of different clarinet styles played in ensembles in countries around the world, some examples of which are 
noted in the journal of the International Clarinet Society The Clarinet $(1998,1996$, 2005).

\section{Ethno-organology}

The study of the role of musical instruments as items of expressive and material culture, works of art, symbols, technological inventions and tools for earning a livelihood as discussed by Wade (2004:28) and Dawe (2003:276).

\section{Pre-linguistic song/vocalising}

It has been discovered that song is a predecessor of language and that vocal and language functions occupy separate places in the brain (Burrows 1989:395). In Studying Popular Music Middleton suggests that music is assigned to a world that is 'pre-linguistic', pre-symbolic', 'pre-rational' and 'pre-logical' (Middleton 1990:189), suggesting a deep and ancient voice which operates at a subconscious level.

\section{Transcend boundaries}

Clarinettists have the ability to transcend gender, ethnic and ensemble boundaries due to the inherent versatility, flexibility and heterogeneous sound qualities of the clarinet, the vocal-clarinet links and the blender-soloist qualities of the clarinettist. (Stokes 1994:24).

\section{Vocal - clarinet links}

The physiological links and similar musical mechanisms for tone production between the voice and the clarinet, allows the clarinet to act as an extension of the voice and to imitate, mimic, partner, and replace the voice in different musical contexts. 


\section{CHAPTER ONE: The Clarinet as Extension of the Voice}

\section{Introduction}

A singer has the ability to act as an initial 'expressive conduit of music' by conveying emotions and aspirations or simply telling a story, thereby influencing an audience. As described in the Introduction, the clarinet is also an expressive conduit of music in diverse ensembles, due to its distinctive 'vocal' timbre. This chapter explores the physiological links between the tone production in voice and the clarinet, in order to prove the deep affinity that exists between them. Each human being communicates with others in their specific language and song, using their voice as the mediator of semantic meaning and expression. As the voice generates a vast range of sounds at various pitches and volumes, it is capable of expressing a spectrum of emotions from joy and sorrow to anger and fear. The clarinet imitates so many vocal features in its design, construction and methods of tone production, that it is capable of acting as an extension of the voice. Regarding the similarities between the clarinet and the voice Jack Brymer contends that,

Much of the apparatus used is identical, many of the methods of resonation, articulation and projection very closely related. It is true that in speech the generator is the vocal chords, in the larynx, while in the clarinet it is the reed and the mouthpiece in the mouth; but the resonation of the sound, once produced, is dependant in both case upon the cavities of the head and mouth, and the articulation requires the same sort of tongue motion in each case. (Brymer 1976:148)

The first section of this chapter discusses some specific physiological research describing the bio-mechanics of the human voice, the initial conduit of individual and musical identity. The second section explores the concept of the clarinet as an extension of the voice, by describing the various aspects of resonant tone production such as deep breathing, the mouthpiece and the reed, and the 'vocal' resonance of the instrument. The third section begins with a table of direct comparisons between vocal 
and clarinet tone and continues to reveal the similarities in aspects such as posture, breathing, air pressure, resonators, articulators and range.

The final section in this chapter discusses the historic development in clarinet design to illustrate how clarinet-makers have traditionally worked to enhance the 'vocal' quality of the clarinet tone by improving the intonation, resonance and playing facility on the instrument. There is discussion of aspects such as the resonant material used, the shape of the bore, the various keywork mechanisms used and the effects of using certain mouthpieces and reeds. Ways in which design innovations in clarinetmaking have affected the 'vocal' qualities of clarinettists in jazz, folk and klezmer styles are also discussed in this chapter.

\section{Vocal Tone}

In my view a person asserts their unique individuality through singing, that is influenced to some degree by the regional, cultural and social location they find themselves in. From their first cries as a baby, a person's voice reflects and expresses the individual identity of a person, and it is the main form of communication between an infant and his/her parents, for instance through lullabies. Early childhood musical influences such as singing in their family, at school or in a choir help to form the early social identity of a person. Through listening and participating in the vocal music in their environment individuals also develop a musical identity whose influences are often reflected in their performances in adult life. Interestingly, even though vocal music is sung in a vast array of different languages, much of the emotional meaning will be conveyed through the musical line regardless of the text.

As this thesis is concerned with the functions of the clarinet as an expressive extension of the voice and conduit of music between diverse ensembles, I will first outline the vocal subsystems, the physiology and some techniques of vocal production 
in the early part of this chapter. By providing an in-depth explanation of the processes of vocal tone production, my intention is to provide a framework from which I can precisely compare this with clarinet tone production.

Vocal sound production uses three linked subsystems, an air pressure, a vibratory and a resonating system as shown in the figure below. The air pressure system includes the lungs supported by the diaphragm, ribs, chest and abdominal muscles, which regulate air pressure to the vocal folds causing them to vibrate. The vibratory system includes the larynx and the vocal folds, which change air pressure to sound waves and varies the pitch of the sound (Anatomy and Physiology of Voice Production 2004).

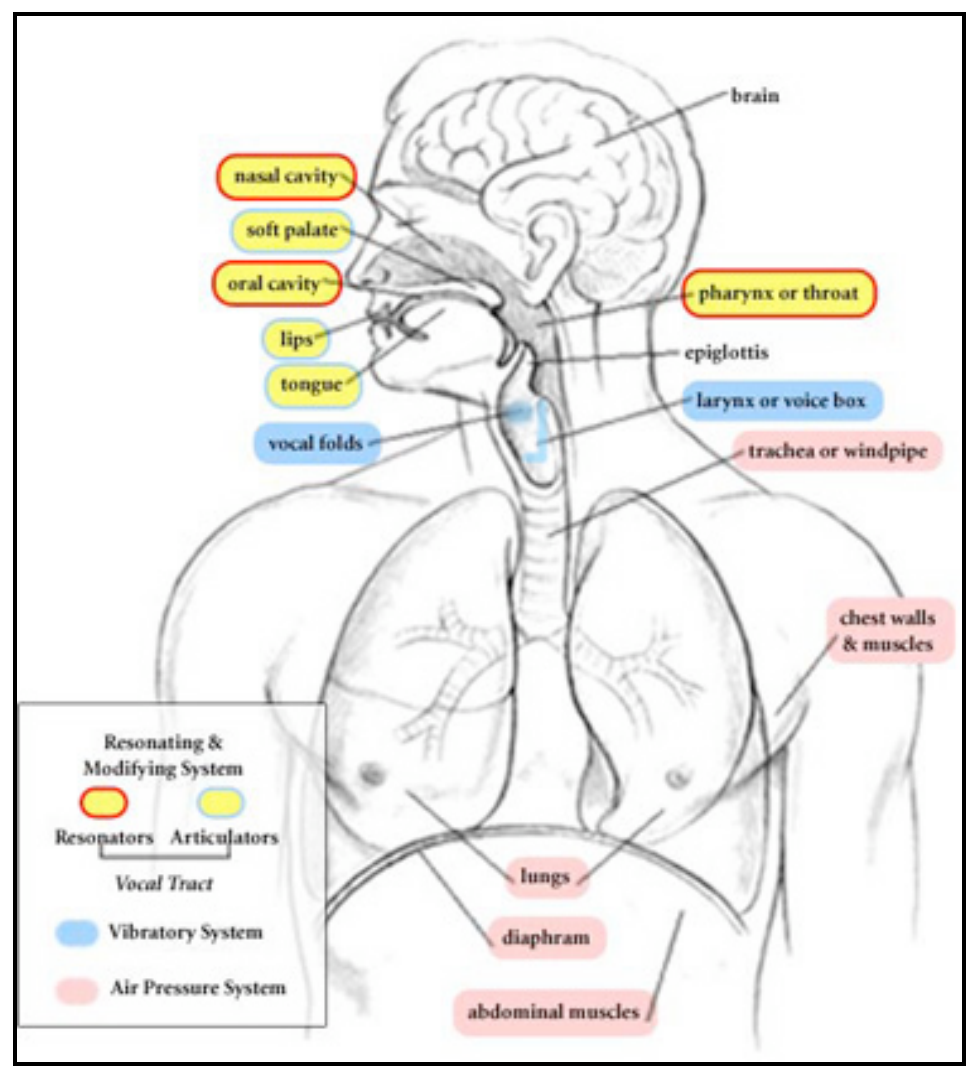

Figure 1: Vocal Subsystems: Air Pressure, Vibratory and Resonating Systems (Anatomy and Physiology of Voice Production 2004)

The third system is the resonating system, which includes the vocal tract, the pharynx, and the oral, sinus and chest cavities. This system transforms the original sound into a distinctive individual voice. 
The neocortex in the brain coordinates voice production through specific nerve connections and signals from motor branches of the Recurrent Laryngeal Nerve (RLN) and the Superior laryngeal nerve (SLN) (Anatomy and Physiology of Voice Production 2004) as shown in the figure below. These nerves send messages to the vocal ligament and muscle, adjusting its tensioned position, and when the airstream creates vibration in the vocal folds, vocal tone is generated at a specific pitch.

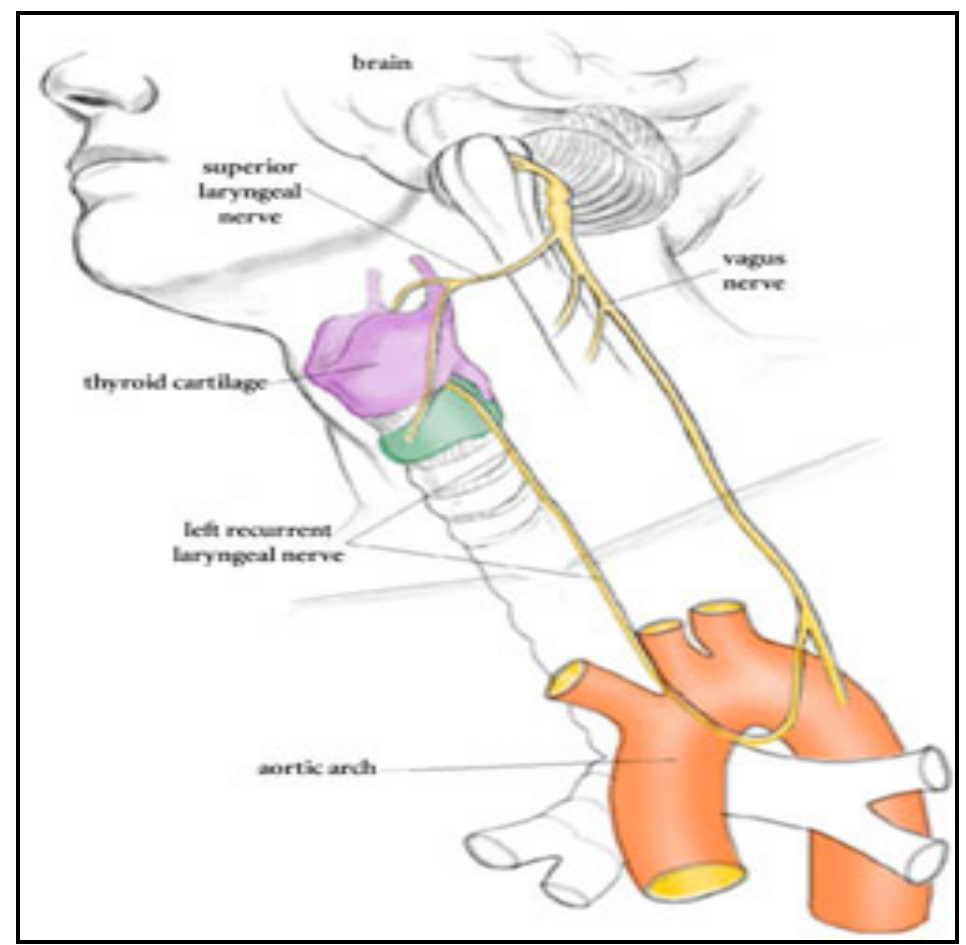

Figure 2: Neocortex Messages to Larynx via Laryngeal Nerves (Anatomy and Physiology of Voice Production 2004)

It is the conscious adjusting of the tension in the vocal ligament and muscle thereby manipulating the pitch that affords humans the ability to sing musical notes (Urban 2002: 235).

As the key function of the larynx is to open and close the glottis for the functions of breathing, coughing and swallowing, language and singing are secondary functions (Trollinger 2005:44). Due to the lower position of the larynx in humans than in other primates it is afforded better protection, more complexity in its design and functionability, and ability to link to both chest and head resonance cavities. Although 
infants are born with a highly placed larynx, this starts to lower at around the age of six months, and continues to lower throughout life, which partially explains why people's voices get lower as they age (Trollinger 2005:45).

The vocal folds are attached by three cartilages within the larynx: by the thyroid at the front under the chin which houses the vocal folds, by the arytenoid cartilages, which are attached at the back near the spinal cord and by the cricoid cartilage further down the vocal tract as shown in the figure below.

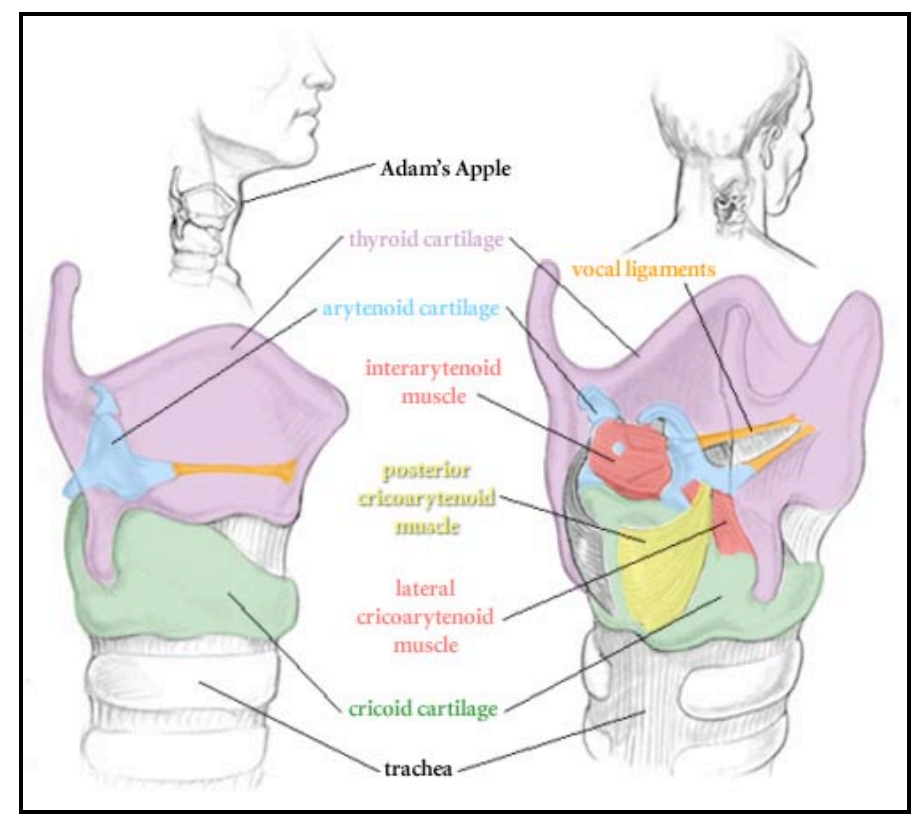

Figure 3: Larynx Cartilage and Muscles

(Anatomy and Physiology of Voice Production 2004)

These cartilages are held in place by their respective muscles. The vocalis muscle within the thyroarytenoid muscle is attached ( $\mathrm{R}$ and $\mathrm{L}$ ) to both the thyroid and arytenoid cartilages, and it shortens and lengthens the vocal ligament. The lateral cricoarytenoid muscle ( $\mathrm{R}$ and $\mathrm{L})$ is attached to the cricoid and arytenoid cartilage on each side, and its function is to close the vocal folds. The cricothyroid muscle tilts the thyroid cartilage, increasing tension of the vocal folds and affecting high pitch and portamento singing. The inter-arytenoid muscle (transverse and oblique) is attached between the right and left arytenoid cartilages, and its function is to close the inlet of the larynx. The posterior 
cricoarytenoid muscle is attached to the cricoid and arytenoid cartilages, and its function is to move the vocal folds apart, and to allow breathing (Anatomy and Physiology of Voice Production 2004).

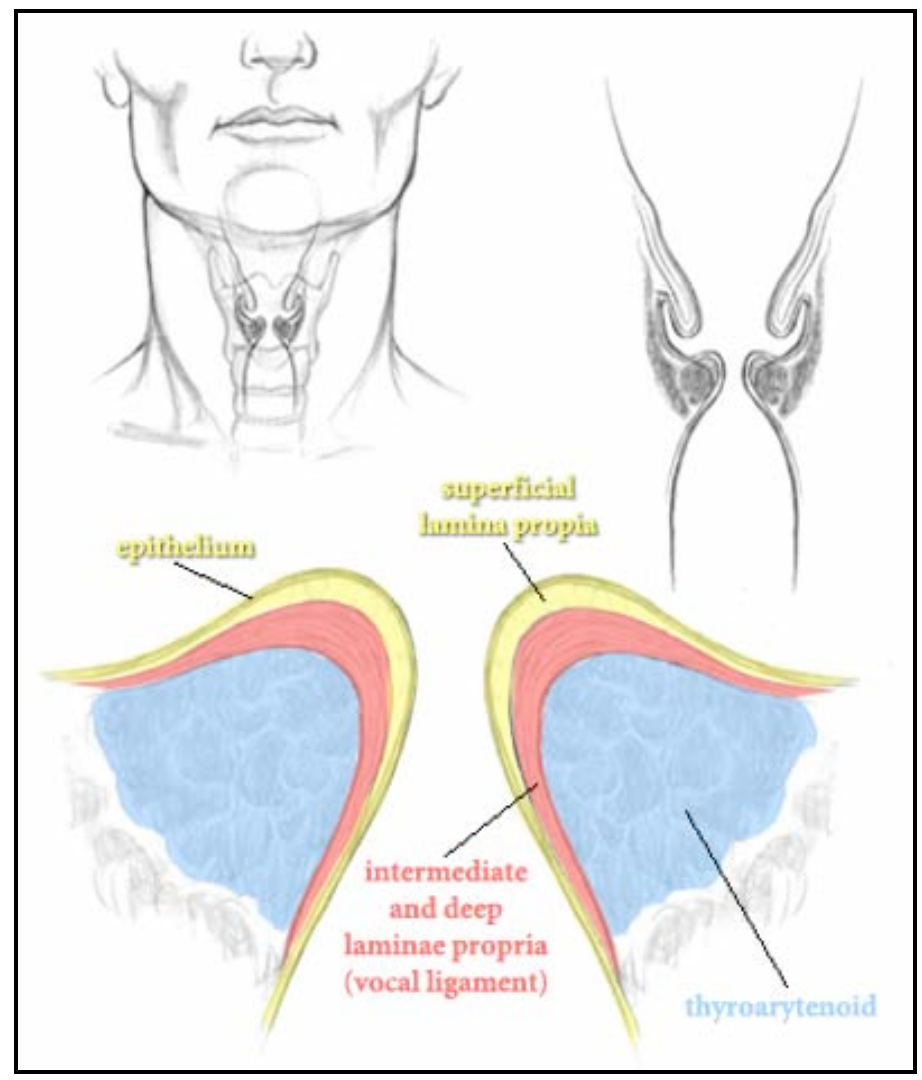

Figure 4: Vocal Folds

(Anatomy and Physiology of Voice Production 2004)

As the human body develops, the muscles and cartilage of the larynx change in position, size, strength, and texture, affecting changes in range, power and tone of the singing voice (White and White 2001:39). As can be seen in the figure above the triangular vocal folds move in a similar way to a car's windscreen wipers, which are attached in the middle of the screen and open outwards.

There are also three components of voice production: voiced sound, resonance and articulation, which work in alignment to produce language and singing. The basic sound produced by vocal fold vibration is called 'voiced sound', often described as a 'buzzy sound', which varies significantly for speech and singing. As shown in the 
figure below resonance is the process by which voiced sound is amplified and modified by the vocal tract resonators to produce a distinctive voice. Articulation is the process by which the vocal tract articulators (the tongue, soft palate, cheeks and lips) modify the vocal sound to produce consonants and vowels, and therefore syllables and words (Anatomy and Physiology of Voice Production 2004).

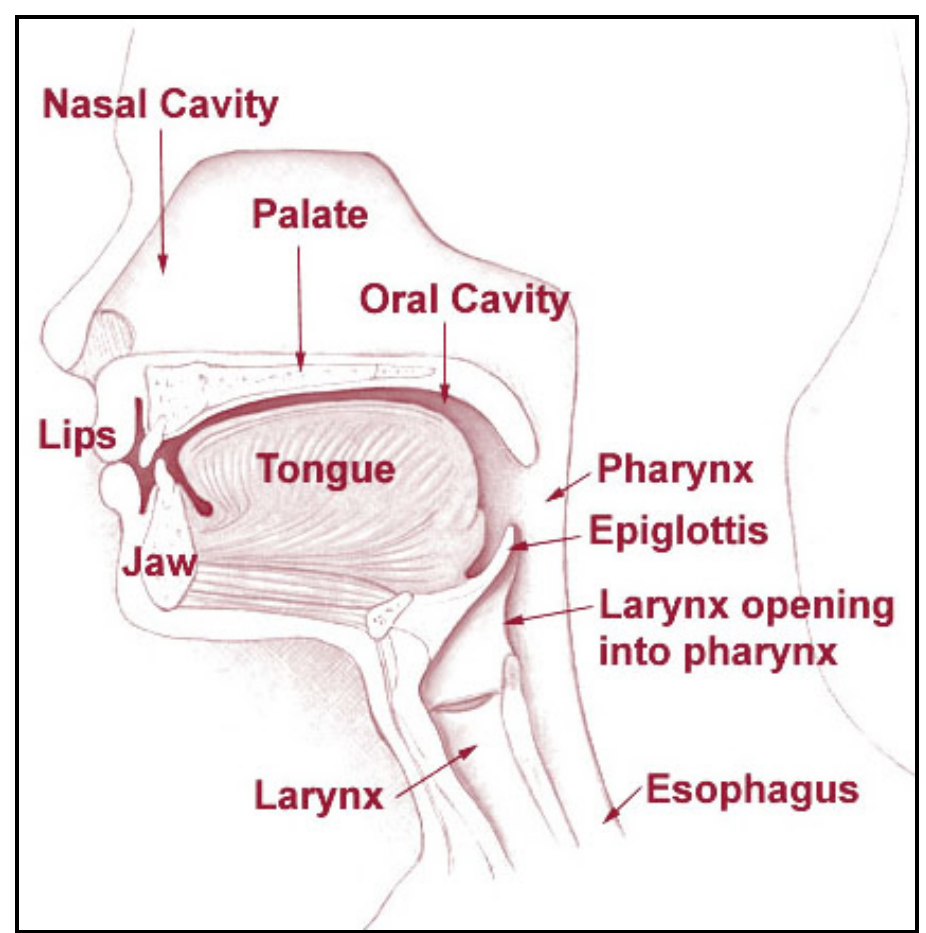

Figure 5: Head and Neck Resonators and Articulators in Vocal Production (Diction Domain 2010)

Vocal coaches and choral directors need to have an understanding of vowel production at different pitches in a variety of languages. They also need to have an understanding of the composer's intention, the musical line and all the musical elements which are embodied in that line such as pitch, rhythm, timbre, legato, volume, colour and vibrato. In addition to this they need to understand how the head voice and the chest voice operate, and how to help singers find ways to meld them together at certain pitches in order to avoid a break in the voice. In the article Performing Arts Medicine and Music Education, Trollinger describes succinctly how the muscles affecting the vocal ligament control these different voices. 
A number of muscles and ligaments work with the larynx to make sound, but two muscle pairs, the thyroarytenoids and the cricothyroids, are primarily responsible for what we commonly call head voice and chest voice. The muscles work in an antagonistic relationship, mediated by the vocal ligament. The vocal ligament, which is embedded in the muscles and aids in directly controlling the vocal bands, allowing the bands to vibrate when making sound. (Trollinger 2005:45)

Each individual's voice sounds unique due to the shape size and position of the vocal cords and vocal tract, the resonators (pharynx, soft palate and sinus cavities), the articulators (tongue, lips, cheeks), the neck and chest, and the overall size and bone structure of the individual. Holding patterns of tension in the body can have a major impact on tone quality, resonance and projection. Posture, balance, stance, emotions and breathing all have an effect on an individual's tone quality for speech and singing (Heman-Ackah 2005:176).

In his book Vocal Success, renowned singing teacher Foster reiterates the importance of resonance in singing, and recommends relaxing the throat to allow its muscular apparatus to work in a natural and unforced way. His concern is that pressure on the vocal chords and contraction of the throat muscles might interfere with the vocal resonance, and would require more physical effort from the singer. Foster also expresses his views on breath control suggesting that the lower abdominal muscles act as a support to the upper chest, which should remain firm and lifted for maximum air pressure to the vocal folds (Foster 1935:19). As the voice is produced inside the mouth and pharynx, (the opening between the back of the tongue and the soft palate), and in the resonating cavities, rather than with the lips and cheeks, he suggests that a singer should keep a natural mouth position (ibid:10).

In a personal interview with Flora Edwards, an experienced opera singer, recitalist and singing tutor at the New Zealand School of Music, she discussed what she considered to be the most important details of vocal production. She commented that breathing is 'all important' and that the rib cage needs to expand sideways engaging the 
latissimus dorsi muscles for power. Her view is that the voice convects through the air, and that the bones of the face and body act like a heater in that they conduct the vibrations of the voice. With new students she starts by asking them to sound a 'vocal fry', an initial vibration of the vocal folds with minimum breath. The sound is gravelly, and is technically the lowest part of the singing range, where the vocal folds are only just vibrating. Flora mentioned that it is very important to produce the correct vocal and consonant sounds in a particular language to ensure the expressive quality of the sound. She also commented that in the opinion of a previous London-based lecturer of hers, the clarinet imitated the mezzo-soprano voice, whereas the oboe imitated the soprano voice as it has more compression in the air column (Edwards, 7 September 2010, pers.comm).

As the singing voice is an initial form of human musical communication it acts as a conduit for individual expression within the parameters of a specific culture. Having examined tone production for the human voice, I will now detail tone production in clarinet playing and it will become apparent that there is a very close relationship between the two.

\section{Clarinet Tone}

If we accept that the voice is the initial conduit of expression, and we understand the complexities of vocal tone production, it is intriguing to examine in detail the very similar physical processes for clarinet tone production. Air pressure, vibratory, resonating and articulatory systems are used in both singing and clarinet playing, although the complexity of the human larynx is replaced by the mouthpiece and reed in the clarinet. Although the B flat and A clarinets are pitched at an extended soprano range, they require the addition of the fingers to shorten and lengthen the cylindrical tube of the instrument and so create the required pitch. I contend that the clarinettist 
who 'sings' through their instrument is using the clarinet as a tool to extend their voice, revealing their individual identity in the process, in a similar way to singers.

\section{Deep Breathing}

As in singing, deep and relaxed breathing is an essential element in the production of a good clarinet tone, while shallow breathing will not provide the required steady air stream. In order to produce a tone on the clarinet the abdominal muscles need to initiate movement in the diaphragm to enable the airstream within the bore of the clarinet to vibrate. English virtuoso clarinettist Anthony Pay believes that the muscles of the abdomen both support and resist the movement of the diaphragm, and he states that 'The central fact is that the diaphragm is a muscle that can only exert force downwards, to draw air into the lungs' (Pay 1995:108-109). After the clarinettist has initiated this breathing process, the player is then required to maintain a certain muscular control from the abdomen to the chest, and also the back muscles, to give a clear tone at a given pitch. In his book The Art of Clarinet Playing, American clarinet teacher Keith Stein makes the following comment,

Real breath control implies that the breath which has been taken down is maintained there by a muscular control (support) and is distributed upward at exactly the rate that it can be received into and through the clarinet... The flow should feel billowy, fluffy and light. (Stein 1958:18)

Sometimes players will attempt to compensate for shallow breathing by tensing their throat muscles, (especially the large sternocleidomastoid muscle), but this produces a constricted tone, just as it does in singing.

When the airstream leaves the lungs it rises up through the trachea until it reaches the pharynx. 'There are four separate exits from the pharynx: the trachea which leads to the lungs, the oesophagus which leads to the stomach, the mouth, and the velopharyngeal port which leads to the nose' (Gibson 2007:1). The airstream travels from the pharynx at the back of the throat through the oral cavity, past the hard and soft 
palates, and over the tongue to reach the mouthpiece opening. Once the air stream has reached the lips, it is ready to act as a generator of sound as it vibrates the reed against the mouthpiece, 'the most powerful source of variety in tone production'

(Brymer 1976:65). Just as the airstream in the vocal folds creates an initial tone, which is then resonated in the oral and sinus cavities, the airstream in the clarinet reed and mouthpiece creates an initial tone which is then resonated in the hollow clarinet bore.

\section{The Mouthpiece and Reed}

Made from ebonite, plastic, glass or metal, each part of the mouthpiece has a specific function in helping to create the tone. The lay of the mouthpiece is the shape of the curve created by the rails at the top on the back, and it sets the position for the distance of the reed to the mouthpiece. English clarinettist and author Jack Brymer comments in his revered clarinet teaching compendium Clarinet that 'The shape of this curve is probably the most individual part of any clarinettist's equipment' (ibid:111). The mouthpiece on its own is not able to produce a sound as it simply has a wind-cut hole, with no means of creating a vibration to make sound.

It is the addition of the reed that allows sound to be produced, as the air stream causes it to vibrate against the mouthpiece. The reed is made of a piece of bamboo called arundo donax, or sativa, which grows well in the South of France, and it is matured for three years in the sun after cutting to season the cane (ibid:115). To act as a pliable spring in the mouth, the reed needs to be made from medium cane, and have a firm raised crest with an even pattern of golden yellow fibres.

Clarinettists need to play with a firm embouchure to control the reed vibrations against the mouthpiece, and it is the varying speed of these vibrations which produce their distinctive sound quality. 'Generally speaking, bright sounds are produced by more tension and quicker opening of the cycle, more mellow sounds by a slowing of the 
opening and closing action... it is what makes one player sound totally different from another...' (Brymer 1976:64). Vibrations of the reed move the air column within the bore of the clarinet, so it is not the wood of the instrument but the air within it which is moving (ibid:62). The concept of resistance is integral to the relationship between the reed and mouthpiece; a mouthpiece with an open lay needs less resistance and a soft to medium reed, whereas one with a closed lay needs more resistance and a much harder reed to reach the same tone quality.

\section{Clarinet Resonance}

Clarinet tone is created by a supported air stream vibrating a mouthpiece and reed (the generator) which moves the air in a cylindrical wooden tube (the resonator). This process creates an extremely complex wave form with a rich sound spectrum and overtones, giving it 'the characteristics of a 'stopped pipe', similar to those used in organ-building' (ibid:66).

Having this cylindrical-shaped pipe means that the clarinet can achieve middle $\mathrm{C}$ from about one foot of tube, in comparison with the oboe which requires two feet of tube for the same pitch (ibid: 69). Certain acoustic idiosyncracies of the clarinet tube mean that there is an initial air column vibration followed by a reaction vibration back up to the mouthpiece end. This process takes place twice so there are two outgoing and two incoming phases (ibid:67).

A varied palette of tonal colour over a large range can be produced by the clarinet due to the inherent nature of its design. Extremely complex wave forms are produced which explains why it has such a rich sound spectrum, as well as many characteristic acoustic advantages and disadvantages' (ibid:69). It is possible to play at both extremes of the dynamic range without shutting off the reed vibrations as tends to happen in other 
woodwind instruments which allow the clarinet an expansive dynamic range from niente to fortissimo (Brymer 1976:61).

Extending over four octaves the clarinet has the largest range in the woodwind family. The instrument is divided into three voices, a 'male tenor voice' (chalumeau register from concert pitch D3 to G4), a 'female soprano voice', (clarion register from concert pitch A4 to D6) and the 'ultra-feminine or altissimo voice' (concert pitch E6 to D7), affording opportunities for composers and musicians to exploit both voices for particular effects. Discussing the flexibility of the clarinet compared to that of the other orchestral woodwind instruments, Brymer comments,

The clarinet has the most extensive compass of them all, almost four complete octaves, inaudible pp to a trumpet-like fff; a subtler variety of tone-quality, from velvet-soft to steely-hard - and a consequent ready ability to blend with other instruments which makes it the essential 'binding' factor of the wood-wind section. (Brymer 1976:8-9)

Clarinet pitch is affected by the addition of fingers covering various tone holes, which lengthen or shorten the length of the clarinet bore. Progressively sliding fingers off tone holes can help to create a 'vocal' glissando effect such as that found in the opening bars of the clarinet solo in Gershwin's 'Rhapsody in Blue', an effect which is greatly aided by the use of a flexible embouchure and a supportive air stream.

\section{Clarinet Technique}

Many clarinettists are tempted to blow hard into the instrument in order to produce a sound, but this is not necessary, and will instead produce a loud breathy tone (ibid:173). A sustained gentle exhalation which just vibrates the reed will produce an acceptable tone just as singers only need to initiate a gentle vibration of the vocal folds for a good tone to be produced.

In his book The Art of Clarinet Playing Keith Stein comments how important it is to shape the tone as it moves from the pharynx to the front of the mouth. 
Voicing is the manner in which one shapes the tone, using the breath as the moving vehicle. We will include the throat, tongue, larynx, oral cavity, overhead sinuses, nasal and head cavities to accomplish this voicing. (Stein 1958:21)

He encourages students to 'open up' their oral cavity, and soft palate by yawning with closed lips, and comments that "opening up" is nothing more than learning to relax the inner wall membranes and muscles of the channel along the path of the air column' (ibid:22). This method of 'voicing' is used constantly in singing to improve the tone quality, vowel sounds and intonation.

English clarinettist Roger Heaton confirms the importance of 'voicing' in clarinet playing in his comment, 'Moving onto tone, this can be changed in three different ways: the choice of the hardware itself (clarinet, mouthpiece and reed), by changes in the oral cavity and throat (the real source of a player's particular tone) and finally by alternative fingerings' (Heaton 1995:169).

\section{Embouchure}

Whereas singers control the vibrations in the subtle musculature of the vocal folds, clarinettists need to use a firm but flexible embouchure to control the reed vibrations throughout the wide register range regardless of air pressure differences and intonation difficulties. When discussing instruments mouthpieces and reeds, English clarinettist Nicholas Cox comments that 'the best players aim for a set-up where the instrument sounds homogenous and focused throughout its range and dynamics, without losing the vital elements of colour' (Cox 1995:153).

The fact that the clarinet is played with approximately two centimetres of the mouthpiece in the mouth means that the vibrations from the instrument can be felt in the facial muscles and bones, which is very similar to a singer's experience. By comparison, flutists and brass players use their lips to create vibration outside their instruments. Another distinctive similarity of the clarinet and the voice is that the width 
of the vocal tract nearly matches the width of the clarinet mouthpiece, unlike the oboe or bassoon reed which is much narrower. This means that the airstream coming through the particular shape of the vocal tract is able to pass unimpeded into the mouthpiece of the clarinet, which literally amplifies the volume of the sound.

Physical attributes of individual clarinettists such as lip formation, underbite or overbite, short or long upper lips, tooth length, jaw shape and general facial contours also need to be taken into consideration. These all play a role in determining the amount of correct pressure that can be applied to the mouthpiece and reed via the embouchure to create a resonant tone (Stein 1958:14).

Flexibility in the vocal musculature allows for a natural vibrato which affords health and longevity to a singer's voice. However there is some debate amongst professional clarinettists about the use of vibrato in clarinet playing, as some argue that the instrument's value is in its capacity to '...depict the sort of cool flawless beauty of a marble statue or a piece of perfectly polished wood' (Brymer 1976:204). In my experience it is possible to add vibrato from the abdomen or from the lips if this sound quality is required by the player, and Brymer advocates its use in certain contexts where it would provide a warmer vocal tone.

By its inherent design, the clarinet allows players to breathe deeply in a natural cycle using breath support, to use the mouthpiece and reed to create resonant sound, and the pharynx, oral cavities, throat and tongue to shape the tone. I suggest that the clarinettist who 'sings' through their instrument is using the clarinet as a tool to extend their voice, revealing their individual identity in the process, in a similar way to singers. The physiological similarities between vocal and clarinet tone production are explained in the next section. 


\section{Vocal and Clarinet Tone Comparisons}

Posture

Correct posture in singing and in wind instrument playing ensures a natural alignment of the muscles which support deep breathing, phonation and resonation. In an article on posture and voice Rubin, Mathieson and Blake refer to Rolf's term of 'equipoise' which states that if you dropped a plumb line from the plane between the ears, it would pass directly over the plane of the shoulders and hip joints (Rubin, Mathieson and Blake 2004: 271). Just as standing or sitting in a naturally correct posture is essential for singers, it also applies to clarinettists. As the well-known clarinet teacher Paul Harris comments, 'Correct posture - an upright position to allow for maximum use of the lung capacity - and a lack of tension should be emphasised' (Harris 1995:131).

\section{Breathing}

As explained in the previous sections, effective deep breathing is essential for both singers and clarinettists. Complete exhalation of breath allows the natural rise and fall of the diaphragm, which acts as a bellows to draw fresh air into the lungs on inspiration. General firm muscular support provides a consistent pressure to air in the lungs, which in singers then becomes available for release up through the trachea causing the vocal folds to vibrate and create sound. In clarinet playing the air partially bypasses the larynx and reaches the mouthpiece opening and reed to create sound. It is not only the diaphragm which is involved, but a complex interaction between many different muscles that provides a consistent airstream to the clarinet. Paul Harris comments that 'in terms of breathing it is clearly essential to teach the concept of support via the appropriate use of the abdominal, intercostal and diaphragmatic musculature' (ibid:128). Due to the free-blowing nature of the reed on the mouthpiece 
clarinettists need to breathe in a natural and regular way, inhaling and exhaling fully, in a similar way to singers.

\section{Air Pressure}

It is interesting to compare the following two descriptions of the Bernoulli Effect in the vocal folds, and also in the clarinet mouthpiece and reed. Daniel Bernoulli an eighteenth century Swiss scientist, discovered that when a constant flow of fluid or gas is passed through a tube and a section of the tube is constricted, at the point of the constriction the flow will speed up and there will be a drop pressure against the walls of the tube (Reeve 2005:1). The vocal folds and the clarinet reed and mouthpiece are both reliant on a cyclic process of low and high air pressure for tone production.

\section{Vocal folds}

When the vocal folds are adducted during phonation, the airstream is momentarily stopped by the vocal folds. At this point subglottic pressure begins to build up below the vocal folds. When the pressure is high enough, the soft tissues of the vocal folds are forced to separate and the airstream is allowed to flow through the vocal folds...the airstream through the vocal folds then accelerates causing a drop in pressure. This drop in pressure then sucks the vocal folds back together.

Subglottic pressure then builds up again and the process continues. This cycle of vocal folds motion create the air compressions and rarefactions that cause sound. (Reeve 2005:1-2)

\section{Clarinet}

[...] the reed is deflected by the passage of air over its surface; it snaps shut cutting off the air supply, and since it is in fact a wooden spring, it then immediately returns to its open position and so repeats the cycle. This action provides a rapid series of puffs of air to the column inside the instrument, and these contain the basic potentials for different harmonic patterns.

(Brymer 1976:63)

\section{Vibration}

The sound of the voice (vocal phonation) is created by an airstream causing vibration of the vocal folds that resonate in the vocal tract and oral cavity, and emit from the open mouth as sound. In the clarinet the same process takes place except that 
the airstream bypasses the vocal folds and vibrates the reed against the mouthpiece.

This vibration then resonates as an air column within the cylindrical tube of the clarinet body.

\section{Vocal Tract and Clarinet Bore}

Sound production in both the voice and the clarinet both rely on the resonance of a cylindrical pipe (vocal tract and clarinet bore), the length and shape of which affects the pitch, range and tone quality of the note. 'A useful mechanical analog to the aspect of speech production that is of concern to this discussion is a pipe organ' (Lieberman, Crelin, and Klatt 1972:288). Brymer also notes that the bore of the clarinet imitates a pipe organ, '...the clarinet is unique in that it presents a cylindrical cavity. This gives it the characteristics of a 'stopped pipe' - like that used in organ building (Brymer 1976:66). The similarity between the 'pipe organ' qualities of both voice and clarinet tone production indicate how the clarinet is capable of acting as an extension of the voice in many different musical styles.

The width of the vocal tract nearly matches the width of the clarinet mouthpiece which means that the airstream coming from the vocal tract is able to pass naturally into the mouthpiece of the clarinet. The shape of the vocal tract can be altered by muscular pressure which affects the quality of sound in both vocal and clarinet tone production. The ability to consciously modify this shape is used to elicit particular musical effects by singers and clarinettists.

\section{Oral Cavity}

Not only does the vocal tract modify the airstream in both voice and clarinet playing, but the entire oral cavity affects the quality of the tone in both instances. The fact that the clarinet is played with about two centimetres of the mouthpiece in the mouth means that the vibrations from the instrument can be felt in the facial muscles 
and bones, which is very similar to a singer's experience. In my experience it is important to keep the pharynx open and relaxed, and the soft palate raised for ideal tone and pitch quality in both singing and clarinet playing. The position and function of the tongue also affect the speed of the airstream, and the resulting tone. Increased resonance and projection in both voice and clarinet is gained by flexible use of the musculature in the oral cavity.

Although the muscles of the cheeks, jaws and tongue play a part in vocal production, they are used in a much more relaxed way than in clarinet playing. In order to hold the mouthpiece firmly in the mouth against the airstream resistance, clarinettists need to develop a firm embouchure which involves strengthening the jaw and labial muscles. In clarinet playing the tongue is also required to exercise a certain degree of muscular strength in order to facilitate the precise opening and shutting of the reed against the mouthpiece in staccato playing.

\section{Pharynx: Vowel Sounds}

Experienced singers use the International Phonetic Alphabet (IPA) system of phonetic notation to identify exactly which vowel sound they are required to sound for a particular language (The Diction Domain 2010). Clarinettists also change the shape of various vowels for particular tone colours, for instance using the 'aw' sound for more depth of tone colour. Brymer suggests that there are many subtleties for clarinettists to explore using a variety of vowel shapes, in the way that singers use IPA. 'To a great extent its application is a question of playing and obtaining resonance on the various vowel sounds not only of the player's own language, but of an international selection' (Brymer 1976:149). Virtuoso clarinettist Antony Pay takes this one step further by suggesting that clarinettists should use not only varied vowel shapes, but different tones of voice, including whispering to achieve subtle and varied tonal effects 
(Pay 1995:111). For example, a comparison of various different pronunciations of the word flute, pronounced in English as 'flute', in French as 'la flute', in German as 'die flote', and in Spanish as 'la flauta', reveals that the words are influenced by a specific vowel tension. Just as this variable tension affects the tonal quality of each dialect and language, it also can affect the tone quality of the clarinettists in these regions.

\section{Legato}

One of the fundamental qualities of the voice is its ability to 'glide' effortlessly from one pitch to another, including microtonal pitches. This effect is achieved by a controlled airstream vibrating the vocal folds which are then adducted to vary the pitch of the note. The clarinettist is able to imitate this 'gliding' effect by also controlling the airstream, opening the pharynx and allowing an unimpeded airstream to vibrate against the reed, as the fingers move on the clarinet tube altering the pitch of the note in melodic phrases or glissandi. 'The quasi-vocal quality implied by a seamless progression between notes is a characteristic that can be cultivated in both the clarinet and the violin' (Cottrell and Mantzourani 2006:33). In my opinion this quality is an important reason why the clarinet has been used in so many different genres to imitate or replace the voice. Brymer declares that legato is the 'vocal heart' of the clarinet, and that it has provided the inspiration for many composers to write significant works for the instrument (Brymer1976:170). In my experience an excellent example of this 'vocal heart' can be found in the legato passages in the slow movement from Mozart's Clarinet Concerto K.622, as it is the 'vocal' and effortless gliding between the notes which creates such a poignant mood for the performer, the orchestra and the audience.

\section{Staccato}

In voice production syllables are separated by consonants that prevent the airflow from the vocal tract. Clarinettists imitate the separation of syllables by touching the tip 
of the reed with the tongue which prevents the reed vibrating. The consonants ' $t$ ' and ' $d$ ' are mainly used, with ' $k$ ' and ' $g$ ' occasionally employed for double tonguing, as in 'tuku tuku'. These sounds are pronounced into the instrument creating a staccato effect. Vibrato

A healthy voice will produce a natural vibrato as tension varies in the vibrations of the vocal ligament. When a more deliberate effect is required, controlled impulses from the diaphragm can affect the width of the vibrato. It has not traditionally been used in clarinet playing, unlike in other members of the woodwind family, perhaps because the clarinet has had the capability of producing a pure rounded sound without

it. On the rare occasion when vibrato is required for expressive warmth of tone or to correct intonation, in my experience the best option is to use a diaphragmatic vibrato, or a subtle lip vibrato on the clarinet. In jazz clarinet playing, a jaw vibrato is often used which gives a very wide vibration and a rather 'wild' quality to the sound.

\section{Voice and Clarinet Range}

The $\mathrm{Bb}$ clarinet range includes notes a little lower and quite a lot higher than the soprano voice (concert pitch D3 to D7). Other members of the clarinet family such as the small E flat clarinet and the large Bass clarinet extend the possible range of the clarinet voice to cover nearly six octaves. As Brymer comments, this gives huge possibilities for expression in an orchestral setting. 'It can mean, consequently, a sound which can be the shrill altissimo in the register of the piccolo or a gruff voice in unison with the double bass of the strings' (Brymer 1976:9). Similarly various members of the clarinet family are capable of extending or mirroring voices across all pitch ranges, from bass to soprano. 


\section{Musical Phrasing}

I have observed that speech and song involve phonology (voice production), morphology (syllable formation) and syntax (word organisation) to communicate meaning. This is in addition to vocal timbre, register, and dynamics, making vocal production a highly complex activity with many variable factors. Many clarinet teachers encourage the study of the connections between the spoken word and music, and how this aspect can affect the performance of a musical line. 'What we want is the general ability to group the notes in the same natural way that we group syllables into words in speech' (Pay 1995:112). Just as language has a complex internal structure with each part dependant on another, musical language operates in a similar way. As Bouhuys states, meaning in language is derived from linked systems of words, sentences and paragraphs within text, whereas meaning in music is derived from linked systems of melody, harmony and rhythm within a musical form (Bouhuys 1969:1203).

\section{Individual Tone}

Perhaps the most exciting aspect of the voice is that it represents an autobiography of a particular individual's body. No two singers will sound exactly alike due to their individual physical differences combined with their specific musical experience. Individual physical characteristics in the body, oral cavity, teeth length and face shape of clarinettists also affect the quality and timbre of their tone. Clarinettists also find ways of being individually expressive through their particular combination of instrument, barrel, mouthpiece and reed. The airstream can be shaped by the oral cavities and expelled via the reed opening to create a variety of complex and colourful 'vocal' tones in the bore of the clarinet. Although there is a generic clarinet tone, experienced players tend to experiment with their sound until it becomes their own 'voice', and it is these subtle nuances that are detectable between each clarinettist. The 
many similarities between the physical processes of vocal and clarinet tone production are outlined in the following table Voice and Clarinet Comparisons.

\section{Table 1: Voice and Clarinet Comparisons}

\begin{tabular}{|c|c|}
\hline Voice & Clarinet \\
\hline $\begin{array}{l}\text { Posture } \\
\text { Relaxed aligned standing posture }\end{array}$ & $\begin{array}{l}\text { Posture } \\
\text { Relaxed aligned standing posture }\end{array}$ \\
\hline $\begin{array}{l}\text { Breathing } \\
\text { Firm support from abdominal and back muscles } \\
\text { High rib cage } \\
\text { Deep exhalation allows natural inhalation as } \\
\text { diaphragm moves vertically }\end{array}$ & $\begin{array}{l}\text { Breathing } \\
\text { Firm support from abdominal and back muscles } \\
\text { High rib cage } \\
\text { Deep exhalation allows natural inhalation as } \\
\text { diaphragm moves vertically }\end{array}$ \\
\hline $\begin{array}{l}\text { Air pressure } \\
\text { Bernoulli effect of high and low air pressures on } \\
\text { vocal folds causes them to vibrate } \\
\text { Air pressure for singers is } 1 \text { kilopascal } \\
\text { Vibration } \\
\text { Airstream vibrates vocal folds }\end{array}$ & $\begin{array}{l}\text { Air pressure } \\
\text { Bernoulli effect of high and low pressures on } \\
\text { clarinet reed causes them to vibrate } \\
\text { Air pressure for clarinet is } 2 \text { to } 4.5 \text { kilopascals } \\
\text { Vibration } \\
\text { Airstream vibrates reed on mouthpiece }\end{array}$ \\
\hline $\begin{array}{l}\text { Resonators: } \\
\text { Vocal Tract like a stopped pipe organ to vocal } \\
\text { folds for resonance } \\
\text { Oral and sinus cavities } \\
\text { Raised soft palate, open pharynx } \\
\text { Airstream resonates in sinus cavities } \\
\text { Pharynx -Vowel Sounds } \\
\text { Vowel sounds affect tone quality and pitch }\end{array}$ & $\begin{array}{l}\text { Resonators: } \\
\text { Clarinet Bore like a stopped pipe organ to } \\
\text { mouthpiece for resonance } \\
\text { Oral cavity } \\
\text { Raised soft palate, open pharynx } \\
\text { Airstream resonates in clarinet bore } \\
\text { Pharynx -Vowel Sounds } \\
\text { Certain vowel sounds affect tone quality and pitch }\end{array}$ \\
\hline $\begin{array}{l}\text { Articulators: Lips } \\
\text { Articulate some consonants such as m, p, b }\end{array}$ & $\begin{array}{l}\text { Articulators: Lips } \\
\text { Clarinet embouchure controls vibrations of reed on } \\
\text { mouthpiece }\end{array}$ \\
\hline $\begin{array}{l}\text { Tongue } \\
\text { Tongue articulates consonants } \\
\text { Vocal folds and relaxed pharynx } \\
\text { Vocal tone glides from note to note legato style }\end{array}$ & $\begin{array}{l}\text { Tongue } \\
\text { Tongue on t, d, k articulates notes } \\
\text { Fingers on keys and relaxed pharynx } \\
\text { Clarinet tone glides from note to note legato style }\end{array}$ \\
\hline $\begin{array}{l}\text { Vibrato } \\
\text { A natural function of the vocal ligament when the } \\
\text { airstream vibrates it }\end{array}$ & $\begin{array}{l}\text { Vibrato } \\
\text { Used sparingly with diaphragm or lips to vibrate the } \\
\text { reed }\end{array}$ \\
\hline $\begin{array}{l}\text { Range } \\
\text { Soprano vocal range is concert pitch G3 to C7 }\end{array}$ & $\begin{array}{l}\text { Range } \\
\text { Bb clarinet range is concert pitch D3 to D7 }\end{array}$ \\
\hline $\begin{array}{l}\text { Vocal Lyrics } \\
\text { Syllables, words, phrases and sentences give } \\
\text { musical and semantic meaning }\end{array}$ & $\begin{array}{l}\text { Clarinet Phrasing } \\
\text { Tone colour of melodic line gives musical meaning }\end{array}$ \\
\hline $\begin{array}{l}\text { Individual Identity of Vocal Tone } \\
\text { Affected by individual posture, breath, vocal folds, } \\
\text { vocal tract, pharynx, oral and sinus cavities, soft } \\
\text { palate, lips and tongue, body, personality and } \\
\text { musical experience of performer }\end{array}$ & $\begin{array}{l}\text { Individual Identity of Clarinet Tone } \\
\text { Affected by individual posture, breath, soft palate, } \\
\text { pharynx, lips and tongue, fingers, body, personality } \\
\text { and musical experience of performer }\end{array}$ \\
\hline
\end{tabular}




\section{Clarinet Construction and Historical Development}

During many years as an orchestral clarinettist I have noticed that clarinet tone and facility of playing is affected by its overall design, including the material used, the keywork, the size of the instrument, the width of the bore, the choice of mouthpiece and its accompanying reed and ligature. Similar to variations in vocal production, the choice of clarinet and mouthpiece, combined with the breath control of the clarinettist and the specific shape of the throat and oral cavities, creates an individual sound for each player.

The density of various woods affects the resonance of the clarinet, and in my experience well-seasoned wood improves the sonorous tone and longevity of the instrument. Early clarinets were often made of boxwood, and an African blackwood cocus, however over the past three centuries clarinet makers have preferred to use ebony, rosewood and cocobolo from Central America (Hoeprich 2008:215). Grenadilla blackwood from East Africa is similar to ebony and remains the favourite wood for clarinet manufacture due to its hard smooth surface, its resistance to moisture absorption and its ability to resonate. In the twentieth century clarinets have also been made out of plastic, ebonite and metal all of which impart a brighter tone to the instrument with less resonance than their wooden counterparts (Gibson,Oscar 1994:14).

Although the choice of wood and the shape of the bore contribute to the resonant tone of a particular clarinet, the most influential section of the clarinet is the reed and mouthpiece whose vibrations create sound, just as the larynx does in the human voice. Early mouthpieces were made of wood, and ebonite, which was first used in 1870, has continued to be favoured due to its improved pitch stability and resonance in temperature variations. Plastic and glass mouthpieces were first manufactured in 1930, and continue to be used by some players (Zakian n.d:6). I have found that plastic 
mouthpieces tend to produce a light and clear sound, while glass ones produce a more mellow and even sound over the entire range of the clarinet. By 1900 mouthpiece dimensions became standardised making it possible to play in tune on different clarinets with the same mouthpiece. Most of the current differences between the various models now have to do with the material used and the minute variations of the dimensions of the bore, chamber and facing, resembling the subtle variations of the vocal tract. French clarinettists generally prefer to use a mouthpiece with an 'open' lay, which is relatively large with a short opening (Hoeprich 2008:214). The effect of this is to produce a brighter tone which can be contrasted with the darker more 'covered' tone of German and Austrian clarinettists who tend to prefer a 'close' lay with a smaller but relatively long opening (Hoeprich 2008:214). I suggest that comparisons could be made between a soprano voice and the French clarinet tone, and a coloratura voice and the German clarinet tone, indicating the influence of the mouthpiece on tone production.

Ligatures to secure the reed in place are available in vinyl, metal and rubber and they play an important role in controlling the reed vibration against the mouthpiece, which is similar to the vibration in the vocal folds. Many German clarinettists still tie their reeds on with a piece of cord to ensure that the reed can vibrate freely and evenly (Hoeprich 2008:215). As the reed vibrating against the mouthpiece resembles the vibration in the vocal folds, the quality of the reed plays a very important role in clarinet tone production. In my experience a softer reed allows the clarinettist a very flexible tone with the ability to play glissandi, and an extreme of dynamic levels. In orchestral situations, where the intonation and tone are required to be consistent and even, a much harder reed is needed. 


\section{Historical Development}

When Joseph Denner invented the clarinet in Nuremberg by adding a 'register' key to the original chalumeau, the overblown notes became the clarion register, giving the instrument a second voice and a revised mezzo-soprano range (Hoeprich 2008:2021). By 1700 the clarinet possessed two keys, a conical bell and it could overblow a twelfth, producing a range of more than three octaves (ibid:19). The distinctive new timbral quality in the clarion register in addition to the existing chalumeau tone, led clarinet maker Jacques Simiot to observe in 1808 that,

The range, the variety and the quality of sound of the clarinet distinguish it from all the other winds, it has all the characteristics which composers desire, and can play equally well the hymn of the warrior or the song of the shepherd. (Hoeprich 2008:123)

In this quote Simiot is suggesting that composers welcomed the large pitch range and diversity of timbres on the clarinet, which allowed them the flexibility to write 'vocal' music in a wide range of musical styles.

Many new features were added to clarinet design in the nineteenth century to improve the resonance, the intonation and the ease of playing technical passages at fast tempi. In the early 1800s Iwan Muller's inventions of key pads, pad cups and metal ligatures improved the resonance and intonation of his thirteen-key clarinet (Zakian n.d:4). The introduction of 'needle springs' mounted onto posts by Auguste Buffet in 1837, and the addition of seventeen keys and six rings on the KloseBuffet clarinet greatly enhanced the ease of playing the clarinet so that the focus could be on tone production (ibid:5). Eugene Albert developed the large-bored Albert system clarinet in 1840 which remained popular until the early twentieth century in American jazz and English and European folk ensembles, partly due to its large resonant tone. The revised fingering system of the Boehm clarinet was patented in 1844 (ibid:5), and this model replaced the Albert System in orchestral and chamber music ensembles in 
the nineteenth century, and in jazz and folk ensembles in the twentieth century due to its sophisticated keywork and smaller bore size.

The rush by many European clarinet-makers to continually improve clarinet design was reduced in the early twentieth century, as more attention was given to the mass manufacture and distribution of the instruments to a world-wide market. Military band, jazz band, folk band and orchestral directors recognised the versatility of the clarinet as an expressive 'voice' and used it in their diverse ensembles (Hoeprich 2008:206).

Clarinet-makers faced a challenge to produce instruments with an even resonant tone over the entire range of the instrument, with near perfect intonation. Gibson has offered some interesting research on the historical development of the clarinet. In the first part of the nineteenth century French Boehm-style clarinets made by Buffet, Selmer, Leblanc and Noblet in France produced a bright resonant tone. Belgian Albertsystem clarinets with a large bore were also made at this time, producing a 'woody' tone (Gibson 1994:10-11). In Germany Oehler started clarinet production in 1910, Wurlitzer started in 1940, and in Austria, the Hammerschmidt family started in the 1950s (ibid:11-12). These instruments produced a darker tone quality due to the bore shape and the choice of mouthpiece and reed. In the United States Conn made excellent quality instruments, and between the two world wars many other firms made a variety of wooden, ebonite, plastic, plywood and metal clarinets with large variations in tone quality (ibid:14). Due to the qualities inherent in each of these materials these clarinets played with very different vocal tone qualities: some warm, some resonant, some bright and some harsh tones.

In the UK Boosey \& Hawkes produced its famous 1010s in 1970 with their large bore and resonant tone, and in Italy Orsi clarinets which are especially suited for vocal 
accompaniment in theatre orchestras were widely used (Gibson 1994:12-13). From the 1970s the Japanese company Yamaha started to produce a range of professional instruments, including a French and German style Boehm clarinet, by harnessing the technical skill of some of the European clarinet-makers (ibid:12). Meanwhile in Chile, Louis Santiago hand-made resonant one-piece clarinets with excellent intonation in blackwood or rosewood (ibid:13).

Clarinet-makers have historically had many difficulties to surmount in order to design instruments with a good resonant tone, including the intonation issues caused by the overblown twelfths (unlike the overblown octaves in the other woodwind instruments). Variations in air pressure in each register, the effects of temperature and humidity on the clarinet, and the variable combinations of the mouthpiece and reed also affect the tone quality. To address the ongoing issues of intonation and tone quality, in the early 1950s many of the Boehm-style manufacturers made significant changes to the clarinet bore size and shape, changing from a parallel cylindrical bore to a polycylindrical or a reversed conical bore, as in the famous Buffet R13 instruments (ibid:36).

Since 1955 Buffet Crampon's R13s have been the most popular clarinet ever made, mainly due to their rounded tone quality in a smaller bore (ibid:68). French clarinet manufacturers such as Buffet, Leblanc and Selmer were very influential in promoting revised narrow bore Boehm-style instruments with matching mouthpieces which allowed clarinettists to produce a bright 'ringing' tone over the range of the instrument. In the middle of the twentieth century the French style of playing also gained popularity in the United States, Belgium, the United Kingdom, Australia and New Zealand (ibid:10-15). 
Meanwhile in Germany, Fritz and Herbert Wurlitzer combined the larger German bore with improved Boehm fingering (twenty keys and seven rings) to create the Reform-Boehm system. Their addition of a double-speaker key improved the quality of the 'throat B flat' as previously this note was provided by the register key. Rollers between the E flat and C keys were added for ease and agility when playing fast passages (Stier 2010:1). The addition of mouthpieces with a 'close' lay and a long opening with very hard reeds produced a distinctive dense and woody tone. Wurlitzer clarinets gained popularity from the 1950s in Germany, the Netherlands, Austria and Scandinavia, having initially gained acceptance in the Royal Concertgebouw Orchestra in Amsterdam (ibid:1). They are still the instrument of choice in Germany in 2010, although French clarinets, especially those made by Buffet Crampon, are played professionally in most other countries.

The distinctive tone and the ability to bend notes meant that the Albert-system clarinet was often favoured over Boehm-system clarinets by early jazz players in New Orleans, and also by klezmer, Turkish and Greek clarinettists as they sought to imitate their vocal counterparts. American jazz clarinettist and author Oscar Font comments that in his opinion there are three main differences between the Boehm and the Albert system. He comments that the Albert system makes it easy to bend notes and make glissandi, it has a 'big wood sound' on the low register and a 'shine funky sound' on the high register, but its keywork makes it difficult to play fast passages. In comparison the Boehm system is not able to bend notes easily, it has the same classical sound in all registers, and its keywork makes it easy to play fast passages (Font n.d.:10). Early jazz players such as Alcide Nunez in the Original Dixieland Jazz Band, Leon Rappolo in the New Orleans Rhythm Kings, and Johnny Dodds in the New Orleans Wanderers played Albert system clarinets, but later players such as 
Benny Goodman and Artie Shaw popularised the Boehm clarinet. As Hoeprich comments, 'From a thin biting tone to a lush and warm singing quality of sound, Goodman's playing energised, seduced, amused and amazed his audience' (Hoeprich 2008:310).

In folk music, klezmer, Hungarian gypsy and Bulgarian traditional music, the B flat clarinet has traditionally been the instrument of choice, with the occasional use of clarinets in C, E flat or high A flat. Albert-system clarinets and simpler models with fewer keys have been used, but clarinettists in some of today's groups play Boehmsystem instruments (ibid:312). In Turkey the Albert-system clarinet was picked up by the local population and found to work well in traditional music with its ability to play microtones, glissandos and unusual tonalities, and so imitate the vocalists in the ensemble. Turkish clarinettists also played clarinets pitched low in $\mathrm{G}$, which were usually made of metal, producing a harsher and deeper tone than their wooden B flat cousins. (ibid:314).

A wide variation in tone quality and an individual style of playing is encouraged in jazz and folk music styles, where the clarinettist partners, imitates, amplifies and extends the expression of the vocalist. In relation to the expression of clarinettists in the jazz and folk genres, Hoeprich comments that,

In the jazz and folk genres, 'expressive intonation' can be heard in most performances...by most technical standards many jazz or folk clarinettists might be said to possess an unformed embouchure, sloppy articulation and a less-thanperfect sound quality. It is of course these qualities that give players of jazz and traditional folk music their enormous range of expression and the ability to affect their audience deeply...(ibid:316).

The varied options in clarinet, mouthpiece and reed combinations offers clarinettists a choice of instruments with which to reflect the musical style of their particular ensemble, yet still allows them an individual and 'vocal' tonal quality. This 
approach to choosing clarinets and accessories is outlined in the following table

Instrument Choices of case studies.

\section{Table 2: Instrument Choices of case studies}

\begin{tabular}{|c|c|c|c|c|}
\hline Clarinettist & $\begin{array}{l}\text { Make of } \\
\text { Clarinet }\end{array}$ & $\begin{array}{l}\text { Mouthpiece } \\
\text { and Reed }\end{array}$ & $\begin{array}{l}\text { Other } \\
\text { Instruments }\end{array}$ & $\begin{array}{l}\text { Individual } \\
\text { Tone Quality }\end{array}$ \\
\hline $\begin{array}{l}\text { Andrzej Nowicki } \\
\text { SMP Ensemble. }\end{array}$ & $\begin{array}{l}\text { Pair of Buffet } \\
\text { Crampon R13s } \\
\text { in B flat and A } \\
\text { Backun Barrel }\end{array}$ & $\begin{array}{l}\text { Backun } 0+\text { and } \\
\text { Vandoren \#4 reeds } \\
\text { Uses softer reeds } \\
\text { when needs to } \\
\text { produce } \\
\text { multiphonics. }\end{array}$ & $\begin{array}{l}\text { E flat, Bass } \\
\text { clarinets } \\
\text { Andrzej thinks } \\
\text { these are an } \\
\text { extension of the } \\
\text { B flat 'soundworld' } \\
\text { Alto Saxophone. }\end{array}$ & $\begin{array}{l}\text { Describes his sound } \\
\text { as 'intense and } \\
\text { dolce'. He believes } \\
\text { personal } \\
\text { physiology affects } \\
\text { individual tone } \\
\text { colour. There is } \\
\text { more expressive } \\
\text { tonal freedom } \\
\text { allowed in smaller } \\
\text { ensembles. }\end{array}$ \\
\hline $\begin{array}{l}\text { Debbie Rawson } \\
\text { The New Zealand } \\
\text { Clarinet Quartet. }\end{array}$ & $\begin{array}{l}\text { Pair of Yamahas in } \\
\text { B flat and A } \\
\text { Suited to classical } \\
\text { playing }\end{array}$ & $\begin{array}{l}\text { Uses the most } \\
\text { effective } \\
\text { mouthpiece and } \\
\text { reed combination } \\
\text { for each instrument } \\
\text { and each ensemble. } \\
\text { Uses softer reeds } \\
\text { when doubling on } \\
\text { different } \\
\text { instruments. }\end{array}$ & 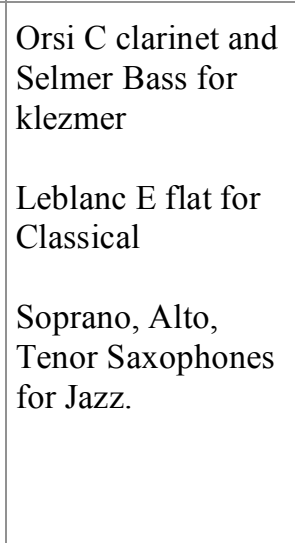 & $\begin{array}{l}\text { The lower clarinets } \\
\text { have a darker tone, } \\
\text { higher ones are } \\
\text { brighter, with the E } \\
\text { flat clarinet having } \\
\text { the most 'evil } \\
\text { brightest one'. } \\
\text { Thinks there is an } \\
\text { individual sound on } \\
\text { any clarinet. } \\
\text { Clarinet design still } \\
\text { needs } \\
\text { improvement. }\end{array}$ \\
\hline $\begin{array}{l}\text { Greg Rogan } \\
\text { The Blackbird Jazz } \\
\text { Trio. }\end{array}$ & $\begin{array}{l}\text { Pair of Yamaha CS } \\
\text { clarinets produce a } \\
\text { 'floating, oily } \\
\text { sound' } \\
\text { Suited to jazz }\end{array}$ & $\begin{array}{l}\text { Flexible } \\
\text { mouthpiece and } \\
\text { reed combinations } \\
\text { for each instrument } \\
\text { and each ensemble. } \\
\text { Softer reeds used } \\
\text { when doubling on } \\
\text { different } \\
\text { instruments. }\end{array}$ & $\begin{array}{l}\text { Flute } \\
\text { Soprano Alto and } \\
\text { Tenor Saxophone } \\
\text { Singer }\end{array}$ & $\begin{array}{l}\text { Clarinettists all } \\
\text { have an individual } \\
\text { sound regardless of } \\
\text { their instrument. } \\
\text { All clarinets should } \\
\text { have an alternative } \\
\text { left E flat key for } \\
\text { ease of playing in } \\
\text { sharp keys. }\end{array}$ \\
\hline $\begin{array}{l}\text { Urs Signer } \\
\text { The Klezmer Rebs. }\end{array}$ & $\begin{array}{l}\text { Buffet Festival } \\
\text { B flat } \\
\text { Buffet Daniel } \\
\text { Gautier A. }\end{array}$ & 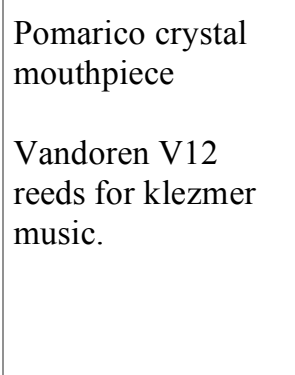 & Bass clarinet & $\begin{array}{l}\text { Describes his tone } \\
\text { as 'earthy' and } \\
\text { 'squeaking'. } \\
\text { Notices differences } \\
\text { between American } \\
\text { and European } \\
\text { styles. Wants to } \\
\text { create an individual } \\
\text { sound. }\end{array}$ \\
\hline
\end{tabular}




\section{Conclusion}

In this chapter detailed comparisons between the methods of vocal and clarinet production and tone quality were discussed, leading to some significant conclusions about their close musical relationship. A close analysis of the tone production in both the voice and the clarinet revealed the specific aspects of their mechanisms, which were further explored in a direct table of comparisons. The affinity between the voice and the 'vocal' tone of the clarinet was further explored in the section on clarinet construction and historical development.

In the Table of Comparisons there are numerous similarities between voice and clarinet tone production. Both share the need for an aligned posture to allow for maximum use of the lung capacity, and deep and regular abdominal breathing with full exhalation and inhalation on every breath. The vibrations of the vocal folds in the larynx can be compared with the vibrations of the reed against the clarinet mouthpiece, and the Bernoulli effect on the air pressure is evident in both instances. The vocal tract and the clarinet bore act as resonators, are a similar shape, and they both function like a 'stopped pipe organ'. In both vocal and clarinet tone production the shape of the pharynx plays a large part in the airflow and the quality of the tone. Similarly the oral and sinus cavities also act as resonators in both cases, with the raised soft palate improving the tone production. Both voice and clarinet are capable of gliding effortlessly over melodic phrases; in the voice this is achieved by an open pharynx and smooth movement from note to note in the voice, and in the clarinet by an open pharynx and smooth movement of fingers over the key-work. The range of the clarinet is very similar that of a trained soprano, with a slightly extended lower and higher range.

In vocal tone production the individuality of the performer is clearly in evidence, as the physiology of the performer plays a significant role in their tone quality. 
Clarinettists are also capable of playing in an individualistic way through their choice of clarinet design, their mouthpiece, reed and ligature, and their own particular facial and physical attributes.

Since the invention of the instrument, clarinet-makers have continuously experimented with different woods and other materials, bore and mouthpiece shapes, reeds and ligatures to try to improve the 'vocal' resonance and intonation of the clarinet. Depending whether a clarinettist is playing in a classical, folk, klezmer, jazz or tango ensemble, they can combine different clarinets, reeds and mouthpieces to achieve the specific tone they are seeking. The clarinettists in the case studies chose specific combinations of instruments, mouthpieces and reeds to reflect the musical style of their particular musical ensemble, and also to retain some individual 'vocal' quality in their playing.

From this research it is clear to see that there are very many physical similarities in the way that musicians produce vocal and clarinet tone. The composition of the clarinet mouthpiece, reed and cylindrical tube, allows its players to 'sing' into the instrument, using the clarinet as an extension of the voice. In the following chapter the performance research on the four clarinettists in the case studies demonstrates how they imitate, partner, mimic and replace the voice to become conduits of musical styles in and between diverse ensembles. 


\section{CHAPTER TWO: Case Studies of Four Clarinettists in Wellington}

\section{Introduction}

In order to illustrate ways in which the clarinet is an extension of the voice and therefore an expressive conduit of musical styles, the research is focused on the links between the voice and the clarinet and also refers to the cultural heritage of the clarinettists within their ensembles. As the clarinet is used in diverse musical styles in many different countries, I selected members of ensembles in Wellington, New Zealand, who would provide a representative sample of four distinct playing styles: Western art and contemporary music, jazz and klezmer music. It was important for my research that the clarinettists were professional freelance players in established ensembles who performed regularly, so that I could often attend their rehearsals and performances. My research methodology included personal interviews, email communications, and ethnographic fieldwork at the rehearsals and concerts of the four ensembles in 2009 and 2010. Each case study includes a section on the clarinettist's specific ensemble, their profile, descriptions of their performance, their cultural heritage, their leadership roles in their ensembles, and the ways in which they act as expressive conduits of music in diverse ensembles. Below I provide a brief introduction to each clarinettist to outline their style of music, and the reasons for their inclusion in this project.

As a regular performer in the contemporary music collective, called the Summer Music Project Ensemble (SMP Ensemble), clarinettist Andrzej Nowicki's use of contemporary clarinet techniques illustrated ways in which the clarinet extended and replaced the human voice. On many occasions Andrzej demonstrated innovative clarinet techniques in works by New Zealand, Polish and European composers. 
Debbie Rawson is an experienced clarinet and saxophone soloist, chamber musician and orchestral player, and she is currently Head of Woodwinds at the New Zealand School of Music. Debbie also works with singers in a variety of ensembles from opera to chamber music, and she is currently a member of the New Zealand Clarinet Quartet. In each of her many ensembles Debbie instigated commissions for new works by New Zealand composers and championed the performance of existing New Zealand compositions, revealing her close identification with New Zealand culture.

Greg Rogan is a clarinettist with the Blackbird Jazz Trio in Wellington and has professional experience as a singer, clarinettist and saxophonist, moving easily from one role to another. At the time of writing it was unusual to find a contemporary jazz ensemble where it is the clarinettist who takes a leading role rather than the alto or tenor saxophonist. In this trio Greg illustrated links between the voice and the clarinet in his playing, and he revealed his New Zealand heritage combined with his affinity with jazz from the United States of America.

Ashkenazic Jewish culture is reflected in klezmer music, which is often performed for weddings and bar mitzvahs at synagogues and other venues in the community. In klezmer music both the clarinet and the violin are both used to imitate the 'wailing' voice of the cantor in the synagogue. Urs Signer has been playing the clarinet with the Klezmer Rebs ensemble in a variety of venues in Wellington for several years, using specific playing techniques to create maximum 'vocal' expression. His mix of a Swiss cultural background combined with his engagement and identification with Jewish and Maori culture made him a very interesting case study.

By researching the four clarinettists' cultural heritage, their choice of clarinet design and mouthpieces, their approach to clarinet playing, their roles in their particular 
ensembles, where they played, and the way they influenced their audiences, I explored the ways in which the clarinet acts as an expressive extension of the voice and as a conduit of musical styles in and between diverse ensembles.

\section{The SMP Ensemble: Andrzej Nowicki}

\section{Ensemble}

The SMP Ensemble is a fairly recent addition to the contemporary music scene in Wellington, having started as The Summer Music Project in 2008. Based at The New Zealand School of Music in Wellington, initially the performers were entirely NZSM performance students; however as the ensemble has developed it has included other musicians from Wellington's musical community. Repertoire choices for this contemporary collective include music from different time periods, often featuring theatrical, visual, humorous, serious, absurd, or aleatoric elements. In response to a question about the direction of the group, director Andrzej Nowicki, commented that the ensemble 'aims to explore a diverse range of music for political or satirical comment and to provide an opportunity to showcase its talented young performers' (Nowicki, 30 September 2009, pers.comm).

\section{Profile: Andrzej Nowicki}

By observing Andrzej's performances and in interviews with him about his leadership and performance roles in the ensemble, it has become apparent how the combination of his Polish and New Zealand cultural heritage have influenced the SMP Ensemble and its musical directions and how this has been transmitted to the audience. Although currently living in New Zealand, Andrzej has a strong Polish heritage, as all four of his grandparents were born in Poland, his mother was brought up in a Polish community in Canada, and his father in a Polish community in England after World War II. As Polish ex-patriots Andrzej's parents decided to retain their language 
and their cultural traditions, and as a child Andrzej attended a Polish school, sang in several Polish choirs and later danced in a Polish folk dancing groups. He spent his early years in New Zealand, later moved to Melbourne with his family where he studied dentistry, and returned to New Zealand in 2005 (Nowicki, 26 June 2010, pers.comm).

\section{Vocal Influences on Clarinet Playing}

In our interviews Andrzej referred to playing the clarinet with 'his head, heart and soul' to communicate emotional expression to the audience. He also commented that he would like to do more singing in the SMP Ensemble and he sees many similarities between the voice and the clarinet. Andrzej commented that 'the clarinet is a wind instrument, powered by breath like a singer, and the reed vibrates like the vocal chords to create a sound. The dynamic range is similar to a trained voice, and you can sing into the clarinet and resonate into it as well' (Nowicki, 30 September 2009, pers.comm). Very often the clarinet took the role of vocal expression in the SMP Ensemble performances, by playing high lyrical lines or colourful motifs in the clarion or altissimo register, as could be heard in the Allegro Moderato of Penderecki's Sextet at the Podroze-Journeys concert.

When asked whether he alters his playing style for orchestral and contemporary works, Andrzej responded that he always aims for the best expressive tone and technique in all ensembles, but he is guided by musical requirements such as theatrical, improvisatory or contemporary technical elements in the music (Nowicki, 30 September 2009, pers.comm).

The clarinet repertoire in the SMP ensemble allows for a wide range of 'vocal' expression on the instrument, through the use of such performance techniques as playing over the entire four and a half registers, multiphonics and flutter tonguing, amplification, using percussive possibilities on the clarinet, removing the mouthpiece 
and blowing directly into the pipe, and performing with mixed media (Nowicki, 30 September 2009, pers.comm). As well as performing standard repertoire the ensemble has performed many works which present technical challenges to the clarinettist, such as the Sonata for Solo Clarinet by Denisov, and Concertino $5 b$ written by Andrzej Nowicki and Richard Robertshawe as shown in the figure below. In the Denisov Sonata for example, the use of extended techniques and mixed meters was exhibited in the development from a slow first movement into a second movement featuring vocal 'wailing' and 'frantic morse code-like' motifs, expressing a mood of desperation.

Due to Andrzej's direction, the repertoire of the SMP Ensemble has included several contemporary works for clarinet in solo and ensemble pieces, such as Penderecki's Prelude for Solo Clarinet, Hindemith's Two Sonatas for Violin and Clarinet, Aaron Copland's Sonata for Clarinet and Piano and Poulenc's Sonata for Clarinet and Bassoon, which highlight the expressive capabilities of the clarinet.

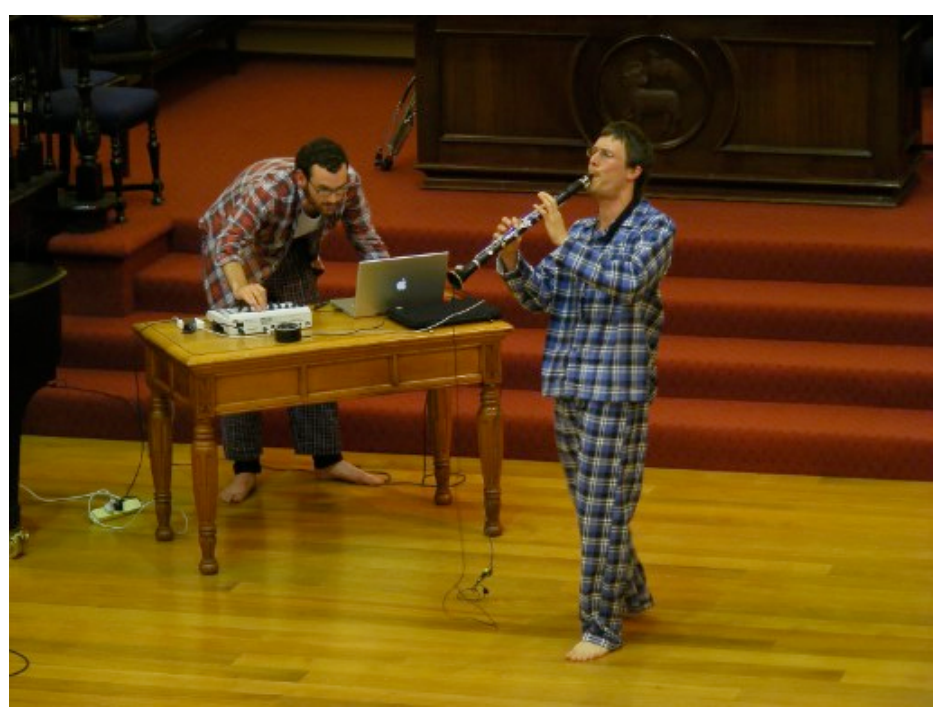

Figure 6: Concertina $5 b$ by Andrzej Nowicki and Richard Robertshawe Performed by Andrzej Nowicki. 13 June 2009

Photograph by Megan Ward 


\section{Performance Descriptions: The SMP Ensemble}

In my interviews with him, Andrzej discussed how some of his repertoire and concert choices for the SMP Ensemble drew in part from his wish to engage with his Polish heritage. The most notable example of this was the Podroze-Journeys Concert on $1^{\text {st }}$ November 2009 held at the Wesley Church in Taranaki Street. The concert featured works by Polish composers and those by New Zealand composers writing on a Polish theme. This concert was supported by the Polish Embassy, the Polish Charitable Trust, the Polish Children's Reunion Committee and the Polish Association of New Zealand (Podroze - Journeys:2009).

The programme included several vocal works such as Polskie Kwiaty, a Polish folk song that communicated memories of the homeland to the Polish migrants in the audience, and Carol Shortis' work Tesknota (Yearning), in which several members of the Wellington Youth Choir and Polish soprano Olga Gryniewicz joined members of the SMP Ensemble. As Carol commented in the programme notes, 'this piece has been written for the sixty-fifth anniversary of the arrival in New Zealand of Polish refugee children in 1944. Most of them were children who had been separated from, or who had lost their parents and other family members' (Nowicki 2009:4). Other works by Polish composers in this concert were Three Pieces in Olden Style by Henryk Gorecki for String Orchestra, Melodie Ludowe by Lutoslawski for String Orchestra, Allegro Moderato from the Sextet by Penderecki (violin, viola, cello, horn, piano, clarinet) and Rymy Dzieciece - Children's Rhymes Op 49 by Szymanowski (Olga Grniewicz soprano, Claire Harris piano). In the works where Andrzej performed as a clarinettist it was apparent that he identified strongly with his Polish heritage and in his playing he was acting as a conduit for Polish music. 
Andrzej was the Master of Ceremonies and co-ordinator of this concert, and he also performed in the instrumental work Allegro Moderato from the Sextet by Penderecki, and in the Hommage to W.L (Witold Lutoslawski) by Karlo Margetic. In the Penderecki work Andrzej played several 'sing-song' solos in the high register of the clarinet, as well as playing many lyrical passages. In the work by Margetic, Andrzej began with a haunting clarinet theme in the high register before passing it on to the bass clarinet, and finally to the french horn. The 'vocal' clarinet themes then developed into an intense 'musical conversation' with various percussion instruments, before the violin, viola, cello, french horn, piano, and bass clarinet entered to create a chaotic sound world.

At the 'Vistas' concert on 26 March 2010 the SMP Ensemble performed a programme of contemporary instrumental works with the well-known Dutch conductor Lucas Vis, in the Adams Concert Room at the New Zealand School of Music. The venue is central and suitable for the performers, most of whom are NZSM music students. All of the works were composed by Dutch or New Zealand composers, and Andzrej played in Zilver by Louis Andriessen (the Netherlands), Two Moments by Anton Killin (New Zealand) and Tinkling by Yannis Kyriakides (Cyprus/The Netherlands). In these minimalist contemporary works the clarinet tended to feature as an integral part of the instrumental texture, rather than as a soloist.

Exciting and diverse programmes are a feature of the SMP Ensemble concerts, and in the Echoes for the Environment on $31^{\text {st }}$ July 2010 concert each work had a distinctive dramatic and visual impact. For example in Five Sacred Trees, Kylie the solo bassoonist, wore leaves in her hair and in her bassoon, and her face was painted to resemble a tree. The works were performed by solo instruments, small sized groups, a large group of the gamelan orchestra and three singers who performed 
Ketawana Wellington by Lou Harrison. Andrzej featured as a clarinet soloist in two works by New Zealand composers, Waipoua by Gareth Farr as shown in the figure below, and Bellbird's Cry by Simon Eastwood.

In the programme notes Gareth Farr is quoted,

Waipoua is an exploration of the lyrical and emotional capabilities of my favourite wind instrument, the clarinet. It is also a recollection of echoing sounds, and the overwhelming sight of Tane-Mahuta, the giant Kauri. (Farr, 31 July 2010)

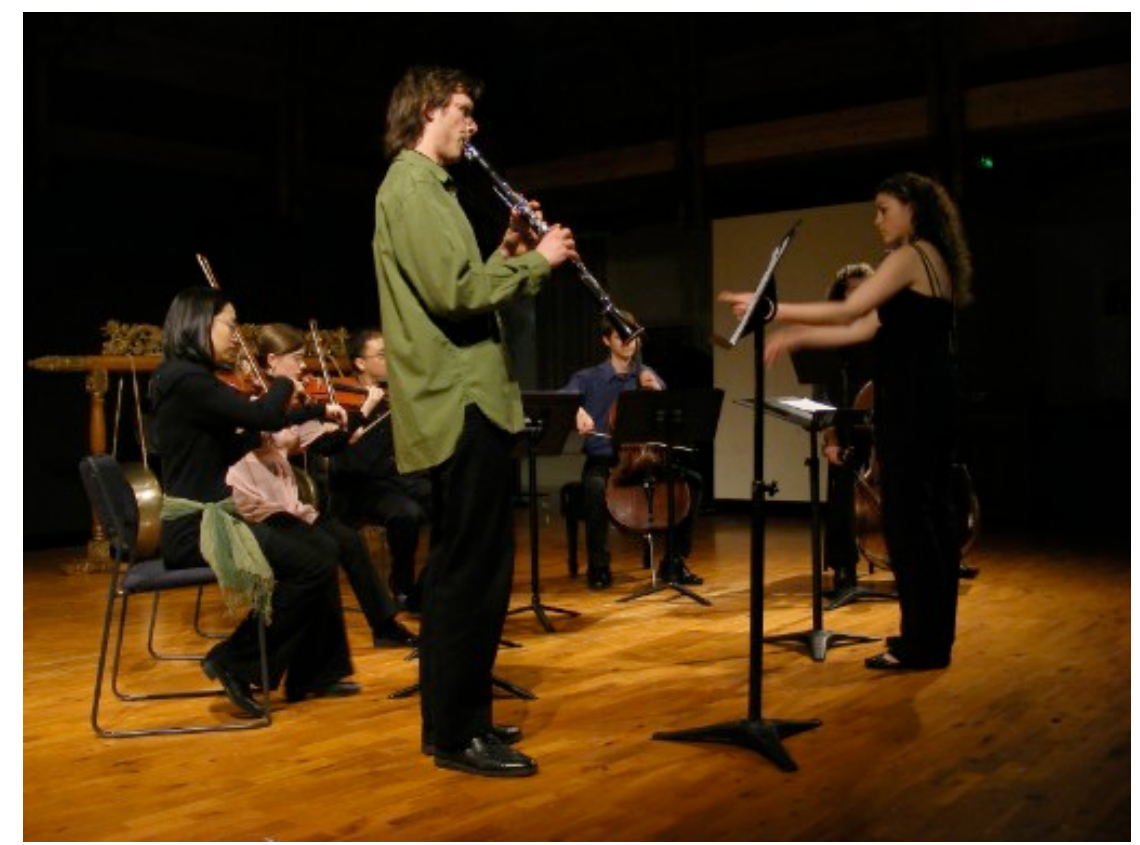

Figure 7: The SMP Ensemble in Waipoua Forest by Gareth Farr

Judy Guan, Tabea Squire, Andrew Filmer, Andrzej Nowicki, Charley Davenport, Simon Eastwood, Conductor Karla Norton, July 312010

Photograph by Megan Ward

It seemed as if the role of the clarinet was to imitate a female voice in this work, as it performed an expressive lyrical line with a rounded tone in the clarion and altissimo registers. In Bellbird's Cry, Andrzej imitated the bellbird's song by playing short phrases in the upper registers in a sweet ringing tone. Using bird-like trills in both high and low registers and playing rising arpeggiated patterns, Andrzej imitated and extended the native New Zealand Bellbird's song. 


\section{Cultural Heritage}

Andrzej's Polish heritage features strongly in his leadership of the ensemble, and it influences his choice of repertoire and the associations the ensemble chooses to support with their concerts. His affinity with New Zealand is also an important factor in the ensemble, especially in the way he champions commissions of works by New Zealand composers (Nowicki, 26 June, pers.comm).

The Podroze-Journeys Concert featured European and New Zealand musicians such as Justus Rozemond from Holland, first violinist Martin Jaenecke from Germany, soprano Olga Gryniewicz from Poland, and Andrzej Nowicki on clarinet (PodrozeJourneys:2009). I observed that the European flavour continued in the Vistas concert when Guest Conductor Lucas Vis from the Netherlands conducted a programme of music from the Netherlands and New Zealand. In the final SMP Ensemble concert of 2010, entitled Mirrors of the Heart, Andrzej performed in one of his own compositions entitled The Curse of Katyn accompanied by a violinist, violist, cellist and pianist. The programme notes explained that this work alluded to the Soviet Secret Police slaughter of thousands of Polish nationals in the woods of Katyn in Western Russia in 1940. Expressive lines played in the altissimo register of the clarinet, low bass motifs in the piano, together with pizzicato and spiccato motifs in the strings combined to create an intense and emotional mood which reflected Andrzej's Polish heritage.

Under Andrzej's direction the SMP Ensemble has commissioned several works by New Zealand composers such as Simon Eastwood's Jericho: Walls Will Fall, Anton Killin's Podroze, Karlo Margetic's Hommage to W.L. and Carole Shortis' Tesknota, indicating his strong link to New Zealand musical culture. Works by other New Zealand composers include those by Gareth Farr, Jack Body, Eve de Castro 
Robinson, Douglas Lilburn, Lyell Cresswell and Jonathan Berkahn as shown in the figure below (Nowicki, 26 June, pers.comm).

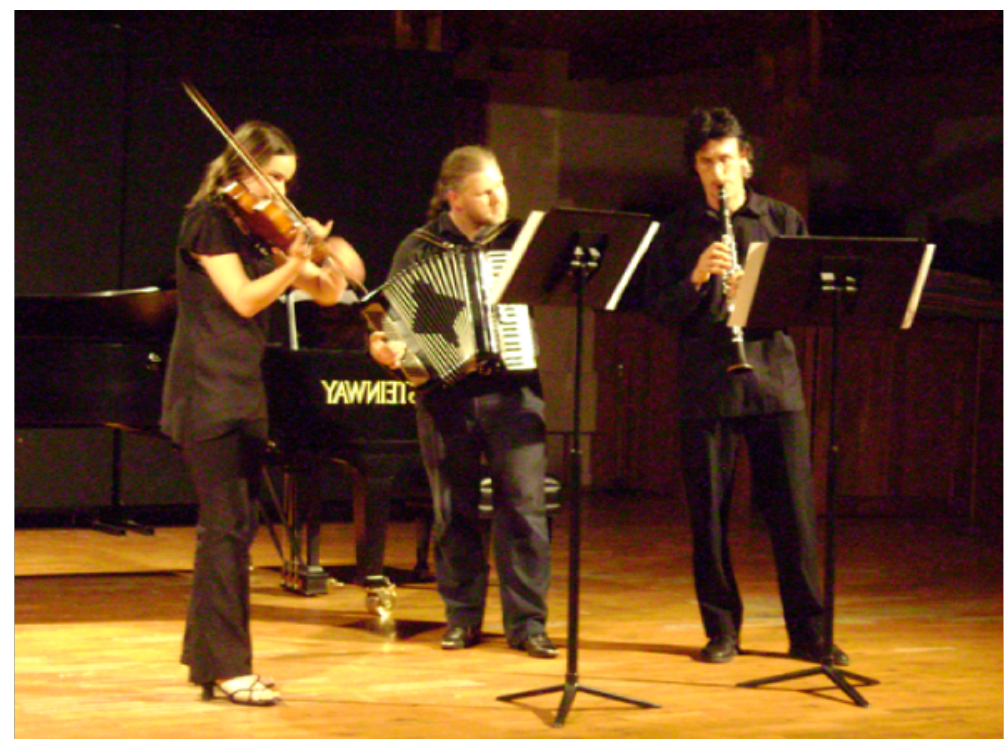

Figure 8: Tango Oscuro by Jonathan Berkahn

Andrzej Nowicki, Jonathan Berkahn, Kylie Nesbit, 2009

Photograph by Mike Lemmon

Since December 2008 Andrzej has also included works by European composers such as Bartok, Britten, Gorecki, Ligeti, Lutoslawski, Messiaen, Schoenberg and Stockhausen, the American composers Reich, and Riley and the Japanese composers Takemitsu, highlighting his keen interest in twentieth century music. He often intersperses performances of contemporary works with performances of works by historical composers such as Bach, Scarlatti and Vivaldi (SMP Ensemble 2010). In these works the emphasis is on the expressive capabilities of the performers to communicate with the audience, in particular Andrzej's use of the clarinet as an extension of the voice as in the Abime des oiseaux by Messiaen.

\section{Leadership Role}

In 2010 Andrzej coordinated several concerts of contemporary music with a variety of musicians and composers at many different venues in Wellington. Many of the works performed were by student composers at the NZSM, some were by 
established New Zealand composers and many were premiere performances. In his leadership role in this ensemble Andrzej spent many hours on administration, as well as undertaking part-time music studies at the NZSM and working part time as a dentist. Andrzej commented that the target audience for the ensemble comprise 'people who are keen to go on a journey into different sound worlds' and that 'the repertoire challenges peoples' perception of the role of music'. He commented that the SMP Ensemble performances were appreciated best by musicians, as they required a certain amount of musical and cultural understanding (Nowicki, 3 June 2010, pers.comm).

Andrzej's ability to perform a variety of roles has been evident in each of the SMP Ensemble concerts I have attended. At the concert entitled 'Echoes: a Concert for the Environment' on $31^{\text {st }}$ July 2010, Andrzej featured in the role of MC, clarinet soloist, composer, arranger and singer. Although he performs in several of the works at each concert, he also enjoys giving other composers and musicians the chance to perform new compositions. In his MC role Andrzej usually introduces the works on the programme and invites the audience to share a supper provided by the SMP Ensemble, which encourages the audience members to mingle and chat freely together.

When I first interviewed Andrzej in September 2009 about the aims of the ensemble, he suggested that they were to discover new music, support new compositions by members of the group, offer leadership opportunities, and provide a sense of purposeful musical belonging. Andrzej commented that 'members of the group provide the stimulus to find challenging new pieces to perform' (Nowicki, 30 September 2009, pers.comm). On re-visiting this topic in the June 32010 interview, the aims had evolved to include aspiring to become a semi-professional ensemble which included experienced players in the Wellington community as well as performance 
students at the NZSM, with age ranges from twenty to fifty, highlighting the diversity of the musicians involved.

At the time of writing in 2010, the aims included seeking sponsorship to bring together composers and performers to perform contemporary works and premieres of new works. In the recent concert Vistas with the internationally renowned conductor Lucas Vis, Sunniva Zoete-West from the Caprice Arts Trust found sufficient funding to pay the conductor and several of the SMP Ensemble musicians (Nowicki, 3 June 2010, pers.comm). Producing the two recent concerts Podroze - Journeys and Vistas (a New Zealand and Dutch concert) with Lucas Vis from the Netherlands, required the SMP Ensemble to be better organised and more professional than previously. They were required to improve their individual and ensemble musicianship in order to meet the excellent musical standards of the visiting conductor Lucas Vis, which had the added benefit of improving the public perception of the ensemble (Nowicki, 3 June 2010, pers.comm).

In order to address these revised aims the SMP Ensemble committee meets monthly to select new repertoire. In an interview Andrzej commented that the committee works as a cooperative to decide on a vision and a theme for each concert. His specific role is to edit the repertoire, provide administration and produce the concerts in accordance with the vision and theme (Nowicki, 3 June 2010, pers.comm).

\section{Conduit of Music in Diverse Ensembles}

In his role as both director of and clarinettist in the SMP Ensemble, Andrzej often chooses to reflect his Polish heritage in the inclusion of repertoire by Polish and European composers, and in his choice of concert themes. Andrzej also encourages and commissions works by New Zealand composers for the SMP Ensemble, indicating his special affinity for New Zealand. In the ensemble Andrzej's clarinet tone often 
becomes an extension of the voice, as it replaces or extends the 'vocal line' with its own flexible timbre, as in the Lutoslawski and Gorecki works. Concert themes include new commissions by New Zealand composers, Polish music, music from the Netherlands, women composers and ECO. The diversity of contemporary repertoire coupled with dramatic and visual elements provides musicians and audiences with distinctive and memorable performances. This dynamic contemporary collective has the clarinet at the core of its leadership and performance, which provides a depth of emotional resonance to the cultural music in the ensemble.

\section{The New Zealand Clarinet Quartet: Debbie Rawson}

\section{Ensemble}

The New Zealand Clarinet Quartet 2010 is Debbie's most recent clarinet ensemble comprising Debbie Rawson, Haydn Sinclair, Tui Clark and Richard Haynes, who play the entire family of clarinets. In an interview Debbie commented that the clarinettists tend to choose their preferred 'vocal register' on the high E flat, B flat, A, Alto or Bass clarinets, regardless of their gender (Rawson, 4 August 2010, pers.comm). The New Zealand Clarinet Quartet is especially relevant to my research as the musicians play as a 'clarinet choir' in imitation of a vocal choir. Using the clarinet as an extension of the voice Debbie and the other members of the ensemble illustrate deep connections between the voice and the clarinet in their performances.

\section{Profile: Debbie Rawson}

Debbie Rawson's extensive experience includes playing the clarinet and bass clarinet for many years with the Wellington Sinfonia Orchestra, the New Zealand Symphony Orchestra (NZSO) and the Vector Orchestra. She also played tenor saxophone in the Rodger Fox Big Band in the 1970s and 1980s. As a freelance musician she has played an important role in setting up some of New Zealand's well- 
known chamber music groups, such as The Zelanian Ensemble, Saxcess, Tango Virtuosi, and most recently The New Zealand Clarinet Quartet (Rawson, 4 August 2010, pers.comm). Debbie's cultural heritage as a New Zealander with a European background has significantly influenced her clarinet playing, in terms of the ensembles she has initiated and performed in and the commissions for New Zealand music she has undertaken. Owing to her mother's musical interests she was brought up listening to Dixieland Jazz, the Glenn Miller Big Band, classical symphonies and concertos, and shows such as My Fair Lady and Gigi. In an interview with me, she said that it was when she heard the principal clarinettist with the NZSO Frank Gurr play the slow movement of the Mozart Clarinet Concerto, that she knew she wanted to play 'this beautiful mournful instrument'. She started playing the clarinet at age thirteen with teacher Anton Radaich, before completing a Diploma in Music at Canterbury University in 1974 with teachers Rolf Just and Frank Gurr. She was later the recipient of a scholarship to study with Yona Ettlinger, former principal of the Israel Philharmonic, at the Guildhall School of Music and Drama in London in 1975 (Rawson, 4 August 2010, pers.comm).

On her return from overseas study, Debbie played as principal clarinet with the regional orchestra the Wellington Sinfonia from 1976-1989. After this she started freelancing in a variety of ensembles and working as an extra player on the B flat, E flat and Bass clarinets for the NZSO, and for the newly named regional Vector Orchestra until 2000. Debbie initiated several chamber music ensembles in the 1980 s, one of which was entitled Constanza, comprising herself as clarinettist, Anna Reissar as soprano and pianist Colleen Rae Gerrard. Another musical group she initiated was the Zelanian Ensemble comprising herself as clarinettist, Uwe Grodd, as flutist, Donald Maurice as violist, and pianist Rae de Lisle as shown in the figure below. Debbie and 
the other members of the ensemble identified strongly with New Zealand culture and they showed their support for New Zealand composers by commissioning and performing new works by them on a regular basis. (Rawson, 4 August 2010, pers.comm).

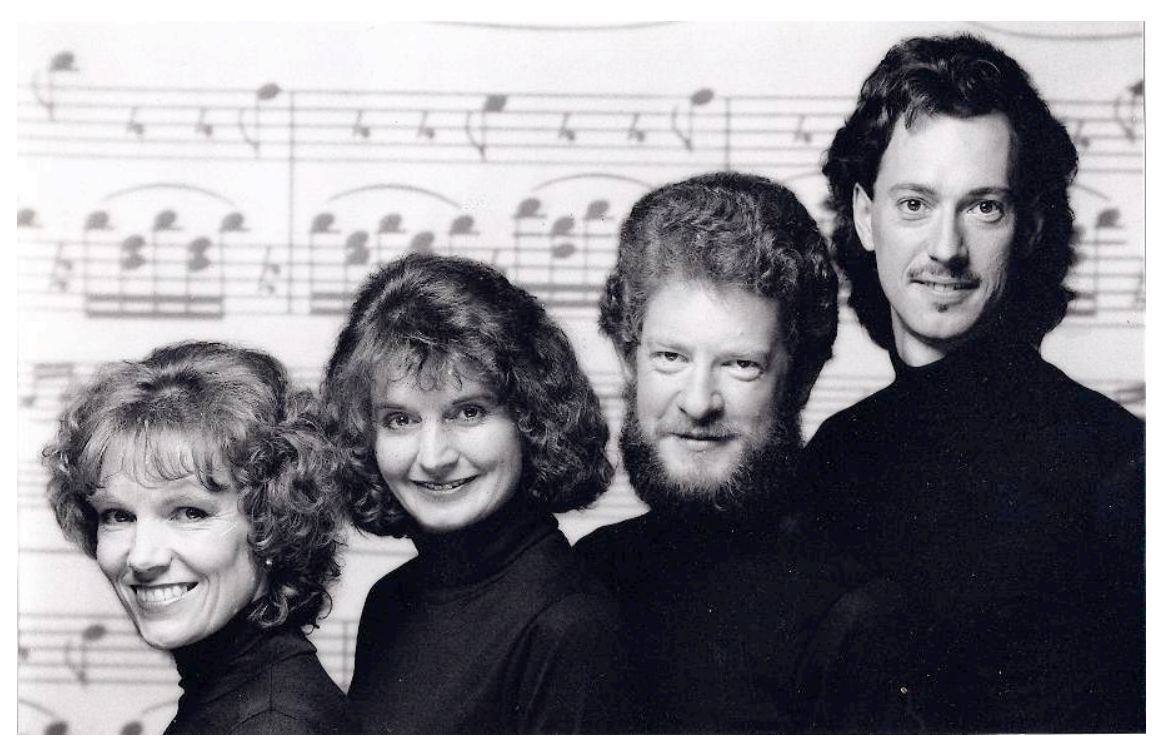

Figure 9: The Zelanian Ensemble Rae de Lisle, Debbie Rawson, Donald Maurice, Uwe Grodd, 1988 Photograph by Sal Criscillo

In the past decade Debbie has initiated three other ensembles, Saxcess, Klezmer Cafe and Tango Virtuosi, in which she plays a mixture of clarinets and saxophones. These ensembles have performed locally, nationally and internationally to enthusiastic audiences (Rawson, 4 August 2010, pers.comm).

\section{Vocal Influences on Clarinet Playing}

In our first interview Debbie commented that the clarinet is 'a mirror of the soul', and that because of its reflection of the personality, 'you have to bare yourself when you play' (Rawson, 4 August 2010, pers.comm). She believes that if you want to play the clarinet well 'you can never fake it, you have to be open and give yourself totally to the music'. In Debbie's view 'the clarinet is a megaphone of the inner voice' (Rawson, 4 August 2010, pers.comm). Debbie mentioned that she believes that there is an 
integrated relationship between singing and playing the clarinet, in the way both activities require abdominal breathing and the entire body is involved in producing sound. She made a perceptive comment that because the clarinet mouthpiece is situated inside the body, clarinettists feel the vibrations of the sound internally. Linked to this is the fact that in her view the pharynx, oral cavities and tongue position all play a crucial role in both singing and clarinet playing, noting in particular that 'the tongue is a very strong muscle and its position in the mouth directly affects the quality of the tone' (Rawson, 4 August 2010, interview). As an example of the variations in tongue positions for clarinet playing, Marina Sturm, an American principal clarinettist with the New Zealand Symphony Orchestra in the 1990s commented to Debbie that the relaxed position of the throat and the low position of the tongue created a broad 'aw' tone by New Zealand clarinettists compared to her more forward 'ee' sound, which was produced by a less relaxed throat and a higher tongue position by American players. In this instance the accent in which she was speaking had a direct effect on her American clarinet tone, creating a bright 'ringing' tone, which is aligned to the French school of playing.

In addition to describing the physical links between singing and clarinet playing Debbie believes she has learned more from singing teachers how to play well on the clarinet than from clarinet teachers. When she first started to accompany singers for opera in the orchestra she learned how important it was to 'go with' the singer in a rubato style instead of playing metronomically, as is often required in instrumental groups such as orchestras and concert bands (Rawson, 4 August 2010, pers.comm).

In the Constanza ensemble Debbie responded to Estonian soprano Anna Reissar's emotional singing, realising how much easier it was to play with singers as it lifted the level of expression in her own playing. One of the favourite works in their repertoire 
was Shepherd on the Rock by Schubert, which clearly illustrates the ways in which the clarinet part imitates partners and echoes the vocal part. Debbie also commented on the way that the clarinet is often used to mimic birdsong in such works as the cuckoo in Beethoven's Symphony No 6, Messiaen's Abime des Oiseaux, and the recent work Bellbird's Cry by Simon Easton. In The New Zealand Clarinet Quartet a work by Natalie Hunt entitled Plight of the Flightless showcases clarinets imitating two types of native New Zealand birds, the kakapo and the kiwi (Rawson, 4 August 2010, pers.comm).

Debbie believes that because clarinettists are very often given the major role of partnering and imitating operatic singers, it is vital to develop a 'singing approach' by imitating their subtle nuances of tempi, rubato, phrasing and tone colour. In her opinion orchestral clarinettists who play for opera need to be constantly alert to variations in tempi, as the singers dictate the tempo which the conductor follows. To Debbie the virtuoso aspect of clarinet performance is as appealing as its expressive qualities, and she hopes to move and excite her audiences by taking them through a range of emotions from heartfelt, to exciting and brilliant (Rawson, 4 August 2010, pers.comm). 
Performance Descriptions: The New Zealand Clarinet Quartet

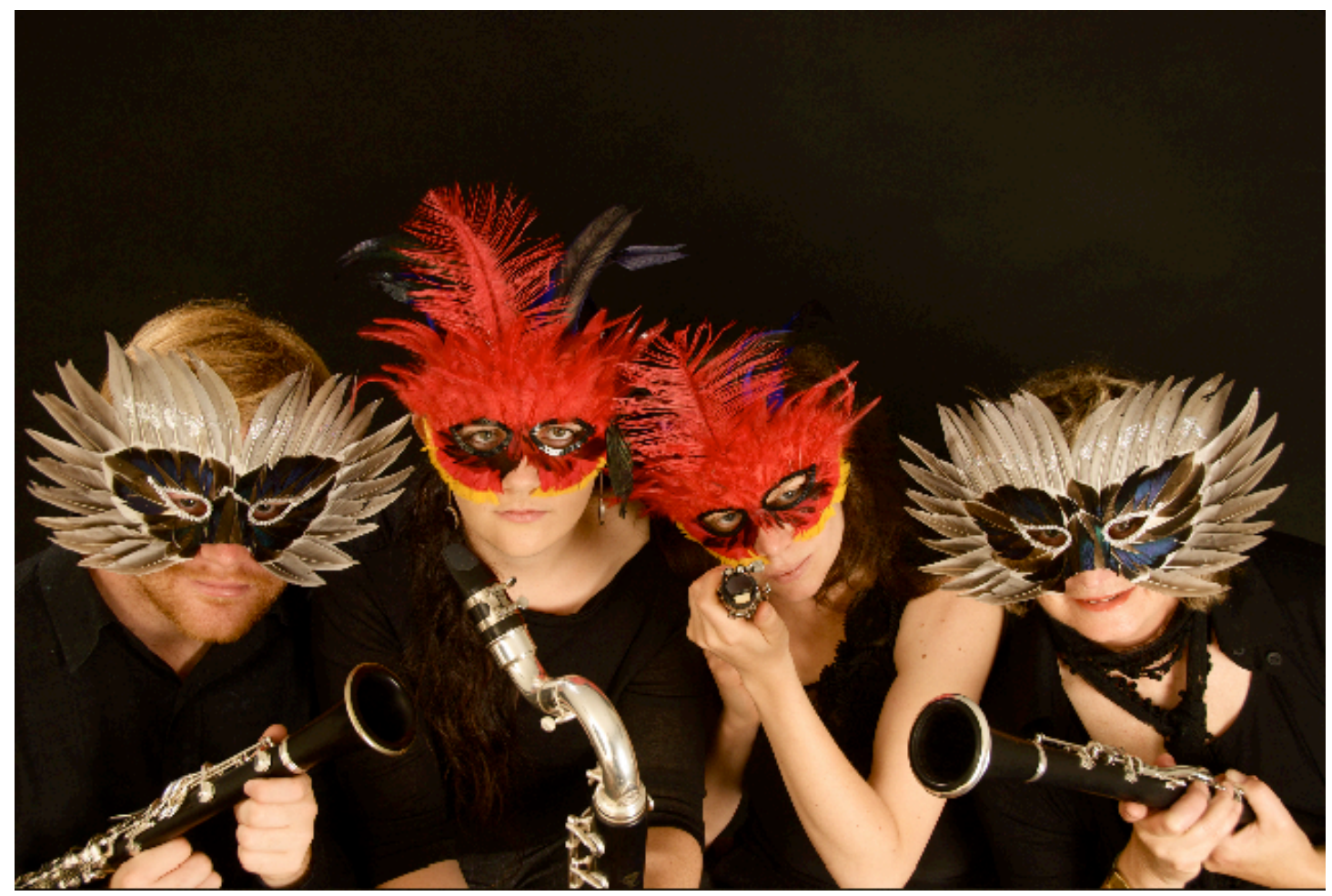

Figure 10: The New Zealand Clarinet Quartet

Haydn Sinclair, Anna McGregor, Tui France, Debbie Rawson, 2010

Photograph by Debbie Rawson

This section discusses a performance by The New Zealand Clarinet Quartet in the Adam Chamber Room at the NZSM on Friday 14 August at 5.30pm. Debbie informally welcomed the audience before introducing the first work Little Suite by Robert Burch, commenting that it was the first clarinet quartet written by a New Zealand composer in 1964 and that it was originally composed for Ron Weatherburn, bass clarinettist with the NZSO for many years. Scored for two B flat clarinets, one E flat and one bass clarinet, the five movements in this work were an attractive collection of dances displaying an overall melodic sense. The clarinet quartet performed seated, and it was interesting to note that three out of four players used neck-straps. These relieved the weight of the clarinet off the thumb and allowed relaxation of the right hand, arm, shoulder and neck and a relaxed and open tone quality. Similar to a choir singing together, the ensemble displayed a distinctly 'choral' sound as the clarinettists played 
with a matching smooth rounded tone, excellent intonation, and they exhibited a close rapport within the ensemble, enabling them to match various musical nuances.

Later in the programme American composer Evan Ziporyn's Hive (2007) for two B flat clarinets and two bass clarinets required the four clarinettists to depict a vibrant aural picture of a bee-hive in motion. In this work the role of the clarinets was to replace and extend the song of the bees, prompting me to consider that a similar effect could have been gained by scoring particular buzzing and blowing sounds for a choir. The overall effect of the clarinets' continuous medium-soft blown sounds in repeating intervallic patterns in thirds and fourths created a 'bee-like buzz', which seemed to take on a life of its own as members of the 'hive' moved together into different areas. The effect of 'ghost' notes, finger-slapping keys with breath sounds by the two B flat players, and repeated notes played with crescendi and decrescendi by the entire quartet in the low register reinforced this gentle buzzing quality to create a soporiphic effect. It seemed that Ziporyn wrote Hive for a clarinet quartet because of the 'vocal' and choral qualities embodied in this particular ensemble which allowed it to depict various 'songs' of bees in a beehive.

Debbie introduced her Guest Artist Richard Haynes as an established virtuoso clarinettist and bass clarinettist with the comment that, 'what he can't do on the clarinet isn't worth knowing about'. Richard has specialised in contemporary art music for clarinet and bass clarinet, and he uses these instruments as extensions of the voice to express a broad range of moods and emotions to his audience. In his introduction to the work Charon (1996) by the Welsh composer Richard Barrett, he explained to the audience that it was about a ferryman who takes souls across the river Styx to Hades, that it was in two sections and that it used 'quarter-tone language'. Wearing a chest harness to take the weight of the bass clarinet, Richard played standing, and he 
frequently stretched one leg out behind him and leant forward to help with the strenuous breathing requirements of the piece. Given the 'otherworldly' and intense subject matter, Richard's interpretation of the music brought alive the 'voice' of the character Charon in a powerful way. Using the large bass clarinet as an extension of the voice, Richard amplified and mimicked the voice of Charon, allowing an enormous range of expression over a four and a half octave range. This was achieved by his use of subtones, breath impulses before entries, repeated notes, changing timbres, varied moods, flutter-tonguing, multiphonics with 'elephant-like trumpetings', trills, humming and playing together, and extended rhythmic staccato passages in the low register.

Demonstrating perfect mastery of contemporary techniques on the bass clarinet, Richard appeared to be 'at one' with the instrument as if he were singing with a megaphone, so that the performance had an immediacy and intensity over extreme dynamic, register, timbral and multiphonic ranges.

To complete the programme Richard Haynes then conducted a Masterclass with two students at the NZSM. Nick Walshe performed Penderecki's Prelude and Richard commented that Nick demonstrated 'excellent expression' in his playing. He drew Nick's attention to two different 'voices' in one particular section, and suggested that Nick separate these out and give them a bit more attention. Richard was also very encouraging of Marcus Norman's performance of Messiaen's Abime des oiseaux (Abyss of Birds), commenting that all the birds in the work have their own song character, and that each one needed to have "more room to show the schizophrenia and capriciousness of the gesture'. He suggested that better breath support would allow Marcus the ability to 'float' on the harmonics in the piece. In both these works the clarinet was used to replace, amplify and extend the songs of people in the Prelude by Penderecki, and of birds in the Abime des oiseaux by Messiaen. 


\section{Cultural Heritage}

As a resident of Owhiro Bay on Wellington's blustery coast-line, Debbie reflects the drama and intensity of her surroundings in her passion for commissioning and performing music by New Zealand composers. She feels a strong sense of identification with her place of birth: its land, its heritage and the music which reflects its unique culture. In response to a question about New Zealand music Debbie commented that "promoting New Zealand music is important, which is why so many grant applications to Creative New Zealand are done to pay for the commissions' (Rawson, 4 August 2010, pers,comm). In her role as initiator of many new ensembles Debbie has commissioned a large number of works by New Zealand composers over the past thirty years. This is reflected in the high level of New Zealand music content performed by The New Zealand Clarinet Quartet and the saxophone quartet Saxcess. The contemporary classical music Debbie commissions is often unique and challenging for both the players and the audience, and for this reason she intersperses new works with better known ones to balance the programme for the audience (Rawson, 4 August 2010, pers.comm).

Debbie and the other members of the Zelanian ensemble commissioned New Zealand composers such as Jenny McLeod, David Hamilton, Gareth Farr and Jeroen Speak to write new works for the Zelanian Ensemble, many of which are now performed by chamber music groups in the National Chamber Music Secondary Schools Competitions. The New Zealand Clarinet Quartet has recently performed a concert of forty New Zealand compositions, including three by Natalie Hunt entitled Hawk, Kawau and Three Kiwi Meet a Kakapo (Rawson, 4 August 2010, pers.comm). New Zealand composer Gareth Farr has composed several works for Debbie including El Senor Cuchatita se Pone Enfermo for voice, piano and clarinet/soprano 
saxophone, Un Verano de Passion for clarinet, marimba, guitar and alto saxophone, and Four Little Pieces for Two Clarinets in B flat and E flat. The first two works are examples of music written in different cultural styles for unusual combinations of instruments which include the clarinet (Rawson 10 September 2010, pers.comm).

\section{Leadership Role}

Debbie commented that she often takes a leadership role in initiating and managing small ensembles as she has a vision for the group and a desire to actively promote New Zealand music within it. She stated that this vision drives her funding applications for commissions of New Zealand compositions and influences her repertoire choices for the ensembles. Debbie's leadership role includes 'doing promotional work, being a librarian, organising employment and payment, completing grant applications, managing rehearsal schedules, being tea lady, doing studio maintenance, being a diplomat, people skill maintenance, and arts lobbying' (Rawson, 4 August 2010, pers.comm).

Playing in chamber music ensembles allows Debbie the most freedom to express her personality through positive interaction with others, by taking leadership of various groups and by finding new repertoire. Debbie's view is that there is more room for individual and collective expression when playing chamber music, and this makes it her favourite environment to play in. She commented that 'this genre of music has everything: intellect, emotion, communication, collaboration and individual experience' (Rawson, 4 August 2010, pers.comm).

Debbie also believes that clarinettists take leadership roles in orchestral settings by exhibiting an interesting mix of 'blender-soloist personalities'. In her view the central seating position of the clarinet section within the woodwind section and the breadth of their tone helps to blend the woodwind players together (Rawson, 4 August 
2010, pers.comm). This blending attribute also extends to social occasions within the orchestral sections in rehearsal and performance. In opposition to this is their desire to perform as soloists in a variety of different ensembles; 'although they generally exhibit mellow personalities they are capable of despicable behaviour at times when in competition with each other' (Rawson, 4 August 2010, pers.comm).

Debbie commented that in her opinion it is natural for clarinettists to take on leadership roles in music ensembles because of the mixture of 'blender and soloist personality' that they exhibit when they perform in groups such as Tango Virtuosi as shown in the figure below (Rawson, 4 August 2010, pers.comm).

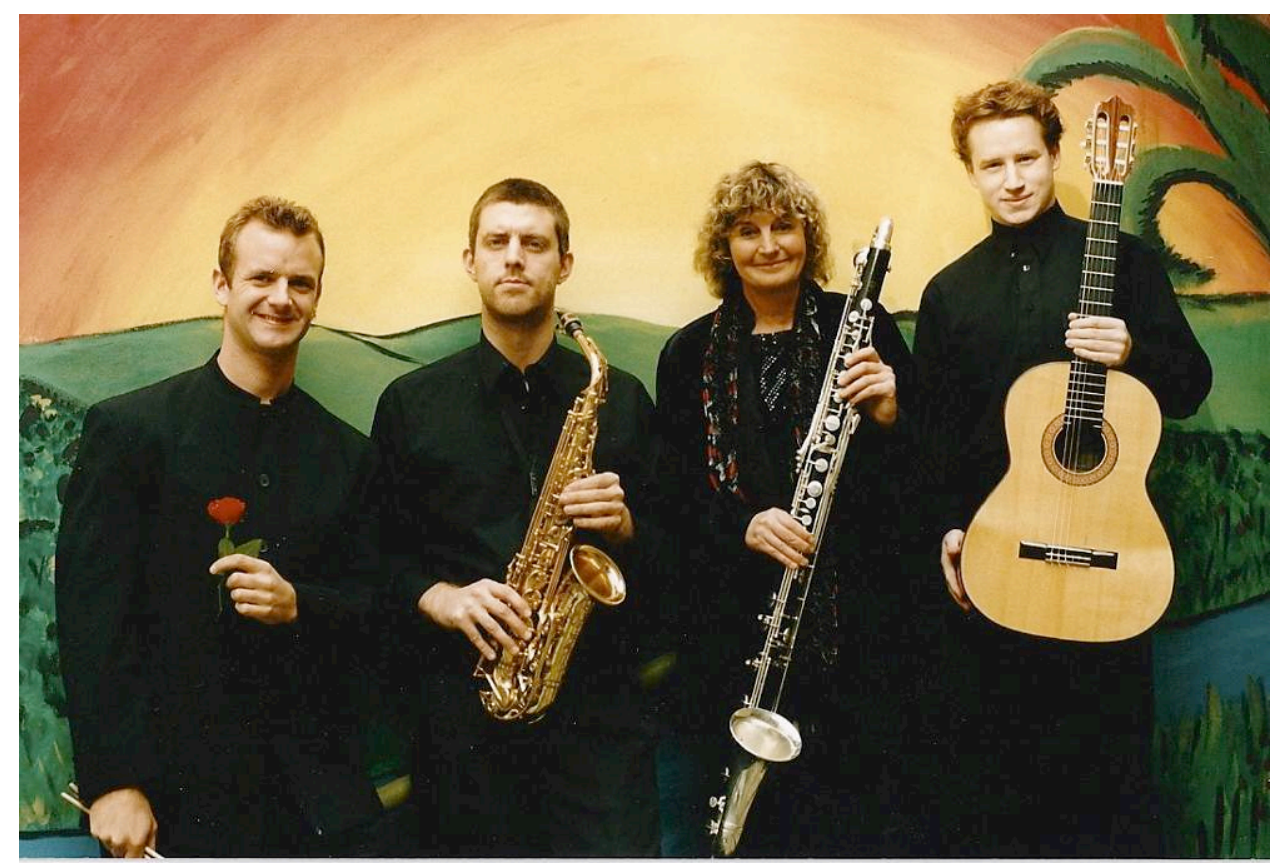

Figure 11: Tango Virtuosi

From left: Anton Wuts, Owen Moriarty, Debbie Rawson, Jeremy Fitzsimons, 2001

Photograph by Debbie Rawson

\section{Conduit of Music in Diverse Ensembles}

In the wide variety of ensembles in which Debbie has played during her musical career, she has always aimed to 'sing' the melodic line on the clarinet to create a mood or a feeling for the audience. She believes that it is the flexibility of the clarinet tone which allows it to be accepted into many different styles of music (Rawson, 4 August 
2010, pers.comm). As a member of the woodwind section in various orchestras she often replaced the voice by playing a lyrical line, such as in Beethoven's sixth symphony, Andante molto mosso. In opera her role was to partner and extend the vocal range of the voice to support the solo singer as in Mozart's Don Giovanni. In chamber music Debbie imitated, partnered and echoed the voice in various different works such as The Shepherd On The Rock by Schubert. In Debbie's opinion the clarinettist's role as a 'blender' of musical tone affects his or her personality so that in musical ensembles clarinettists often take on the role of diplomatic communicators. Yet the 'soloist' in their personality allows them to take a leadership role in solo performance, and to influence the repertoire of their ensemble (Rawson, 4 August 2010, pers.comm). Debbie's leadership role and identification with New Zealand cultural heritage often influenced the ensemble's repertoire and events they chose to perform at. Throughout her career Debbie has acted as a conduit for music by New Zealand composers and also for music in other cultures, such as African American jazz, Ashkenazic Jewish klezmer and Argentinian tango (Rawson, 4 November 2010, pers.comm).

\section{Blackbird Jazz Trio: Greg Rogan}

\section{Ensemble}

The Blackbird Jazz Trio is a Wellington based jazz ensemble comprising Greg Rogan (clarinet, tenor and alto saxophones), Bonnie Riley (voice) and Eoin Williams (guitar). They have been playing together since October 2008 and they regularly perform at the Redhead bar situated upstairs from the Molly Malones bar in Courtenay Place, Wellington (Rogan, 16 December 2009, pers.comm).

Traditionally jazz ensembles of all sizes have demonstrated ways in which the voice can be imitated by other instruments, and how instruments such as the clarinet and trumpet can imitate the voice by incorporating a wide repertoire of stylistic effects, such 
as 'growling', glissandi, and articulations for emphasis. As well as interviewing Greg Rogan several times over the past twelve months, I attended many of his concerts where he performed as a classical singer, a jazz clarinettist and saxophonist. It was apparent that he used the clarinet and saxophone as an expressive extension of his voice, and in doing so he helped to communicate the music of his jazz ensemble to their audience.

\section{Profile: Greg Rogan}

Greg's musical identity was significantly influenced by regular visits to his grandfather in Tauranga who played the piano, saxophone and harmonica in the 1930s. Although neither of his parents was especially musical, he was encouraged to play the clarinet as a teenager, and to become a member of the Waikato Youth Symphonic Band. He enjoyed playing at home with backing tapes and he experimented with audio technology to create a variety of different sounds on the instrument. Greg did a lot of busking at that time, playing from memory, and making a substantial amount of money (Rogan, 16 December 2009, pers.comm). He also played a lot of ballads and enjoyed communicating musically with the audience. Greg's early musical influences were Dixieland jazz and clarinettists Acker Bilk, Benny Goodman, and in particular Artie Shaw. He also respected Eddie Daniels for his melodic improvisation, as well as his flexible tone quality over the entire range of the clarinet.

Greg is currently a versatile musician who sings in the NBR Opera Chorus, teaches instrumental woodwinds, and plays professionally in a variety of ensembles including the Liberty Jazz Band, the Altotude Saxophone Quartet and the Blackbird Jazz Trio as shown in the figure below (Rogan, 16 December 2009, pers.comm). 


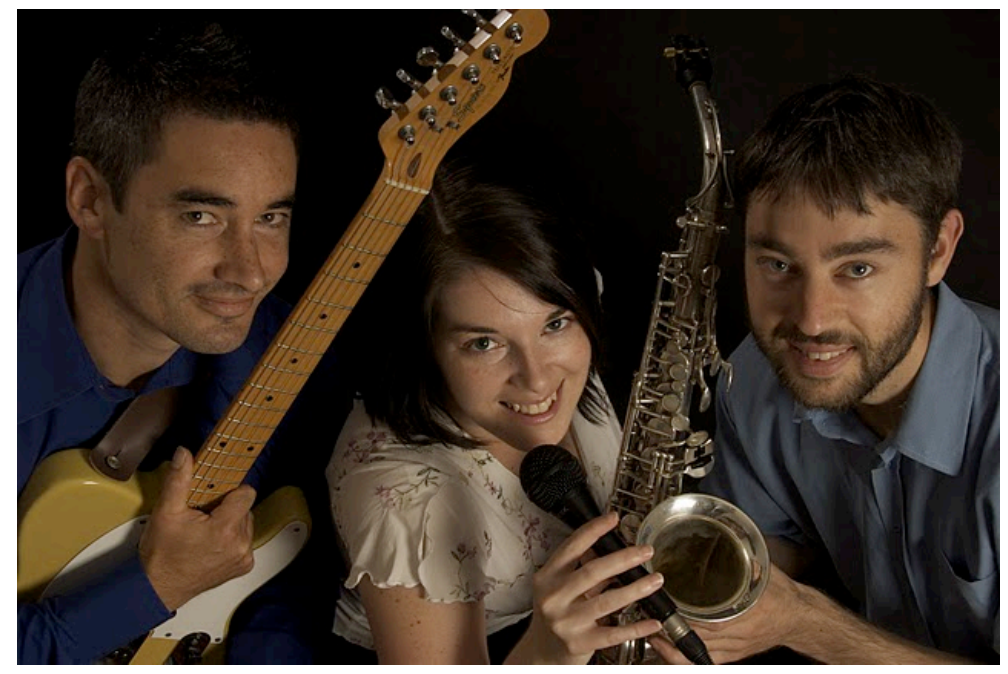

Figure 12: The Blackbird Jazz Trio

From left: Eoin Williams, Bonnie Riley, Greg Rogan, 2009

Photograph by Debbie Rawson

\section{Vocal Influences on Clarinet Playing}

Greg commented to me that, as a musician experienced in both voice and clarinet, he saw strong connections between singing and clarinet playing. He believes that the wide pitch range, the expressive tone quality, the flexibility to play soft and loud, to blend, to wail, to play glissandi and to flutter tongue are all particular instrumental characteristics which allow the clarinet to imitate the voice (Rogan, 16 December 2009, pers.comm). I observed that his role as clarinettist in the Blackbird Trio was to partner the vocalist in close harmony, to replace the voice as a conduit of the melody line, to amplify the melody in volume, or to mimic the vocal inflections as if having a conversation with the vocalist. As the clarinet has a wider pitch range and facility to play faster rhythmic passages than the voice, this allowed the clarinettist to extend this vocal mimicry into the highest registers, as is practised in Dixieland Jazz for example. He often chose lively tunes which sat comfortably in Bonnie's register, and when he accompanied her he often played a third higher or lower as another 'vocal' harmony line. The $\mathrm{Bb}$ clarinet can mirror or partner the female voice very well in this jazz style as it sits mainly in the soprano vocal range, with an added octave in the altissimo 
register and a few extra low notes at the lowest end. The non-vibrato breadth of the clarinet tone, allows it to blend with voices and other instruments very easily, especially in a jazz ensemble. Since the 1950 s the clarinet has generally been replaced by the saxophone in big bands and jazz ensembles, although the clarinet is sometimes still used in intimate surroundings such as a small café, bar or restaurant, as it does not require a microphone to be audible.

Greg is able to make a natural transition between singing to playing the clarinet or the saxophone as he uses different muscle memory for each one and therefore does not experience confusion in his playing technique. He finds that deep breathing is very important for all the modes of performance, which he achieves by focusing on exhalation first and allowing inhalation to follow naturally. In his classical singing he is interested to learn more about the bel canto style, which relies on the inhalation of the tone for resonant head tones and breathing into the 'mask' of the face. In clarinet playing he used a similar breathing pattern, keeping his muscles relaxed and manipulating the air stream in his pharynx and with his tongue (Rogan, 1 June 2010, pers.comm).

In order to develop his singing and his instrumental technique Greg started studying the Alexander Technique to improve his body alignment. He immediately noticed a difference in his natural head position, and although he works on a computer for many hours each day as well as performing regularly, he does not present with any symptoms of Occupational Overuse Syndrome (OOS). This is unusual for such a busy musician who sings, doubles on several instruments, and works long hours at a computer keyboard at his workplace (Rogan, 1 June 2010, pers.comm).

Greg commented that he tries to 'float the tone' which requires the underlying support of a generous but relaxed airstream, rather than playing with a sustained intense 
tone which requires a faster and more focussed airstream. This phrase was also often used by Jack Brymer when describing how to produce a warm tone on the clarinet to his students. Greg is still influenced by the sound of Acker Bilk's playing which he heard as a child: for its 'vocal' phrasing, warm tone, gentle vibrato, easy listening and lush quality of the 'pop' music arrangements. Greg explained that in certain situations he believed he was extending his voice on the clarinet and saxophone to make an operatic or declamatory statement, as opera singers do (Rogan, 16 December 2009, pers.comm).

\section{Performance Descriptions: The Blackbird Jazz Trio}

The Blackbird Jazz Trio performed on Friday $21^{\text {st }}$ May 2010 at the Redhead Bar in Courtenay Place with the same musicians who feature in the figure below. It was a busy evening, and the band created a relaxed ambience at the bar which drifted over to the dining area several metres away. Approximately ten tables of six diners were enjoying their dinner with musical accompaniment, although the music was functioning as background music at that distance. The managers of the Redhead Bar created an intimate setting by situating six tables around a semicircular bar, with an open fireplace at one end. A large decorative lighting feature took centre stage in the room, and the far end of the room operated as a dining area. There were approximately ten people in the bar at $7.30 \mathrm{pm}$, which increased to thirty people by $9.30 \mathrm{pm}$. 


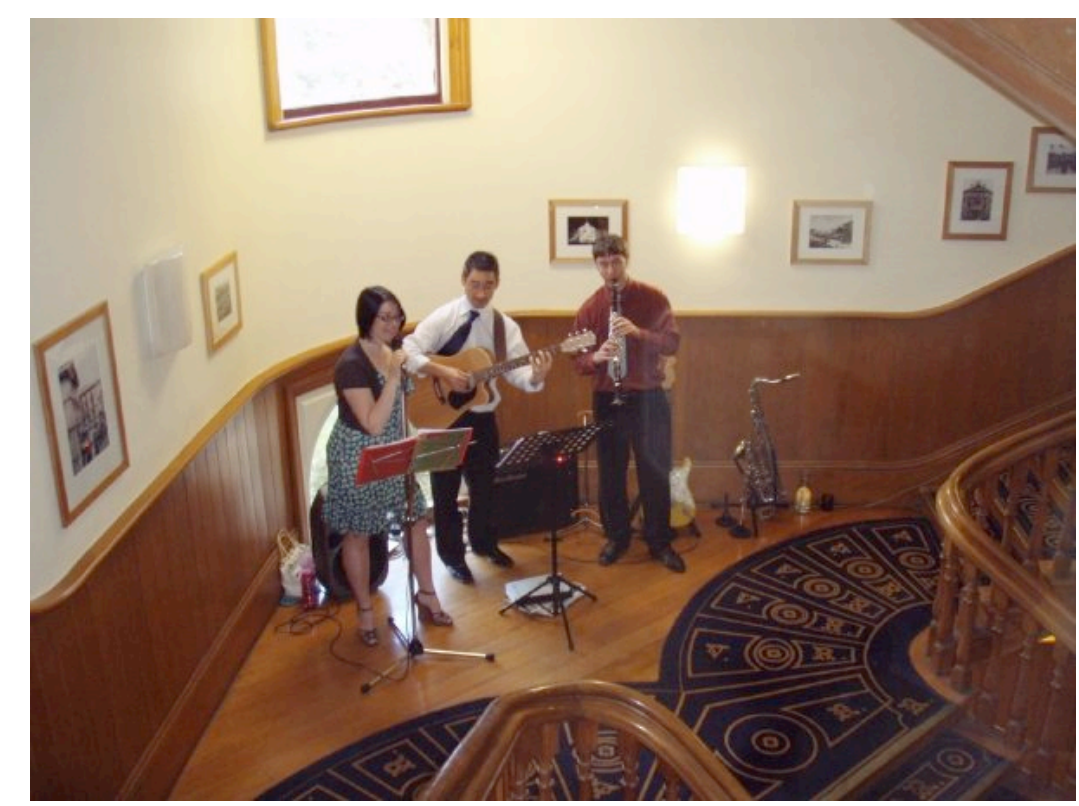

Figure 13: The Blackbird Jazz Trio at the Old Government Buildings, 2008

Bonnie's vocals and Eion's guitar were electronically amplified unlike Greg's clarinet and tenor sax, which were played acoustically. The fact that there was no bass guitar or drums meant that the volume was suited to the intimate venue, allowing for conversation at both ends of the room. The trio performed in a small space at one end of the bar, and the audience was initially comprised of a mixture of men and women in the thirty to sixty years age group, which was augmented later in the evening when a younger crowd in the twenty-five to thirty age group arrived. The presence of the rhythmically lilting music added to the sociability of the bar, so that as the evening progressed, members of the older age group at a table started to mingle with younger members at the bar, and even started dancing to some of the more upbeat tunes.

Although Greg performed in an unusual jazz trio comprising voice, guitar and clarinet/saxophone, it is interesting to reflect on the history of earlier jazz clarinet playing, to put the Blackbird Jazz Trio into a musical context. I have often observed that the clarinet acts as an expressive conduit of the Dixieland jazz style, where the volume level is intense and each instrument claims a particular musical register and 
style as their own. It appears that the clarinet takes the role of a high-pitched expressive 'voice', which is often chromatic, colourful and exuberant, with special effects such as 'growling' and glissandi. In a similar Dixieland style Greg uses his clarinet to amplify, imitate, partner or replace the singer Bonnie in many of the jazz tunes from a later period, revealing his affinity with music of this jazz style.

Although Greg was playing both the clarinet and tenor saxophone in a 'vocal' style on this occasion, I have mainly focused on the clarinet tunes to illustrate certain points. It is worth noting, however, that there are many similarities between the clarinet and the tenor saxophone. The most significant similarity is that they are both B flat instruments which makes 'hearing' the pitch of the notes simpler than if Greg were playing a B flat clarinet and alto saxophone, which is an E flat instrument. The approaches to deep breathing, blowing the reed against a mouthpiece, and the same fingering on the tenor saxophone as that of the clarion register of the clarinet mean that the two instruments are often used in similar 'vocal' ways in this jazz context. Several of the jazz standards Greg performed are regularly performed on both instruments by various musicians, such as ‘Goody Goody' by Matty Malneck and Johnny Mercer, which was originally performed by Benny Goodman on clarinet, but was performed on tenor saxophone by Greg on this occasion. 


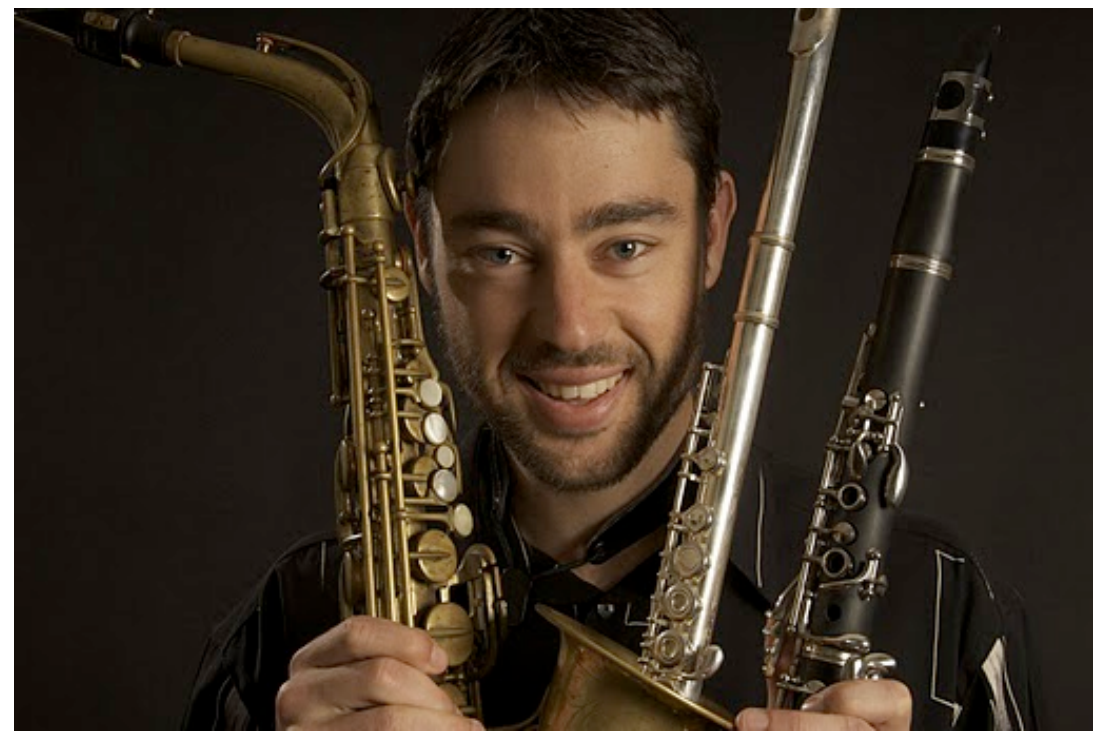

Figure 14: Greg Rogan Multi-instrumentalist, 2009 Photograph by Debbie Rawson

The most noticeable role that the clarinet performed in this ensemble was to partner the voice in range, dynamics, legato style, and timbre. In the song 'Here's That Rainy Day' by Jimmy Van Heusen and Johnny Burke, this was achieved by harmonising in thirds below the voice at a similar dynamic level with a warm woody tone. By playing the clarinet with a medium soft reed and his cheeks in a relaxed blown out style, Greg achieved colourful inflections to his tone and some vibrato to match Bonnie's vocals.

The clarinet replaced the vocal line in the tune 'There Will Never Be Another You' by Harry Warren and Mack Gordon, by playing the 'head' like a vocal line with a rounded tone, in a legato style, with occasional punctuated accents, mainly in the soprano range of the instrument. In the same tune Greg extended the vocal line by playing some very fast runs in the altissimo register in an improvisatory style. This style of playing imitated and extended the pitch range of the scat style of jazz singing.

In the tune 'Taking a Chance on Love' by Duke Latouche and Fetter, the clarinet initially partnered the voice, then replaced the voice for a second verse, and finally 
amplified the vocal melody in volume and extended the pitch range, adding in colourful inflections.

The pieces on tenor saxophone such as 'My Romance' by Rodgers and Hart, and 'They Can't Take That Away From Me' by Gershwin \& Gershwin, also demonstrated clear examples of partnering, replacing, mimicking and extending the voice although at an octave lower pitch. In 'My Romance' the melodic solos and harmonies mimicked and partnered the voice, adding interest to the musical exchanges. Vocal mimicking is an interesting concept as it suggests an imitative musical response which is coloured with the clarinettist's own meaning. In many contexts this process could be described as a parody, but in this context the mood was sophisticated and the clarinet lines were altered subtly for colourful and 'conversational' effect. The tenor sax also mirrored the raunchy upbeat vocals in 'Give Me One Reason' by Tracey Chapman in the solo section, and the gentler vocals of 'What a Wonderful World' by Weiss and Thiele. The mood of relaxed ambience which the Blackbird Jazz Trio generated through its performance in the bar and dining area concluded with a friendly announcement from Bonnie as she introduced the final number for the evening and thanked the audience for their support.

\section{Cultural Heritage}

In an interview with me Greg commented that he aims to communicate directly to the audience when playing jazz clarinet in the Blackbird Trio. He enjoys the expressive quality, and the 'open-ness' of jazz because it allows the performer the freedom to improvise. He enjoys playing with the Liberty Swing Band because it promotes improvisation within a dance genre, generating spontaneous communication with an enthusiastic audience (Rogan, 16 December 2009, pers.comm). Greg's keen interest in technology, prompted his desire to include such instruments as the EWI (Electronic 
Wind Instrument) and to create different sonic effects using a microphone and reverberation in the trio (Rogan, 1 June 2010, pers.comm).

As it appears that most of Greg's musical influences are from the United States of America, I asked him if he thought there was a New Zealand flavour in the jazz played in Wellington. Greg explained that international trends tended to influence jazz ensembles in Wellington especially in terms of repertoire played at the New Zealand School of Music Jazz School (Rogan, 16 December 2009, pers.comm).

Playing the clarinet offers Greg some opportunities for cultural interaction in jazz ensembles as he often plays with international musicians in Wellington and he finds an immediate connection with them through music. He enjoys the communication with these musicians and he often takes a leadership role in helping to find repertoire for singers and instrumentalists (Rogan, 16 December 2009, pers.comm). When asked how eclectic he thinks the clarinet could be in modern jazz ensembles, Greg responded that the clarinet could play effectively in many different genres such as dub, reggae, gipsy, klezmer and café style as long as the rhythm section was strong (Rogan, 16 December 2009, pers.comm).

\section{Leadership Role}

Greg takes a leadership role in the Blackbird Jazz Trio by making repertoire choices such as jazz standards from a Benny Goodman anthology or the Real Book of jazz standards. He is interested in providing more variety in the Blackbird Jazz Trio repertoire through the addition of more blues and pop tunes, and he is researching clarinettist Buddy de Franco's playing style to see if he could add some bebop to the play list as well. Greg also takes on the management role of organising gigs and rehearsals for the trio (Rogan, 1 June 2010, pers.comm). 
My observation of his leadership role and performance in the ensemble revealed that Greg's role is one of a supportive 'team player' in order to achieve a blended ensemble sound. He appears to be empathetic to the personal and musical needs of other members in the ensemble, and although very capable of dominating through his excellent improvisatory skills on clarinet and saxophone, he maintains his role as an integrated member of the ensemble during their performances.

\section{Conduit of Music in Diverse Ensembles}

Greg Rogan is an excellent example of a clarinettist who 'sings' when playing the clarinet, using this ability to communicate freedom and spontaneity in his jazz improvisations in his ensemble. His approach to linking the voice with the clarinet and saxophone reflects the long tradition of instrumental vocalisation in jazz. Influenced by the early experiences with his musical grandfather in Tauranga, it is clear that he identifies himself as a New Zealander. European and American clarinettists such as Acker Bilk, Buddy de Franco and Eddie Daniels have also had major influences on Greg's repertoire choices and style of performance. As a 'blender-soloist' personality he is able to blend the style of the vocalist Bonnie with that of the guitarist Eoin, and to play solo improvisations in the Blackbird Jazz Trio. Taking a leadership role in the ensemble, Greg influences the repertoire choices, the style of performance and the venues where the trio performs. I observed that his natural musicianship and leadership style showed him to be an effective leader of the trio, and an expressive conduit of jazz clarinet style in Wellington.

\section{The Klezmer Rebs: Urs Signer}

Ensemble: The Klezmer Rebs

In a chain reaction to a Jewish cultural renaissance in the United States of America in the 1970s, many klezmer bands started playing in other countries, such as 
Kol Simcha in Switzerland, Sabbath Hela Veckan in Sweden, and the Klezmer Rebs who started playing together in Wellington, New Zealand in 2001 (Signer, 16 May 2009, pers.comm). Since this time the Klezmer Rebs have regularly performed at weddings and bar mitzvahs at the Temple Sinai and at many other cultural or political concerts, such as the Newtown Fair and at The Peace Festival in Parihaka in 2008 (Signer, 22 July 2010, pers.comm). The ensemble has a loyal following who relate to the expressive human element in klezmer music, which Mark Slobin describes as the Jewish vocal aesthetic which underlies the 'tear in the voice' and the 'laughter through tears' (Slobin 2000:99). Eight members of the Klezmer Rebs are shown below.

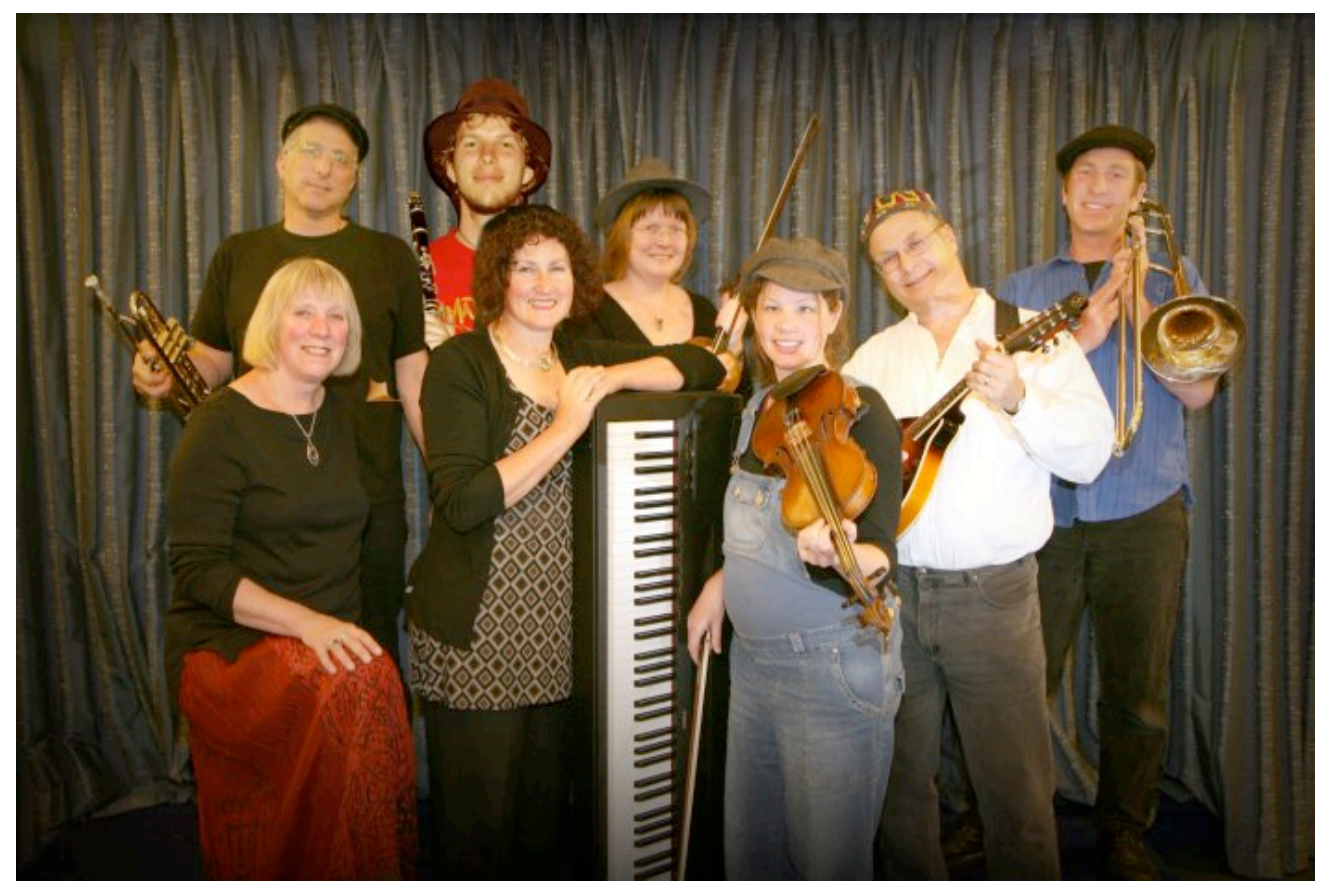

Figure 15: The Klezmer Rebs

Back row left: Dave Moscovitz, Urs Signer, Heather Elder, Dave Weinstein, Jonathan Dunn. Front row left: Sue Esterman, Rose O’Hara, Nikki Lichtner, 2008

Photography by Rob Kilvington

\section{Profile: Urs Signer}

The Klezmer Rebs web-site describes Urs Signer as

An accomplished clarinettist, composer, activist and anarchist. Originally from Switzerland, he's made Aotearoa his home, and prefers to spend his time in Taranaki whenever he has the chance. Urs is a uniquely talented muso whose amazing solos come straight from the soul, seemingly unfettered by structure. His favorite time signatures are dominated by ones containing large odd numbers. (Moscovitz, 2010) 
In the Wellington group the Klezmer Rebs the clarinettist, Urs Signer, plays a pivotal role in extending, partnering and mimicking the vocalists in the ensemble, communicating the Ashkenazic Jewish identity of the group to the audience in his expressive and colourful clarinet improvisations. It is also very interesting to note how Urs' political attitudes have influenced the other members of the Klezmer Rebs, to some extent prompting the ensemble to become a vehicle for their political activist and socialist identity.

With the importance of Jewish culture to klezmer music it would seem natural that Urs would have some Jewish heritage. Interestingly this is not the case, as he grew up in Switzerland in a non-religious social-democrat family of teachers, and he is the only key member of the Klezmer Rebs without direct Jewish cultural links (Signer, 22 July 2010, pers.comm). His introduction to classical music was through singing Schubert songs with his father at a very early age. First playing classical, then jazz at intermediate School, he discovered klezmer music and the world of improvisation at the age of thirteen. Urs explained that he did not know many Jewish people in Basel, but he wanted to convert to Judaism when he was nine years old as an act of solidarity, when he learned about the Holocaust. He commented that it was not until he joined the Klezmer Rebs in late 2004 that he started going to Temple Sinai, the Wellington Progressive Synagogue, where he learned about Jewish culture and religion (Signer, 22 July 2010, pers.comm).

Urs explained that the clarinettist he most admires is Michael Heitzler of the famous klezmer group Kol Simcha, which is also from his home city of Basel in Switzerland. He mentioned that 'his tone and technique are magnificent and he is also an incredible improviser'. When he was still at Secondary School Urs said that he spent many hours trying to transcribe his playing and learning it note by note. According to 
Urs it was Heitzler who introduced him to the extremes of the altissimo register playing in a smooth and virtuosic way up to the very top notes. Urs commented 'that is a really liberating aspect of the clarinettist's role in klezmer music: you can squeak and squeal around the high register and still sound good!' (Signer, 22 July 2010, pers.comm). In addition to klezmer music Urs plays many different genres such as contemporary classical, jazz, free improvisation, funk and hip-hop. He is also a composer and a singer-songwriter and he has written several songs for the Klezmer Rebs.

\section{Vocal Influences in Clarinet Playing}

In Fiddler on the Move Mark Slobin quotes Max Epstein as saying 'never play it the same way twice - never... [there is] the sense that instruments, to be successful, authentically need to sound like voices' (Slobin 2000:95). Urs seems to instinctively understand this concept as he was always told by his teachers that he needed to be able to 'sing' his playing, which he actively tries to do in his improvisation in klezmer, jazz and funk ensembles. Using singing as a practice tool, he uses it to create 'clear licks and lines'. As he commented, 'I could be walking down the street humming melodies in my head not for the sake of singing, but for practising my solo skills on the clarinet'. Urs also commented that in order to produce a good tone on the clarinet, a combination of a good clarinet and reed, abdominal support and a developed embouchure is necessary (Signer, 22 July 2010, pers.comm).

Klezmer Rebs' singer and trumpet player Dave Moscovitz commented that 'the clarinet and the violin are the central authentic voices of early Klezmer' (Moscovitz, 20 April 2009, pers.comm), and it is these instruments which are used to extend the voice to display humour, pathos and everyday life in the Klezmer Rebs. In the songs 'Kumt Kumt Khaverim' and 'Ochi Chorniye' Urs demonstrated a 'vocal' style of playing in his improvised solos where he played the clarinet as if it were an extension of 
the voice. There were also gentler moments as in songs such as 'Ersate Vals' with a male vocalist, and 'Bokserboym' with a female vocalist, where Urs played with vibrato, on repeated held notes, with low trills, then partnered the voice in thirds to convey a close rapport between vocalist and instrumentalist. In an interview with me, Band leader David Weinstein described the vocal qualities of Urs' clarinet playing, commenting that 'Urs does it really well, that it recreates the sound of the human voice, either crying or wailing or in joy or in sorrow' (Weinstein, 27 March 2009, pers.comm). An example of this is shown in the figure below at a concert at the Palmerston North City Library.

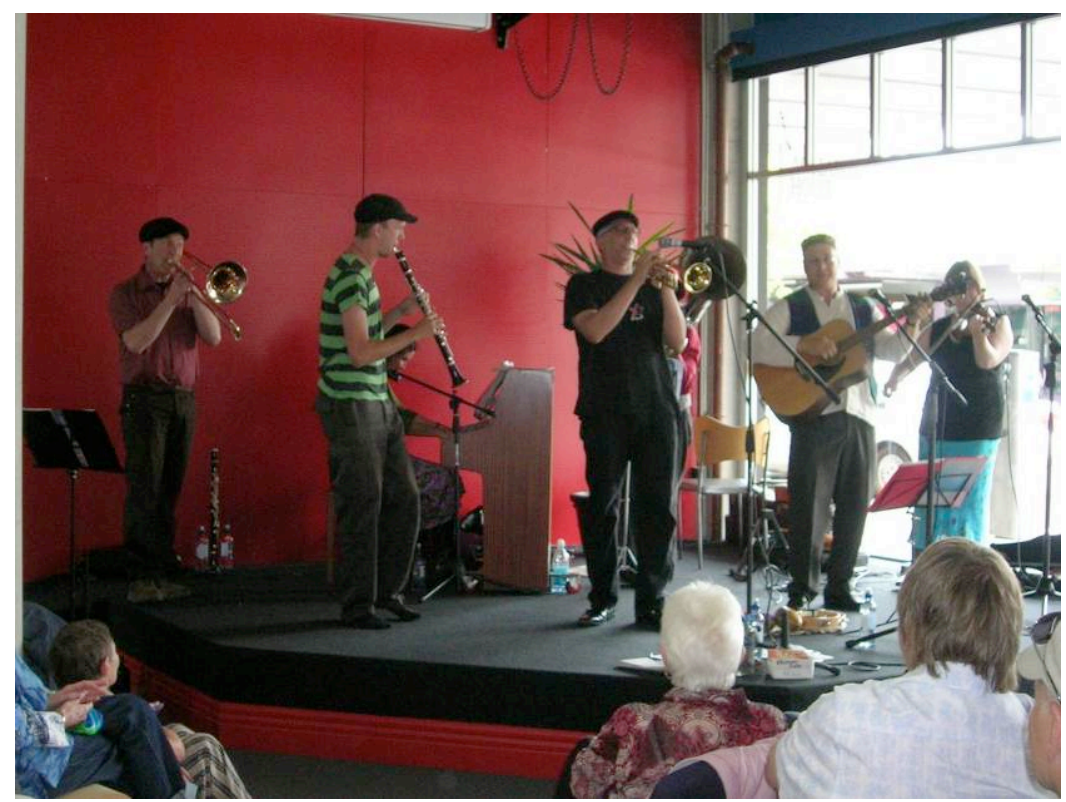

Figure 16: The Klezmer Rebs at the Palmerston North City Library, 2010 From left: Jonathan Dunn, Urs Signer, David Moscovitz, David Weinstein, Heather Elder

\section{Performance Descriptions}

The first Klezmer Rebs rehearsal I attended was in a spacious meeting room at the Temple Sinai Synagogue in April 2009. The cooperative organisation of the ensemble was reflected in the way that members gathered in a loose circle facing each other and started a 'round' of comments from each person about current concerns, upcoming concerts and repertoire. At three rehearsals and one performance, I heard the Klezmer 
Rebs perform about twenty pieces such as 'Als dr Rebel', 'Minnie the Moocher', 'Bashana', 'Lo Gisa Yoy Medley', 'Der Heyser Bulgar', and 'Az der Rebbe Elimelekh'. In these pieces the guitar, keyboards and accordion and helicon (similar to a sousaphone) blended to provide a rhythmic backdrop to the soloists (vocalists, clarinet, violin, trumpet and trombone), and at times they took a lead role as well. The use of a variety of percussion instruments, such as tambourines, shakers and wood-scrapers added different timbres and helped with a variety of rhythmic and tempo changes.

I observed that Urs played his clarinet with an open throat and a flexible embouchure, which allowed him maximum expression of the tonal and pitch colours of the instrument, imitating the singing style of a Jewish cantor. His soft reed contributed to a slightly nasal sound in the upper register, but the clarinet also played gentle soothing patterns in the low register when accompanying a singer, as in the introduction to the song 'Bashana'. In improvised solos Urs played fast arpeggiated patterns, swoops, glides, trills, ornaments, repetitive phrases and flutter-tonguing using the clarinet as an extension of the voice. Employing these dramatic effects allowed Urs to convey humour, joy and creative energy in tunes such as 'Kumt Kumt Khaverim', 'Lebedik un Frelach', 'Sher' and 'Ochi Chorniye'. The intensity and commitment of his sound, the dexterity of his altissimo playing and the 'vocal' interjections such as 'hey, hey' on the clarinet seemed to provide the 'dybbuk' or restless spirit for the group.

The varied instruments in the Klezmer Rebs added an aural and visual character to the ensemble, reinforcing the text of the songs with glissandi, rapid stops and starts, harmonic playing, counter-melodic playing, extreme speed changes, rhythmic feels, syncopation, long held notes and percussive drive. The Yiddish language created a sense of mystery and it was enhanced by the varied styles of different vocalists (tempo changes, voice timbre and expression, and recitative style). 
At a fundraising concert on June 22009 at St Andrews on the Terrace, I observed that the Klezmer Rebs demonstrated their socialist identity to a capacity audience. All nine members were dressed in colourful and quirky outfits, complete with distinctive hats, and they played standing to allow for freedom of movement. The extroverted performers in the Klezmer Rebs encouraged the audience to engage in musical exchanges with the band through clapping, tapping, singing chorus lines in 'Minnie the Moocher' and 'Ot Azoi', and calling out in appreciation at the end of songs. The 'Rebs' appeared to be 'in the moment', chatting amicably through the medium of their instruments and song lyrics and telling jokes to one another in the klezmer musical idiom. The musicians showed their sensitive listening skills so that even at the height of excitement in the songs they did not 'cut across' each others' solos. Their new sound system blended the disparate colour and volume of the nine instruments and several voices, so that every part could be heard clearly, which was an improvement on the balance at rehearsals. During this concert the Klezmer Rebs provided a unique musical platform for Ashkenazic Jewish cultural expression which emanated in an inclusive way to the audience.

In my opinion the Klezmer Rebs CD Just Add Schmalz reflects the eclecticism in klezmer music which was influenced by Turkish, Greek, Moldavian, Romanian, Ukrainian and Armenian cultures, even before it crossed the Atlantic and absorbed swing, jazz and latin styles into the musical mix. Not only is there a mixture of musical styles, but also of musical forms in klezmer music ranging from free-flowing improvisational Doinas, to syncopated beat Bulgars and joyous celebratory Freylachs for dancing. There are songs for the Sabbath, lullabies, love songs, friendly 'insulting' songs, songs about poverty and wedding dances (Weinstein 2008:CD). 


\section{Cultural Heritage}

In his role as clarinettist with the Klezmer Rebs, Urs acts as a conduit for Ashkenazic Jewish identity (Signer, 22 July 2010, pers.comm). By playing for both the Progressive and the Orthodox Synagogues in Wellington, the ensemble draws the two communities together in both formal and celebratory music making. When the band plays for a bar mitzvah at one of the synagogues there could be up to one hundred and twenty families present, and in this way the Klezmer Rebs' music acts as a conduit of Ashkenazic Jewish cultural identity to create a sense of belonging. Urs commented that the overall emotion was 'collectivity' or 'togetherness' in the Klezmer Rebs, and that the most important aspects of playing with the Klezmer Rebs were 'the emotion, the sense of belonging together and creating music together' (Signer, 22 July 2010, pers.comm).

Urs also reflects his identification and engagement with Maori in his choice to live in the Parihaka Maori community in Taranaki. In an interview he commented that although he does not have a Maori heritage, it does influence his thinking, commenting that 'maybe some of that ends up in my improvisations, certainly in my compositions'. He mentioned that he is not religious but he has found the sense of community at synagogue events important. Urs explained that, 'for me that place [the synagogue] is alive, just like the marae here at Parihaka, or our anarchist social centre on Abel Smith Street in Wellington. He commented that 'finding' the Rebs had given him good friends and also an insight into a community that was strong and vibrant with strong values which were similar to his own. In response to a question about musical authenticity in the Klezmer Rebs, Urs answered that, 'together, we were trying to create music, we were not trying to be authentic to someone else's thinking, but to be true to ourselves and our ideas' (Signer, 22 July 2010, pers.comm). 


\section{Leadership Role}

As can be seen in the figure below klezmer musicians were originally the itinerant fringe dwellers in the Jewish shtetl (ghettos), who were both marginalised, but also free agents of musical and political change in society (Klezmer Rebs 2007). Urs identifies with this role as a free agent of change, and he expresses his love of freedom and his deep concern for human equality in his expressive and 'vocal' style of clarinet playing. As a political activist he has also influenced the other members of the Klezmer Rebs to play certain repertoire such as 'Bella Ciao' at certain events to show their political support (Signer, 22 July 2010, pers.comm).

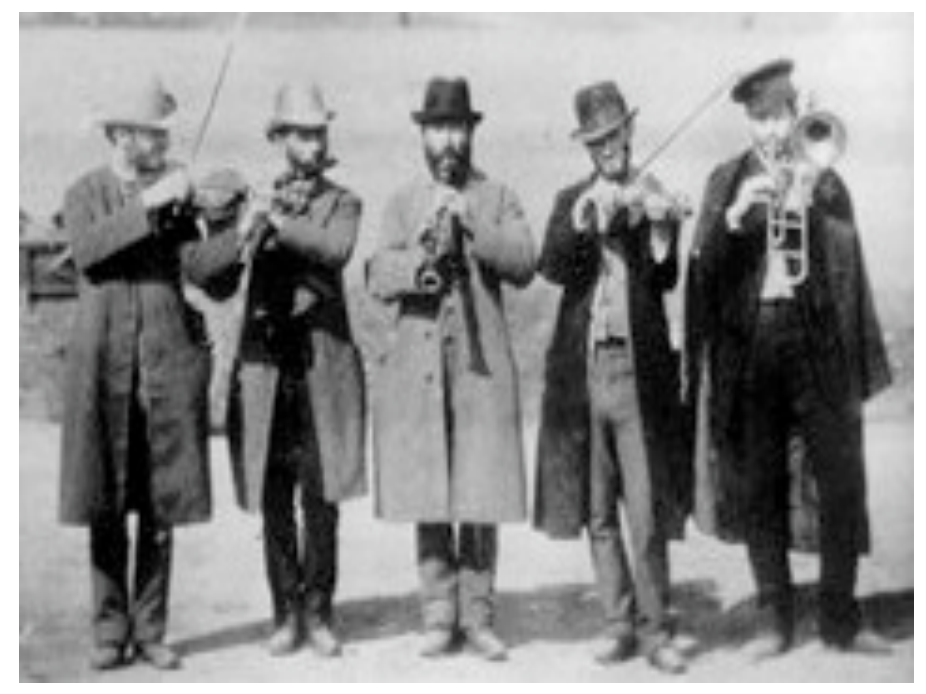

Figure 17: Klezmorim 1910 Photograph courtesy of the Klezmer Rebs web-site

In an interview with me Urs explained that he is interested in the ways in which music has historically been used to document political struggle. In his view it has been one of the survival strategies to cope with persecution over the centuries. He remarked that klezmer music has a rich repertoire of political songs, representing the struggle of the working classes, for example Jewish historical immigration to the United States of America 'The Promised Land.' He described how on their arrival in New York City, immigrants' work conditions were very bad, and as a result they organised themselves 
into leftwing socialist groups. There are many Jewish political songs from that time, for example 'Ale Brider’ which means ‘All Brothers Together' (Signer, 22 July 2010, pers.comm).

This politicisation of klezmer music is not restricted to the United States of America, and because of Urs' influence, it has been adopted to some extent by the Klezmer Rebs in Wellington, New Zealand (Signer, 22 July 2010, pers.comm). Urs researched the issues with Maori land rights and sovereignty, and he became an active supporter of their cause, deciding to spend more time at Parihaka in Taranaki. As a result of his activism in issues supporting Maori sovereignty, the Klezmer Rebs decided to support Urs in this issue, and to be more openly political in their music. It also encouraged Urs to write some political songs such as 'Anarchia Totale', in which he voiced his support for Maori sovereignty. Urs says that when the group wants to convey a political message their playing highlights 'feelings of rebellion, justice and freedom' (Signer, 22 July 2010, pers.comm). The Klezmer Rebs have also played at solemn occasions, for example a remembrance of the Holocaust, at which they choose their repertoire carefully to suit the mood of the event.

\section{Conduit of Music in Diverse Ensembles}

Urs demonstrated what the famous Klezmer clarinettist Giora Feidman said, 'Klezmer means that the instruments are essentially the loudspeakers of the 'inner voice' singing in everyone's soul. A Klezmer doesn't make music, he speaks, prays and consoles with his instrument' (Klezmer Music in a Few Words 2010). Urs extends, mimics, partners and amplifies the voice in his clarinet playing in the Klezmer Rebs, using a variety of klezmer gustn (chromatic modes). In his uninhibited solos he uses the entire range of the clarinet, especially the altissimo register, playing ornaments, trills, glissandi and fast repeated patterns to build intensity and excitement. At these moments 
Urs appears to personify the 'restlessness and spiritual spark of a dybbuk (a displaced soul seeking a body), and he acts as an expressive conduit of Ashkenazic Jewish music (Slobin 2002:68).

The Klezmer Rebs welcome visiting musicians to sit in on their rehearsals and they actively promote the exchange of musical styles that this allows. They feel part of a world music community working in Wellington, surrounded by groups such as the Wellington Community Choir, Tango Vivo, Kugeltov, Sam Manzanza and other musical groups which focus on the cultural context of their music (Weinstein, 27 March 2009, pers.comm).

Urs blends his Swiss heritage and his identification with Jewish and Maori values to create an eclectic cultural mix. Through his political activism and his empathy for Maori sovereignty, Urs has influenced the members of the Klezmer Rebs to become more outwardly political. In his leadership role Urs encourages the ensemble to perform his political activist songs, and to perform at certain activist, socialist, and ethnic minority events. Acting as an expressive conduit of Ashkenazic Jewish culture, Urs' role on the clarinet is that of a creative spark to drive the band to a new state of musical and political awareness.

\section{Conclusion}

In my research with the four clarinettists in the case studies, Andrzej Nowicki, Debbie Rawson, Greg Rogan and Urs Signer, I discovered that each one 'sings' into their clarinet to create different musical effects in their ensembles. Using the clarinet as an extension, they partner, imitate, amplify and replace the voice, using the sonic possibilities offered by the four and a half octave range of the instrument. Playing in four different musical styles means that each clarinettist uses specialised 
mouthpiece/reed combinations and techniques to achieve the appropriate stylistic sound for their ensemble.

I observed that in the contemporary art music collective, the SMP Ensemble, Andrzej displayed vocal expression by playing over the entire range of the instrument, using multiphonics, flutter-tonguing, electronic amplification and by removing the mouthpiece to blow directly into the clarinet bore. It appeared to me that Debbie demonstrated numerous examples where she 'sang' through her clarinet in classical music, using a more conventional classical embouchure and mouthpiece and reed combination to create a pure rounded tone with accurate intonation. It was evident that in The Shepherd On The Rock she partnered and echoed the vocal line throughout the work, and in the New Zealand Clarinet Quartet she used the clarinet to imitate New Zealand birdsong, and a swarm of humming bees. At Greg's performance I noticed that he played his clarinet with a flexible tone to partner the singer in the Blackbird Jazz Trio, and at times to extend the vocalisation through solo improvisation. It was evident that he also replaced the vocal line at times, playing the main tunes before the singer joined him. In the Klezmer Rebs, I noticed that Urs played the clarinet with a flexible tone and variable pitch for maximum vocal expression. He partnered the male and female vocal lines on the clarinet in the slower songs, and in his solo improvisations he often played in the altissimo register, using fast arpeggiated patterns, swoops, glides, trills, ornaments and flutter-tonguing to extend the vocal line.

As Debbie explained, it is because of their 'blender-soloist' personality traits that each clarinettist is able to be both a 'blender' in their roles as accompanists to singers and other members of their ensembles, and to be a 'soloist' when they play the solo melody line or improvisation (Rawson, 4 August 2010, pers.comm). It became apparent that these traits allow them to take leadership roles by providing a vision, 
finding repertoire and offering administrative support to their collectively run ensembles.

I also observed that the heritage of each clarinettist influences their vision for their ensemble, their choice of repertoire and the events at which they chose to perform. For example, Andrzej often reflects his Polish heritage in the SMP Ensemble, Debbie highlights her New Zealand heritage in the New Zealand Clarinet Quartet, Greg demonstrates his New Zealand heritage and American influences in the Blackbird Jazz Trio, and Urs displays an eclectic mix of Swiss heritage, Ashkenazic Jewish and Maori influences in the Klezmer Rebs. In their own distinctive ways the four clarinettists act as extensions of the voice, and expressive conduits of musical styles in and between diverse ensembles. 


\section{CHAPTER THREE: Voice and Clarinet Identity}

\section{Introduction}

The first section in this chapter incorporates concepts of individual, musical and ensemble identity as they intersect at the link between the body and mind of the vocalist and clarinettist. Historically in the Western classical music tradition the mind has taken control of the body as the initiator of instrumental technique and analysis, and in the execution of musical works. Ken Dychtwald states in his well-known book Bodymind that in the West we have chosen to make a duality of the 'bodymind', separating it into two parts. As he explains 'this mind/body dualism is reflected in all our institutions and cultural processes. Because of this split, it is not surprising to find that our minds and bodies often compete and argue, for they lack communication' (Dychtwald 1978:2425). Through developing an awareness of bodymind integration, many positive benefits are possible for both singers and clarinettists.

The second section identifies the role that singers play in an ensemble, how that forms their musical identity and how they exert an influence on their audience. An understanding of this process helps to identify the role of the clarinettist as it extends, partners, imitates, amplifies and sometimes replaces the voice in the same ensemble. In a recent publication on leadership, Paul Aitken commented that leadership qualities include being personally expressive, persuasive, self-assured and confident, qualities which 'free people to new possibilities through making oneself vulnerable and open' (Aitken and Higgs 2010:51 and 54). I suggest that all these qualities are present in singers who use their musicianship and vocal technique to convey stories and a variety of expressive moods to an audience. Expressive singers hold a powerful position in an ensemble and they have the ability to influence the mood or attitudes of their audience. 
Through their musical relationship with singers, clarinettists also display qualities of expressiveness and leadership in their musical identity.

In the final section the 'vocal' clarinettist in the ensemble is discussed to assess how he/she combines musical technique and musicianship with the distinctive 'vocal' qualities of their instrument. There is discussion about the mix of 'blender and soloist' personality traits exhibited by clarinettists to assess how this affects leadership roles in their ensembles. A comparison of the musical traits of clarinettists with their personality traits uncovers some interesting insights into the ways they choose to perform a leadership role. Comparisons between the role of a singer in an ensemble with that of a clarinettist also suggests some of the ways in which clarinettists act as expressive conduits of music in diverse ensembles.

\section{Individual Identity: Bodymind Integration}

\section{Individual Musical Identity}

In his recent article Disciplining Ethnomusicology: A Call for a New Approach, Timothy Rice asked ethnomusicologists to take a more rigorous and interconnected approach to the research of identity in music. (Rice 2010:322). He highlighted salient questions to ask including 'what does music contribute to identity formation?' and 'why is music so effective in this regard?' (ibid:323). In an attempt to answer these questions, I suggest that music works at a deep physiological level activating aural patterns of melody, rhythm, harmony, timbre, volume and texture. These musical patterns have the ability to transform the human organism from a state of disorder or even depression, to a state of order and uplifted readiness, rather like the night-time dreaming process. In the well-known book Studying Popular Music, Richard Middleton suggests that music is assigned to a world that is 'pre-linguistic', 'presymbolic', 'pre-rational' and 'pre-logical' - to the world of each individual in the 
earliest stages of development. (Middleton 1990:189). This primal neural musical pathway, separate to that of speech, symbols, and conscious control, affords an immediate and deep physiological connection from the mind to the body, finding a synthesis in vocal production.

Individual identity is the result of interwoven strands between the body and mind as we constantly adapt ourselves to our environment from childhood to adulthood in order to promote the best outcomes for our wellbeing. As we travel along this path we also develop our social identity and our musical identity. According to Middleton music is assumed to originate from the 'metamusical processes' of this world which are - 'either innate or connected with very deep levels of psychological development' (ibid:189). Music has the ability to bypass ordinary language as a form of communication when the synthesis of musical neural impulses meets the muscular actions of the body.

The voice plays an integral role in individual identity, both in speech and song. The voice, says Middleton, is 'the profoundest mark of the human...this is because vocalising is the most intimate, flexible and complex mode of articulation of the body [and] is fundamental to the creation of human societies' (ibid:262). Taking this one step further, there appears to be an innate connection between voice production and body movements, as Johan Sundberg states as he discusses the relationships between body movements, human emotion, and the physiology of voice production. He notes that 'in other words, it is likely that expressive body movements are translated into acoustic terms of voice production' (Sundberg 1987:154-155). Developing this idea even further we can see how neural impulses leading to vocal production are then mirrored in musical instruments such as the clarinet, as they become extensions of the human body and voice. 
The way in which internal states, somatically experienced, become the source of externally uttered movements, and the way in which this dialectic affects the physiology of voice production, is mirrored in the production of instruments as extensions of the human body and voice. (Shepherd and Wicke 1997:179)

\section{The Feldenkrais Method}

A direct musical pathway is available to everyone providing the neural pathway and corresponding muscular patterns work in an integrated and efficient way.

Unfortunately this is not always the case, and many singers and instrumentalists find that they develop physical problems and mental tension due to practising with a faulty technique. As Moshe Feldenkrais asserts,

This great ability to form individual nervous paths and muscular patterns makes it possible for faulty functioning to be learned...It will remain largely so unless the nervous paths producing the undesirable pattern of motility are undone and reshuffled into a better configuration (Feldenkrais 1949:40).

The Feldenkrais system of movement primarily promotes bodymind integration and flexibility, which are both very beneficial to musicians. Other movement systems which specifically support musicians are the Alexander Technique, Yoga, and Pilates, as they focus on aspects such as correct natural posture, muscle lengthening and strengthening and flexibility of joint rotation.

Dr Moshe Feldenkrais was a physicist and an engineer with an interest in improving human development through movement. The Feldenkrais Method teaches movement sequences which focus on making everyday activities easier for its students. Guided by a teacher in a group class, students do slow and precise movements to engage their brain through their body and nervous system in a relaxed yet focused state. The movements help students to understand and modify their habitual movement patterns, which may have developed in response to injury or bad posture. More parts of the brain are activated through the neuromuscular system helping the muscles move outside their habitual pattern (Feldenkrais Guild 2007). 
As a student of the Feldenkrais method I have experienced the following key concepts. Based on the movement patterns of babies and toddlers, the Feldenkrais Method assumes that a return to the earliest and simplest ways of moving as an infant will benefit adults as well. Exercises are performed on both sides of the body in a symmetrical way, interspersed with many rests. During sleep overnight the neurological patterns in the brain are 're-wired' to the new and more flexible way of moving, so that on rising the next morning, simple actions feel easier.

\section{Bodymind Integration}

\section{Postural Alignment}

The Feldenkrais method enables musicians to retain flexibility in their bodies and minds, which helps them to overcome physical tension and mental stress, and frees them to make expressive music with personal authority. Correct alignment of the vertebra in the spine and the neck positively affects the way the body carries the weight of the head. Feldenkrais outlines his instructions for correct human posture as follows,

Grade A. Excellent mechanical use of the body

1. Head straight above chest, hips and feet

2. Chest up and forward

3. Abdomen in and flat

4. Back, usual curves not exaggerated (Feldenkrais 1949:105)

Although correct spinal alignment is encouraged, it is not meant to be taught as a rigid system of carrying oneself, but as a constantly adaptive and flexible system. As Feldenkrais says, 'I contend that rigidity, whether physical or mental, ie, the adherence to a principle to the utter exclusion of its opposite, is contrary to the laws of life' (ibid:13). It is the flexibility of the spine and the easy rotation of the joints of the body, such as the head, the shoulders, the wrists, the hips, the knees, and the ankles which allow for a freedom of connection and flow of energy between the mind and the body. 
Often we cling to a familiar pattern of movement which we have learned as a protective mechanism somewhere along our life's journey, which is a 'holding pattern' of muscle tension and fatigue. Feldenkrais contends that 'most of us stick to some infantile pattern which is so charged with emotional tension that we cannot even consider the possibility of it being wrong' (Feldenkrais 1949:53). One of the challenges for the performing musician is to learn to recognise areas of blocked tension in the body, and to allow them to release, so encouraging a mood of relaxed concentration.

\section{Role of the Neck and Head}

Very often the neck suffers a huge amount of tension due to incorrect posture or movement, which negatively affects vocal and clarinet tone. The chest expands and amplifies emotional flows before the neck acts as a mediator between the body and mind to sort and refine them, and send them to their appropriate destinations in the throat or the face. As Dychtwald maintains 'Because of its structure and position, the neck must continually mediate between feelings and thoughts, impulses and reactions' (Dychtwald 1978:187). Neck tension reduces resonance in both vocal and clarinet tone as it restricts the airstream and blocks the vocal tract, pharynx and oral and sinus cavities from vibrating. Teachers of the Alexander Technique encourage students to adopt correct neck and head positions as one of its first principles. The head is encouraged to be forward and up slightly which lengthens the muscles of the back, which is highly beneficial for deep breathing, singing and also clarinet playing.

\section{Deep Breathing: The Role of the Abdomen, Chest, Solar plexus, Diaphragm}

The muscles in the abdomen, chest and solar plexus regions are all prone to becoming rigid and unbalanced as they often stiffen in response to some negative emotional stimuli. Tension in these muscles affects the natural movement of the 
diaphragm which in turn restricts the deep breathing which is necessary for good vocal and clarinet tone production.

When this region is open and unblocked, energy flows freely and the bodymind experiences health and pleasure. When this region is tight or restricted, the result is a limitation of feelings, breathing potential and energetic flow.

(Dychtwald 1978:138)

As has been stated in the previous chapters, the most important aspect of singing and playing a woodwind instrument is to learn to breathe fully and deeply. If we breathe shallowly we diminish our oxygen levels and also the extent to which we are stretching and revitalising our lungs. As Dychtwald asserts, 'in order for an individual to make full use of the life force that is available to him, therefore, it is necessary that he make full use of his breathing/living apparatus' (Dychtwald 1978: 142). In her book Voice Power Renee Grant Williams states that deep breathing benefits the cardiovascular system, muscle tone, posture, neck and shoulder tension, energy levels and body balance.

She offers this advice for shallow breathers,

Shallow breathing makes you sound breathy and weak. Tension around the neck stiffens the vocal cords, making them rigid, unresponsive, and vulnerable to damage. It cuts off the resonance and reduces resilience and flexibility. The pitch rises. You feel and sound strangled. In short, you sound uptight... You'll get a richer, fuller voice with low abdominal breathing because your body and vocal cords are free to vibrate. (Grant-Williams 2002:23)

Just as there is a need for an integrated bodymind approach for singers, it is equally important for clarinet players. With many hours spent daily on practice and the pressures involved in performance, professional clarinettists need to take care of their bodies in order to avoid Occupational Overuse Syndrome (OOS). The effect of the misuse of muscles can lead to significant physical problems such as pain, numbness and loss of power in the neck, shoulders, back or arms. As clarinettist Nicholas Cox comments, 'almost all clarinettists and most wind players I have ever met suffer from 
some sort of back or neck problem, normally the result of actually holding the instruments' (Cox 1995:152). Biofeedback machines used by physiotherapists reveal that not only does holding the clarinet on the thumb of the right hand cause tension and pain, but when the right hand starts moving on the keys, the tension increases manyfold. Just as it is beneficial to perform some physical warm-ups before singing, it is also important for clarinettists who wish to develop excellent breathing and postural techniques, to remain free of OOS, and to express their individual identity through a resonant and colourful tone. The warm-ups could include such things as shoulder rolls, spine rolls forward, arm stretches and deep breathing exercises, followed by some scale patterns at a steady tempo to warm up their arms and fingers. As Heizmann illustrates in his book Vocal Warmups, ten minutes of physical warm-ups which help singers will also help clarinettists improve their relaxation, posture, breathing, mental focus and resonance (Heizmann 2003:7).

\section{Musical Identity: Voice and Clarinet}

Current scientific thinking suggests that the speech centres in the brain are recent evolutionary developments, and according to musicologist David Burrows, 'the loss of ability to speak does not necessarily involve any loss of the ability to sing, even to sing words' (Burrows 1989:395). Singing is therefore associated with pre-linguistic vocalising and offers the individual the opportunity to sing 'in their own world' into adulthood. Burrows also suggests that in some of the best realised performances there is a 'voice without a viewpoint' which sings of the commonality of the singer and the audience, 'a voice too deep and too ancient to have a name' (Burrows 1989:396, 400). Given that song is an ancient form of communication, there is a deep and immediate attraction to a singer who is able to sing freely in an 'unmasked' way, showing human 
vulnerability and a spectrum of emotions from joy and sorrow to anger and fear in their vocal inflections.

I find it intriguing that in popular music many highly successful singers do not aim to produce a 'trained' vocal tone, or notes with accurate intonation. Instead of this homogenous sound, singers such as Billie Holliday, Leonard Cohen, and Bob Dylan reveal a distinctive sound to their audience, which reflects their individual personality. Their 'unmasked' storytelling in song is powerful and creates an immediacy between the singer and his/her audience. Clarinettists also have to 'bare their souls' to the audience if they wish to perform in a musically expressive way.

\section{Vocal Identity}

In my experience singers, male or female, are differentiated from instrumentalists in an ensemble in many aspects of their performance. Perhaps the most obvious is the singer's dress code which is usually significantly more colourful and distinctive than that of the rest of the ensemble's attire. Singers are allowed some physical freedom compared with the rest of the ensemble; they have freedom to move location, to use their body and arms for gestural effect and to use facial expressions to enhance their performance. Unlike the instrumentalists in a 'classical' ensemble they do not have to play an instrument and read music at the same time, allowing them the freedom to engage fully with the audience. This physical immediacy creates a direct link with the audience which is further enhanced through eye contact, expressive gestures and of course, through their song. Recognised as the main 'storyteller' of the ensemble for this particular song, the audience focuses its eyes and ears on the singer, regarding the rest of the ensemble as a backdrop to the singer's performance. In the case of an opera performance, the orchestra is literally out of sight from the audience, playing below the stage in an orchestra pit. 
In my opinion, regardless of which musical style he/she performs, a singer has the power to motivate or to inspire their ensemble, to display a particular character or psychological state, and to 'move' the audience from one particular mood to another. A charismatic singer who performs with an inclusive sense of humour can further heighten the audience rapport and influence their emotions and attitudes.

\section{Musical Techniques for Vocalists}

I have observed that as with instrumentalists, singers have many musical tools at their disposal to aid in the presentation of a particular song. Their artistry as a poet and storyteller becomes apparent when they apply their musicianship using vocal timbre, phrasing and inflections to imbue the song lyrics with emotional meaning. Other musical tools available to singers in culturally diverse ensembles include their choices of: inflection, resonance, nasality, vibrato, pitch and micro-pitch intonation, head and chest registers, language, accents, percussive and guttural effects, melisma, falsetto, improvisation, ornamentation, rhythmisation, syncopation, melisma, declamatory singing, talking, crying, wailing, whispering and rubato to express themselves.

I also believe that singers assume leadership and charisma in ensembles in the way they take control of time through initiating rubato, pauses and accelerandi. An example of this is the tempo variations which occur regularly in opera as the soloists lead subtle tempo and rubato flows, which the conductor then conveys to the orchestra players. Rubato and tempo variation is also frequently used by singers in klezmer music for dramatic and humorous effect, however in a rather more informal way than it occurs in opera as no conductor is required in the smaller ensemble. 


\section{The Influence of Singers on Clarinettists in the case studies}

\section{Olga Gryniewicz and Andrzej Nowicki: The SMP Ensemble}

Clarinettist Andrzej Nowicki was influenced by performing with Olga

Gryniewicz, a Polish singer, who was a regular guest soloist at the SMP Ensemble performances. Olga is a charismatic performer with an expressive soprano voice which she employs to demand the audience's attention and involve them in the performance. In the Podroze-Journeys concert in November 2009 which celebrated the sixty-fifth anniversary of the arrival of the first refugees in New Zealand, the programme entirely featured works by Polish composers. Olga was given an important role in carrying the emotional weight of the event by performing a Polish Folk song Polskie Kwiaty, which reminded the audience of their homeland. She also sang Rymy Dzieciece - Children's Rhymes by Szymanowski, accompanied by Claire Harris on the piano, in which she illustrated the child-like text with vibrant vocal inflections. In Carole Shortis' work Tesknota (Yearning) Olga joined several members of the Wellington Youth Choir and several SMP instrumentalists to help create a mood of sadness and longing of the Polish children who had lost or were separated from their families (Nowicki, 30 September 2009, pers.comm).

Olga used a selection of vocal techniques such as vibrato, singing with the head and chest registers of the voice, accenting consonants, syncopating rhythm, melisma, declamatory singing, rubato and dramatic inflection to infuse her performances with the utmost expression. The audience was spellbound by the intensity of her interpretation, despite the lyrics being in Polish, and their reliance on the English translation in the programme.

In the Allegro moderato from the Sextet by Krzysztof Penderecki Andrzej’s clarinet playing reflected the intensity of Olga's performances in other works in the 
programme, in his insistent tone in the high register and his dramatic and colourful performance of the melodic lines.

\section{Anna Reissar and Debbie Rawson: The Constanza Trio}

Singer Anna Reissar in the Constanza Trio influenced Debbie Rawson's clarinet playing with her lyrical and dramatic storytelling. Growing up in Estonia Anna experienced a very difficult childhood which lent her singing an emotional intensity and she imported expressive and haunting songs from Russia and Estonia, for the ensemble to perform.

One of the favourite works in the Constanza Trio's repertoire was The Shepherd on the Rock by Schubert, which features plentiful examples where the clarinet imitates, partners and echoes the soprano voice (Rawson, 4 August 2010, pers.comm.). (Please see the Appendix for a musical example of these voice and clarinet links on pages 83 and 84 of Der Hirt auf dem Felsen /The Shepherd on the Rock).

At the start of the piece, Anna sang in a soprano voice as the shepherd high on a mountainside, with his lover who was represented in the echo of the clarinet part. She sang in a trained western art style with warm expressive vocal timbre, inflections, vibrato and legato. In the next section the shepherd is in despair over the failed love affair and in the final section he becomes joyous that Spring is coming, again accompanied by the clarinet part. The texture and timbre of the German lyrics highlight the musical word-setting of the poem, which is reflected in the sympathetic imitative clarinet part.

Although written as a chamber work, The Shepherd on the Rock is also a fine example of a concertante aria, as the scale of the work is operatic in its character, giving it appeal to a large audience. Anna brought her emotional intensity to the role of the Shepherd, heralding dramatic mood changes in each section to which clarinettist 
Deborah Rawson responded by matching the inflections of the soprano's melodic line (Rawson, 4 August 2010, pers.comm).

\section{Bonnie Riley and Greg Rogan: The Blackbird Jazz Trio}

Greg Rogan's clarinet playing was influenced by singer Bonnie Riley in the Blackbird Jazz Trio, as she created a relaxed and comfortable ambience in a bar and restaurant setting. Accompanied by Greg Rogan on clarinet and saxophones and Eion Riley on guitar, Bonnie sang traditional jazz standards which provided a framework for solo instrumental improvisation over the verses. Due to the small size of the ensemble Bonnie was free to communicate with the other two musicians in a relaxed way, and Greg would often partner Bonnie's vocals, or echo her phrases on the clarinet. In a recent performance she used a microphone to subtly amplify her voice, which allowed her confidence to lead the ensemble. In keeping with the rest of the ensemble Bonnie dressed in a simple style and seemed to enjoy blending with the ensemble rather than attracting attention specifically to herself.

Bonnie sang mainly jazz standard songs in a relaxed and lilting way in her chest voice register, which blended well with the clarinet tone. In the song 'Here's that Rainy Day' by Jimmy Van Heusen and Johnny Burke Bonnie used a little vibrato and many colourful inflections to add interest to this well-known song, which were imitated by the clarinet. In 'Taking a Chance on Love' by Vernon Duke, John Latouche and Ted Fetter Bonnie established a strong rhythmic sense in the opening phrases, which generated some lively rhythmic responses in phrases played by Greg on the clarinet and Eion on the guitar. Greg often imitated Bonnie's vocal timbre and melodic phrasing to create a 'conversation' amongst the ensemble members. 


\section{Dave Moscovitz, Rose O'Hara, Sue Esterman and Urs Signer: The Klezmer Rebs}

Urs Signer was influenced by the lively way the singers in the Klezmer Rebs communicated joy, pathos and good humour in an immediate and informal way to the audience. Singer Dave Moscovitz deftly combined story-telling in English with fluent singing in Yiddish, English, French and Maori using movement, humour, individuality and dress (black T-shirt, jeans and black socialist cap). He used a variety of vocal attributes such as vocal timbre, micro-pitch intonation, nasality, choice of language, interjections, syncopation, laughing, crying, talking and declamatory singing to convey his musical stories. Many of the audience members were familiar with Yiddish and they were often invited to sing along with repeated lines on simple syllables such as ' $\mathrm{di}$ di di' in the choruses. The heightened energy from the audience participation flowed back to Urs to help 'lift' his spontaneous solos on the clarinet. The eclectic mix of songs sung in a variety of languages, communicated a sense of inclusivity to the audience and also radiated out beyond the performance into the community. Urs composed several of the songs in English and Maori, some of which he sang as well as playing the clarinet, giving him a continuous link between his voice and his clarinet.

In a recent performance at the Progressive Synagogue Rose O'Hara left her keyboard and came out to the front of the band to sing her songs, whereas Sue Esterman continued to accompany herself on the accordion as she sang. Both women projected a sense of immediacy with the audience, in their colourful clothing and expressive singing. Rose and Sue varied their use of vocal inflection, nasality, syncopation, head and chest registers, sighing, laughing and declamatory singing to communicate with the audience in an expressive klezmer style. The vibrant folk song verses were enhanced by frequent rubato and pauses, creating a dramatic mood, before the audience was invited to join them in singing the chorus. In his clarinet playing Urs extended, 
partnered and replaced both the male and female voices using rubato, pauses and many of the previously mentioned vocal stylistic idioms of klezmer music.

\section{Ensemble Identity: The 'Vocal' Clarinettist}

\section{The Instrument}

As Bruno Nettl comments 'an important aspect of ethno-organology...is the role of instruments - beyond their musical role - in society and culture' (Nettl 2005:380). In my observation holding a tool or a musical instrument immediately gives the holder a sense of some 'other' power, as it functions as an extension of the human body. In the case of the clarinet this power is displayed as a long black wooden pole with a flared bell at the end, decorated with shiny silver keywork. Although the keywork mechanism has modernised the clarinet, the image and sound of the clarinet resonates back to its earliest form, the chalumeau, which was made from wood, giving it a link to the natural world in its appearance and its resonant 'woody' sound quality. Unlike the brown colour of bassoons which are easily recognised as wooden instruments, or the silver colour of flutes, the clarinet, made from a black African hardwood grenadilla, is similar to ebony in colour. The black colour is striking, and the clarinettist's fingers moving in a flurry over shiny silver keywork add to this image of energy. It appears that the instrument is 'brought to life' by the clarinettist's breath, which perhaps denotes a special relationship between the clarinettist and his/her instrument.

\section{Three Clarinet Voices}

The most distinguishing feature of the clarinet is the way that it embodies three voices, the chalumeau, the clarion and the altissimo registers, each with its own distinctive timbre, volume and overtone qualities. Covering the range of a soprano voice with an added concert F3, E3, D3 and G6, A6, B flat 6, the clarinet offers a variety of timbres within this wide pitch range. Interestingly Elizabeth Wood comments 
on these same qualities in her article about the 'Sapphonic Voice' in which she describes the flexibility, versatility and power of a dramatic soprano voice with its nearly 3 octave range from G3 to F6. She suggests that this voice manages to cross boundaries and integrate the soprano, mezzo and chest registers of the female voice.

The extreme range in one female voice from richly dark deep chest tones to piercingly clear high falsetto, and its defective break at crossing register borders, produces an effect I call sonic cross-dressing: a merging rather than splitting of 'butch' authority and 'femme' ambiguity, an acceptance and integration of male and female. This border-crossing voice I call Sapphonic is a transvestic enigma, belonging to neither male nor female as constructed - a synthesis, not a split. (Wood 2002:86)

The way that the contralto, mezzo and soprano voices in the female voice are imitated in the clarinet point to the special mirroring relationship between singers and clarinettists. This is not shared to the same degree by other woodwind instruments, whose timbre tends to be more homogenous over the entire range, such as the 'string of pearls' tones in the flute. Compared with the high 'feminine' clarion register of the clarinet, the chalumeau with its larger 'earthy' tone has a more 'masculine' quality, allowing both male and female players to relate to the instrument in their own way.

The B flat bass clarinet is able to play one octave lower than the B flat clarinet and its extremely large range (D2 to D6) means that when it is used in contemporary music using extended techniques, it is able to cover the entire range of choral voices from bass to soprano (bass E2 to E4, Tenor C3 to C5, Alto F3 to F5, Soprano C4 to C6). I have observed that compared with the B flat clarinet the wider bore of the bass clarinet produces a larger resonant tone in the chalumeau register, imitating a bass voice, the clarion register imitates a counter-tenor voice, and the altissimo register sounds like a male falsetto voice. In my opinion these three male 'voices' allow the bass clarinettist to perform with powerful expression especially in works by contemporary composers. 
In addition to these similarities both the voice and the clarinet have a natural 'break' as they change register, where the note becomes weak and breathy and it changes its tonal quality. The pitch of the break from chest to head voice tends to vary in individual singers, but in the clarinet it happens at concert pitch A4 where the chalumeau 'voice' changes to the 'clarion' by the addition of the register key. The two notes below this G4 and F4 are traditionally referred to as the 'throat notes' on the clarinet as they have a similar breathy tonal quality to the break note.

\section{Clarinet-Voice Links in the Ensemble}

As can be seen in the case studies, the clarinettists play a variety of roles in the way they extend the voice. At times they amplify the voice as in using a loudhailer, sometimes they partner or imitate the voice, sometimes they echo vocal phrases or extend the vocal phrases into new pitch registers, and, where there is no vocal line, they often replace it with their own cantabile line. This direct and symbiotic relationship with the vocalist means that the clarinet is constantly using its inherent flexibility and instrumental vocalisation to support the melodic line. As Jack Brymer comments in his famous book Clarinet,

Indeed until he can forget that he has a clarinet in his hands, and can actually sing the work with the medium of the clarinet as his voice, the clarinettist has not conquered the task of becoming a recitalist'. (Brymer 1976:204)

Singing is a form of pre-linguistic vocalising, which gives it an emotional resonance as the most ancient form of human communication. The enormous spectrum of emotions and human vulnerability which can be shown in various vocal inflections, phrases, wails and cries in the voice, can be extended, replicated and amplified on the clarinet as was shown in the extraordinary performance of Charon (1996) played on bass clarinet by Richard Haynes at The New Zealand Clarinet Quartet concert and master class. In a similar way to singers, clarinettists have musical tools at their 
disposal which include varying their timbre, vibrato, pitch-bending notes, playing in several registers, playing a legato or a staccato phrase to imitate vowels and consonants, accenting notes, playing in a declamatory style, crying, wailing, and controlling rubato in the ensemble at times. Further comparison highlights that virtuoso clarinettists such as Richard Haynes play each note and each phrase with particular inflections for emotional meaning, in the way that singers do. They are also the only wind instrument which can literally start a note at a niente dynamic and crescendo to a full fortissimo very rapidly, as singers do (Brymer 1976:8-9).

In the four case studies there are numerous examples of the ways in which the clarinet extended, partnered, imitated, amplified and replaced the voice in their performances. In the SMP Ensemble clarinettist Andrzej Nowicki imitated, extended and replaced the voice in contemporary music, playing a dynamic melodic line with vocal inflections in the high register, as in the Sextet by Penderecki. Clarinettist Debbie Rawson partnered and echoed the vocal line sung by soprano Anna Reissar in the Shepherd on the Rock by Schubert. In the Blackbird Jazz Trio clarinettist Greg Rogan partnered and imitated Bonnie the vocalist's line, creating a musical conversation with her and with the guitarist. In the Klezmer Rebs clarinettist Urs Signer partnered, imitated and extended the range of the vocalists, Dave, Sue and Rose, acing like a 'dybbuk' or restless spirit. Just as the singers in the case studies displayed leadership qualities, so the clarinettists displayed similar characteristics in their expression, powers of persuasion and confident performance of melodic lines and improvisation.

\section{Blender-Soloist Personality Traits}

I have observed that the connection between the inherent nature of the performer and the learned experiences of playing the clarinet fuse together and influence each other to create both a clarinettist performer and a clarinettist personality. The contrast 
of 'blender' and 'soloist' personality traits which Debbie Rawson mentioned in our interview are key components in this leadership role, as the 'blender' allows the clarinettist the versatility to blend with other personalities in the ensemble, and the 'soloist' supports the drive and individuality to separate from them when performing and improvising solos. Although it is usual practice for musicians to wear black for performances, it was interesting to note that all four clarinettists in the New Zealand Clarinet Quartet wore colourful tops and trousers for their performances, signifying unity in style (blender), yet also vibrant individuality for each player (soloist).

Although these clarinettists were limited to some extent by having to play with both hands on the instrument, and the mouthpiece in their mouths, when the ensemble played standing they were free to move or even walk around as they play. As singers do, the clarinettists conveyed a sense of physical freedom and unity in the ensemble by raising and lowering their instruments, by sideways swaying movements, by bending their knees and by occasionally looking directly at the ensemble and the audience when they were playing.

\section{Socio-Musical Structures}

In her book Thinking Musically: Experiencing Music Expressing Culture, Bonnie Wade discusses the structures of socio-musical hierarchies, suggesting that an ensemble develops specific musical routines to enable its members to work cooperatively and individually. For example in jazz certain structures are used to reflect the ensemble values,

Performance practice in jazz is of a group, for a group, expressing a cause held in common or remembering that cause. Rather than submerging the individual musicians within the group in the musical structure, however, individual creativity is featured in two ways - cooperatively, in that individual players take the spotlight in turn, and competitively, as musicians engage in fierce cutting contests that display and stretch their explicitly jazz-style musicianship.

(Wade 2004:126-127) 
In the case studies it was apparent that the ensembles were all managed cooperatively with the clarinettists often initiating a vision, before leading and listening to input from the other ensemble members. All the clarinettists, Andrzej, Debbie, Greg and Urs, sourced repertoire for their ensembles and occasionally arranged musical parts. Three of them took responsibility for organising rehearsals, players and concerts, while Urs was a little more removed from that role due to his geographical location out of Wellington. Their vision and commitment to their various musical groups inspired the other ensemble members to be involved, and sometimes had a major political influence such as Urs' role as political activist in the Klezmer Rebs. All four clarinettists brought energy, enthusiasm and a love of performance to their roles in their ensembles. They presented as distinctive individuals and fluent communicators, whose first priority was to make their ensembles successful, using their dynamic drive to achieve their musical potential.

\section{Conclusion}

As the clarinet extends the voice in many musical styles, the deep physiological links between the body and mind, which are felt in vocal production, are also felt in clarinet playing. The clarinet is so closely linked to the voice that it also reflects and shapes musical patterns from an 'innate' place in the brain. As Shepherd and Wicke comment 'equally, there has grown up an intimate relationship between instruments as imitators of the human voice, and the human voice as an imitator of instruments' (Shepherd Wicke 1990:179). John Baily has developed this theme by suggesting that players' movements affect musical structures in fundamental ways. The motor patterns which are implicated in a particular kind of music result, in Baily's view, from interaction between the morphology of the instruments and the player's sensorimotor capacities (ibid:179). This link between the motor patterns of clarinet players and the 
musical styles they play in means that the players help to shape the identity of the ensemble through their individual identity.

The bodymind techniques which reduce tension, enhance freedom of movement and improve the flow of energy throughout the body are of great benefit to the clarinettist, affording improvements in the quality of the tone and in expressive capabilities. Singers and clarinettists who connect their mental focus with the functionality of their bodies demonstrate the leadership qualities of expression, confidence and persuasion in performance. These qualities blended with dramatic, visual and aural aspects of performance allow both singers and clarinettists the ability to influence the social and political attitudes of an audience.

Due to its 'expressiveness, agility and richness of tone' the clarinet has been included in a wide array of ensembles including western orchestral, chamber and contemporary music, military band, balkan folk, jazz and klezmer music (Heaton 1995:163). Andrzej, Debbie, Greg and Urs displayed mastery of their stylistic idiom to other members of their ensemble and to their audience. They also demonstrated their vocal-clarinet links, 'blender-soloist' personality traits and leadership skills in each of their ensembles. In their confident performance of melodic lines and improvisation the clarinettists in the case studies communicated the musical styles of their particular ensemble to their audience, be it contemporary or western art music, jazz or klezmer. In this way they exerted their influence on the ensemble, and in so doing helped to shape the outcome of the performance. 


\section{CHAPTER FOUR: Clarinettists as Conduits of Musical Styles}

\section{Introduction}

In this chapter I explore the ways in which freelance clarinettists are able to transcend gender, ethnicity and ensemble boundaries to act as conduits of musical styles in and between ensembles. Due to its portability, low cost and remarkable versatility the clarinet affords its players the freedom to play in a range of music from diverse cultures. As can be seen in the previous chapters the vocal-clarinet links enable clarinettists to act as leaders in their ensembles and expressive conduits of musical styles. In my opinion it is the combination of all these attributes that has allowed the clarinet to be accepted into musical ensembles in various countries, and to imitate the vocal style of that particular ensemble.

The first section in this chapter looks at the ways in which clarinettists transcend gender boundaries because of the embodiment of the three distinct voices within the clarinet: the chalumeau, the clarion and the altissimo registers. The second section discusses the ways in which clarinettists transcend cultural boundaries through their choice of instruments, their musical style, the repertoire of music performed and the venues and functions they choose to perform at. The third section explores the ways in which clarinettists can transcend various ensemble styles. In my view musical ensembles provide society with potent 'change-agents' and social descriptors by their structure, their repertoire, their performance venue and their audiences. Each different ensemble represents a certain societal paradigm in which both musicians and audiences play their part by adhering to the cultural rules embedded in that paradigm. Clarinettists are capable of playing in classical, contemporary, military, folk, jazz, klezmer, and tango styles enabling them to act as conduits of musical styles within and across diverse ensembles. 
During the course of my research into clarinet playing in Wellington it became clear to me that the invisible character in this thesis was Wellington's musical identity. The second part of this chapter discusses the ways that Wellington City supports its musical performers by providing diverse venues in a range of styles. The current Wellington City Council Events Policy states that its objectives are 'to encourage events that are innovative and creative, that contribute to economic growth, that reinforce the city's position as the arts and cultural capital, that celebrate diversity, culture, nationhood and heritage, that create vibrancy and energy, that highlight the natural environment of the city and region, and that generate media profile for the city' (Wellington Government Policies 2003). Research into the role of the Wellington City Council and owners of other music venues in central Wellington reveals the ways that clarinettists are supported in their role as conduits of musical style.

\section{Clarinettists Transcend Boundaries: Gender, Ethnicity, Ensemble}

\section{Gender Boundaries}

The first way that clarinettists transcend boundaries is in the realm of gender as it relates to the clarinet. In his book The Study of Ethnomusicology: Thirty-one Issues and Concepts, Bruno Nettl discusses the role that gender plays in developing individual identity and that our understanding of musical culture is partly through the way men and women relate to each other within it. His suggestion that gender power relationships underpin the developments in music, offers a lens through which to view the way clarinettists play in ensembles.

One is the recognition that the understanding of gender as a factor in personal identity and of gender relations in all aspects of society is essential to the interpretation of musical cultures; and that this is closely related to the second, the realisation that virtually all relationships and all developments in music, among societies, and of groups of people within a society, can be seen as a function and expression of power relationships. (Nettl 1983:404) 
Although the clarinet has historically been played by males in many musical traditions, it has become a much less gender specific instrument in the late twentieth century. I believe that the clarinet crosses gender boundaries because it embodies both 'masculine' and 'feminine' characteristics in the way it contains three distinctive 'voices', the chalumeau, the clarion and the altissimo registers. I suggest that whereas the chalumeau register imitates either a mezzo-soprano voice in the chest register or a male tenor voice, the clarion and altissimo registers imitate a soprano voice in the head register. Elizabeth Wood explains that a dramatic soprano voice is able to cross gender boundaries due to its exceptionally wide range, flexibility, versatility and power, referring to this border-crossing as 'an acceptance and integration of male and female' (Wood 2002:86). I believe that it is this integration of the heterogeneous timbral voices within the clarinet which appeals to both male and female players, as it offers them the individuality of the 'earthy' or more 'masculine' chalumeau notes, with the more blended and 'feminine' tone quality of the clarion register. In the 1780 s the music writer Schubart, declared that 'the [chalumeau] tone has so much interest, individuality and unending agreeableness that the entire scale of art will suffer a considerable deficiency if this instrument is lost' (Hoeprich 2008:60). In contrast to this, French composer Berlioz noted this about the clarion register of the clarinet ' $I$ have never been able to hear military music from afar without being profoundly moved by that feminine quality of tone present in the clarinets; it has always left me with impressions similar to those received when reading ancient epic poems' (ibid:302).

I have observed that the 'extension' qualities of the clarinet allow both males and females to reflect their unique musical identities, enabling the clarinet to cross gender boundaries. Unlike many other instruments with a strong gender bias, learning to play the clarinet is currently a popular choice with both men and women. As clarinet playing 
does not require gender specific capabilities such as strength or size in the hands, diaphragm, or embouchure, similar numbers of female and male clarinettists are attracted to the freedom and diversity offered by the instrument. During my research and interviews with clarinettists in Wellington it appears that there are fairly equal numbers of male and female professional clarinettists in orchestral, chamber music, klezmer, military band, jazz and tango ensembles. As at 2010 in the New Zealand Symphony Orchestra there are currently two male clarinettists, and one female bass clarinettist, and in the Vector Wellington Orchestra five players are rotated, only one of whom is a male (Nowicki 2010, 28 October, pers.comm). The Royal New Zealand Airforce Band has one female and eight male clarinet players, and there are three males and one female student at the New Zealand School of Music (Rawson 2010, 4 November, pers.comm). Although three out of four of the case studies are male, the one female Debbie Rawson, plays in an extensive number of stylistically varied ensembles, including classical, jazz, tango and klezmer, as well as leading the internationally recognised Saxcess saxophone quartet, and holding the position of Head of Woodwinds at the NZSM.

\section{Cultural Boundaries}

Stephen Cottrell and Evangelia Mantzourani comment that through a process of 'cultural transmission' in Eastern Europe, the simple system clarinet is slowly usurping the place of extant traditional instruments, such as simple and multiple pipes and the oriental shawm, because of its vocal qualities, its agility and compass, and its durability and portability (Cottrell and Mantzourani 2006:32-33). They elaborate further on this theme by suggesting that the Roma Gypsies and the Eastern European Jewish klezmorim probably played a large part in the transmission of the clarinet as a cultural artefact over such a wide area (ibid:34). In addition to the cultural transmission 
throughout Europe, Eastern Europe, the United Kingdom and English speaking countries, the clarinet has also been adopted by multitudinous diverse musical ensembles in such disparate areas as Zimbabwe, India, the Andes, and China for similar reasons (Pitfield 1996:18, Raval 2005:72, Perry 1998:66, Gillespie 2008:71).

Two of the clarinettists in the case studies performed cultural music to Wellington audiences; Urs Signer played the clarinet in a klezmer ensemble representing Ashkenazic Jewish identity, and Andrzej Nowicki represented his Polish identity in several of his concerts. The qualities of expression, extroversion and fluency which are found in klezmer clarinet improvisation helped Urs to create a 'musical conversation' amongst his fellow musicians, strengthening the dramatic, humorous, down-to-earth Jewish identity of the ensemble. In his role as ensemble leader and clarinettist, Andrzej chose to represent his Polish ethnicity in the Podroze-Journeys Concert in November 2009, written for the sixty-fifth anniversary of the arrival in New Zealand of Polish refugee children in 1944 . He achieved this by aligning the SMP Ensemble with the Polish community to celebrate works by Polish composers such as Gorecki, Lutoslawski and Penderecki, and by seeking support from the Polish Embassy, the Polish Charitable Trust, the Polish Children's Reunion Committee and the Polish Association of New Zealand.

In his book Ethnicity, Identity and Music, Martin Stokes refers to the way that music defines distinctive groups and establishes social and political systems. Stokes comments, 'I would argue therefore that music is socially meaningful not entirely but largely because it provides means by which people recognise identities and places, and the boundaries which separate them' (Stokes 1994:5). By performing in certain ensembles such as a klezmer or an ensemble performing Polish music, clarinettists help to establish ensemble identity and ethnic place, and maintain the boundaries of their 
ensemble through performing in a specific musical style. These clarinettists can play within these ethnic boundaries or transcend them to play in another cultural ensemble, depending on the circumstances. This is not such a common occurrence for the other members of the ensembles who tend to be permanently situated in their particular musical group.

\section{Ensemble Boundaries}

The third way that clarinettists are able to transcend boundaries is in the way they are able to move from ensemble to ensemble, playing in different musical styles and often playing different members of the clarinet or saxophone family. The four clarinettists in the case studies combined the leadership skills of expression, confidence and persuasion enabling them to influence their ensemble identity in the way that Bonnie Wade describes here,

One of the most significant uses to which people put music is to express an identity. Performers do this to establish an individual identity as a musician, of course, but music can also be emblematic of a group...The meaning of such music is highly situated and useful for purposes ranging from contestation to solidarity. (Wade 2004:16)

The case studies' ensembles represented examples of western art music, contemporary art music, jazz and klezmer each of which embody societal concepts of 'insider' and 'outsider' as they relate to musicians and audiences. The clarinettists in each of these ensembles helped to define the boundaries of the ensemble by performing in the correct stylistic way. Each clarinettist offered something slightly different to their ensemble and their audience. From an audience's perspective it could be argued that: in the SMP Ensemble Andrzej reflected his Polish identity and constructed new musical concepts, in the New Zealand Clarinet Quartet Debbie represented a choral style of instrumental chamber music, in the Blackbird Jazz Trio Greg reflected a jazz style which united audiences through creating an inclusive mood, and in the Klezmer Rebs 
Urs communicated Ashkenazic Jewish musical identity. What sets these clarinettists apart from other instrumentalists, is that they can also transcend these boundaries by moving in and out of a diverse range of ensembles, collecting and sharing musical and social meanings and transporting them to other groups. An example of this can be found in freelance clarinettist, Urs Signer, who has technical proficiency on several clarinets and saxophones and also styles of music. In his particular case, these styles include the pure and clearly articulated style of classical music, the improvisational styles of jazz and klezmer, the contemporary techniques of twentieth century art music and even the popular styles of reggae and hiphop. Whereas other instruments such as the oboe, the bassoon, the cello or the french horn for example generally play orchestral and chamber music within a western art music style, the clarinet is inherently a much more eclectic instrument.

The clarinet is used in so many stylistically different ensembles that the clarinettist in a leadership role could be described as a 'cross-pollinator' or conduit of musical concepts from one ensemble to another. A typical example of a 'clarinet personality' is to be found in this obituary of Jack Brymer, clarinettist with the London Symphony Orchestra for many years.

In his later years, Brymer broadened his musical activities, describing himself as a 'soloist, chamber music player, teacher, orchestral player, broadcaster, quizzer, lecturer, disc jockey, jazz fan, saxophone quartet leader, transport organiser and map-reader, agent, accountant and tax-gatherer for HM government.' (Emerson 2003)

The skills and knowledge that Brymer learned in each of the above roles allowed him a breadth and depth of stylistic techniques, knowledge of the clarinet and saxophone repertoire and an enhanced understanding of musical styles. His clarinet and saxophone performance also informed his roles as 'a broadcaster, quizzer, lecturer, disc jockey and jazz fan'. 


\section{Wellington City and Musical Diversity}

Wellington City supports musical diversity in many ways: in its compact geography, through the support of the Wellington City Council, and in the provision of a high number of eclectic music bars and venues. Wellington's compact geography supports pedestrian access to music venues in the central city and those travelling are provided for by the current parking and bus services. Wellington City Council provides a very supportive environment to the arts by generous sponsorship of facilities and events and by working in partnership with many community groups to provide access to a number of diverse performance venues. Unlike venues in other countries which are often specific to a musical style, Wellington venues specialise in offering an eclectic mix of musical styles which encourages cultural flow amongst the performers and the audience. An example of this is the Ruby Lounge which featured The Folk Festival Aftermath, Sam Manzanza and his Afrobeat Band, Ruby Sunday Jam Sessions, and the Klezmer Rebs from 25 October to 21 November 2010.

The strong development of cultural activity in Wellington is mainly due to the Absolutely Positively Wellington campaign initially promoted by the advertising agency Saatchi \& Saatchi in 1991. This campaign developed the concept that although Wellington had inclement weather, it also had many natural advantages such as its beautiful natural harbour surrounded with bush-clad hills and a well educated population who supported the arts (WellingtonNZ Absolutely Positively Wellington 2010). The campaign initiated by Mayor Fran Wilde (1992-1995) undertook to rebrand the city as a 'dynamic and prosperous place to live', and was further developed by Mayor Mark Blumsky (1995-2001), who continued to develop Wellington's positive image by setting up the Totally Wellington agency and the Wellington Regional Economic Development Agency. Mayor Kerry Prendergast (2001-2010) and the 
Wellington City Council continued to provide strategies and funding to support community facilities and many cultural and sporting events (Wellington Government Mayors 2010). Alongside this explosion of support for cultural events, Helen Clark, Prime Minister and Minister for Arts Culture and Heritage for three terms from 1999 2008, increased arts funding substantially, some of which was available for use in Wellington, the Capital City (NZ History Helen Clark 2010).

The City Councils' Events Strategy Goals include developing a diverse and vibrant year-round calendar of arts and cultural events, optimising use of city venues and assets, enhancing the profile of Wellington as the leading events destination in New Zealand and encouraging greater support and involvement in city events through partnerships with a diverse range of groups and business interests in the community (Wellington Government Policies Events 2010). Since the early 1990s the Wellington City Council also made substantial investments in Community Facilities such as the Westpac Stadium built in 1999 by Fletcher construction, and the TSB Bank Arena built in 1995 and extended in 2005 to seat 4,570 (New Zealand A to Z Westpac Stadium 2010).

My research confirmed that the Wellington City Council's 'Absolutely Positively Wellington' ethos has vastly improved the cultural life of the city, and the opportunities for musicians to perform in a variety of venues. The availability to hire many local church and community halls has enabled musicians to perform in a variety of central venues giving Wellington audiences access to an abundance of local, national and international concerts on a weekly basis.

\section{Wellington Venues}

For a small city Wellington provides its performers and audiences with an extremely large number of venues of varying sizes, in a range of styles. The larger 
performance venues include the Opera House, the Westpac St James Theatre, the Michael Fowler Centre, the Wellington Town Hall, the TSB Bank Arena and the Westpac Stadium, many of which also include smaller performance venues in their buildings. Added to this are the numerous community spaces available for hire such as the Thistle Hall, the Boatshed, the Newtown Community Centre Hall, the Overseas Terminal Event Centre, and the Loaded Hog Ballroom. Another very significant group of venues with excellent acoustics is the many churches and cathedrals used regularly for acoustic musical concerts, such as Old St Pauls in Thorndon, St Andrews on the Terrace, Wesley Church and Hall in Taranaki St, St Peters in Willis St, St Johns in Dixon St and St Mary of the Angels in Boulcott Street.

Outside venues include the Wellington Botanic Gardens, including an outdoors Dell, a Begonia House Foyer, and a Soundshell where the Council promotes summer festival music events. The two concert halls at the New Zealand School of Music, at the Massey and Kelburn campuses, are in continuous use by jazz and classical performance students, with most concerts available to the general public. The National Museum Te Papa has three performance spaces, the Civic Functions Venue Foyer, Icon, and the Soundings Theatre. The City Gallery, The Victoria University Modern Art Gallery and the National Library Reception Foyer all host performances, and Toi PonekeWellington Arts Centre also hosts many music, drama and dance performances (Venue Hire 2010, Wellington City Entertainment Venues 2010, Wellington Government 2010).

Many of the bars and restaurants in Wellington also operate as music venues, to support a wide range of music including rock, hiphop, drum and bass, jazz and world music. These bars include Bodega, The San Francisco Bath House, the Hotel Bristol, Mighty Mighty, Sandwiches, Happy, and Hope Bros (View Wellington 2010, Mukuna 
2010). Most of these venues offer music events several nights a week, often with an eclectic mix of styles and a crossover of audiences.

To illustrate the number and variety of musical events in Wellington, on 17 October 2010 on the Eventfinder web-site, the upcoming events in the Wellington pages featured one hundred and twenty venues, each advertising between one and thirteen events in the next fortnight. These included Happy which listed three, The St James Theatre which listed six, and the San Francisco Bath House which listed thirteen events. It is in this supportive cultural environment that the clarinettists in the case studies found numerous opportunities to perform with a variety of different ensembles.

\section{Clarinettists Transcend Ensemble and Venue Boundaries in Wellington}

The freelance clarinettists in the case studies moved with ease from ensemble to ensemble playing western art music, jazz, klezmer, tango, contemporary music and in Urs' case, hip hop and reggae styles. Transporting their musicianship and their personalities to each new ensemble, they transcended boundaries and acted as conduits of musical styles across diverse ensembles. Interestingly, the musical environment in Wellington mirrored this eclecticism by offering a variety of multi-purpose venues. The musical exchange was further enhanced by interconnecting with other ensembles at the many multi-purpose venues in Wellington.

The venues which were regularly used by the clarinettists in the case studies included formal performance venues such as the Wellington Town Hall, more informal venues such as the Boatshed and the many churches and cathedrals used regularly for acoustic musical concerts, such as Old St Pauls and St Andrews on the Terrace. Some of the clarinettists performed at the outdoors Wellington City Council summer festival events at the Soundshell and the Dell in the Wellington Botanic Gardens. As Andrzej, 
Urs and Deborah had associations with the New Zealand School of Music, they regularly gave concerts at the two Concert Halls (Venue Hire 2010, Wellington City Entertainment Venues 2010, Wellington Government 2010). Andrzej, Debbie, Urs and Greg also performed in some of the numerous Wellington bars and restaurants in mainly acoustic music ensembles including jazz, folk, experimental and world music. These venues included the San Francisco Bath House the Redhead Bar, Happy, and the Ruby Lounge which offered musical events several nights a week, in an eclectic mix of styles and to a crossover of audiences (View Wellington 2010, Mukuna 2010).

I observed that the clarinettists in the case studies generally had access to professionally managed medium-sized rehearsal and performance venues at reasonable rates in central Wellington. As an example, the churches offered attractive rooms with quality pianos, comfortable seating, efficient heating, adequate stage space, risers and generally good acoustics. Recording facilities were offered at several of the churches, musically literate and supportive audiences attended the concerts and a reviewer was often present to provide a critique of the specific ensemble. It was evident that websites and media promoted eclecticism in Wellington, enabling the clarinettists to promote their musical events at no cost in the arts pages of the Dominion Post, the free weekly newspapers the Wellingtonian and the Capital Times, and the web-sites Feeling Great, the official web-site of the Wellington City Council, Eventfinder, and WotzonNZ.com.

As an acoustic instrument which extends the voice, the clarinet is well-suited to performing in the central churches and the small bars in the city in a variety of ensembles. An example separate to the case studies was a jazz concert entitled Buddhist Rain at St Andrews on the Terrace on Friday 22 October 2010, featuring Norman Meehan on piano, Hannah Griffin with microphone, and Colin Hemmingsen 
on clarinet, bass clarinet, and soprano and tenor saxophones. The ensemble performed a series of poems by E.E Cummings and Bill Manhire, set to music by Norman Meehan, and the acoustic nature of the ensemble suited the highly resonant performance space in the church. This was a successful example of a jazz ensemble which would traditionally play in an informal setting, playing in a church environment in a relaxed and musical way, thereby reaching a different audience.

\section{Audience Reaction}

In Wellington the audiences for the clarinettists in the case studies came together in venues such as a concert hall, synagogue, restaurant, bar and a church. Audience members were an eclectic mix of individuals, couples or small groups who were known to one another, however across the groups there did not appear to have been much recognition. Something extraordinary took place in these performances where the initial disparate mood in the room was transformed and united through the interaction of the clarinettists with their audiences.

As John Moore comments in 'The Hieroglyphics of Love: The Torch Singers and Interpretation',

Something intangible escapes any mere assemblage of the lyrical skeleton. This missing component is the mood, which even recordings can only partly recapture, for the mood coalesces on the interface between the songs, with their evocative capabilities, and the audience, who invest both singers and songs with emotional associations which are formulated deep within the contemporary unconscious...(Moore 198:53)

In the way that singers create 'emotional associations' it was apparent that the clarinettists in the case studies also helped to create that 'intangible' mood, with 'evocative capabilities' to audiences in Wellington. 


\section{Eclectic Use of Venues}

Highlighting this eclecticism are two examples of venues where one of the clarinettists in the case studies played in a variety of different ensembles at the same venue.

\section{Andrzej Nowicki in St Andrews on the Terrace}

St Andrews on the Terrace church is available for hire to ensembles throughout the week, providing an environment which suits acoustic instruments very well. In 2010 Andrzej performed at this venue with the SMP Ensemble in March, the New Zealand School of Music Saxophone Orchestra on the E flat clarinet in May, the Wellington Youth Orchestra in October, and the Wellington Chamber Orchestra in November (Nowicki, 25 October 2010, pers.comm).

Debbie Rawson at the Michael Fowler Centre and the Wellington Town Hall Complex

This performing arts complex has several multi-purpose performing spaces, the MFC Main Concert Hall, the Renouf Foyer, and the Ilott theatre in the Wellington Town Hall building. In 2010 Debbie performed at the MFC with the NZSO in April, at times later in the year she performed in the Renouf Foyer at the MFC with her klezmer band, then with her saxophone quartet Saxcess, and finally in the Ilott Theatre with the New Zealand Clarinet Quartet (Rawson, 6 November 2010, pers.comm).

\section{Clarinettists as Conduits of Musical Styles}

In Wellington's rich and supportive cultural environment, there are very few barriers to clarinettists meeting for rehearsals and finding outlets for their performance on a regular basis. If they want to play at one of the local churches, community spaces, or bars, they can do so for a reasonable hire fee and take a percentage of the ticket sales. The Wellington City Council provides opportunities for performers to be associated with events such as the ASB Gardens Magic Festival, by administering the event, 
inviting local musicians and performers to apply for places, and offering sponsorship to help fund the event.

As is stated on the Wellington City Council web-site,

Every year Wellington city hosts a wide range of events, including concerts, sporting matches, live theatre and dance, exhibitions and festivals. The Council supports many of these events through grants, event coordination, and promotional activities. (Wellington Government Events 2010)

During the course of my research in 2010 I attended performances by Debbie Rawson at St Andrews on the Terrace, St Pauls Cathedral and the Adams Chamber Room at the NZSM, and Urs Signer at the Progressive Synagogue on Ghuznee St, the San Francisco Bathhouse and the Soundshell at the Wellington Botanic Gardens. I saw Andrzej Nowicki play at the Wesley Church, the Adams Chamber Room and St Andrews on the Terrace, and Greg Rogan at the Wellington Town Hall, the Redhead Bar and the St James Theatre. These are just a few of the venues where they regularly performed as they transcended boundaries and played in a wide variety of musical styles at different venues in Wellington. Deborah, Urs, Andrzej and Greg acted as expressive conduits of musical styles between ensembles in Wellington as they took part in many of the events listed above, as well as performing in their own ensembles.

\section{Conclusion}

Due to the inherent versatility of the instrument clarinettists are accepted into a diversity of ensembles which allows them to transcend gender, ethnic and ensemble boundaries, and to act as conduits of musical style. As Martin Stokes comments in his book Ethnicity, Identity and Music, '... it [a sense of identity] can also leap across boundaries and put into play unexpected and expanding possibilities' (Stokes 1994:24). My research revealed that clarinettists regularly 'leap across boundaries' and provide new possibilities for communication within their ensembles and to their audiences. 
The clarinettists in the case studies displayed certain 'blender' and 'soloist' musical traits, prompting the development of leadership qualities such as confidence, expression and the power of persuasion. The combination of these qualities and their ability to 'double' on other members of the clarinet and saxophone family, also led them to play in an eclectic mix of ensembles.

Clarinettists transcend gender boundaries because of the heterogeneous tone quality in each register of the clarinet, which embodies both 'male' and 'female' voices. In addition the compact size and the keywork mechanism affords players of both genders technical agility over the entire range of the instrument. This could help to explain why the clarinet is played in fairly equal numbers by both males and females, as was the case in Wellington in 2010.

Cultural ensembles celebrate and strengthen their identity by playing their particular style of music, both for their own members and for the general public. Clarinettists can play an appropriate musical style within cultural boundaries or transcend them to play in another cultural ensemble, acting as a conduit for musical exchange. Since its inception the clarinet has been written for extensively by western classical composers, and it has been assimilated into other musical ensembles such as folk, jazz, klezmer and military bands more recently (Hoeprich 2008:302-316). What sets clarinettists apart from other instrumentalists is that they vary their musical style according to the ensemble they play in. As an example of this Debbie will alter her musical style depending on whether she is playing classical, jazz, klezmer or tango music. In their roles as expressive conduits of musical styles, clarinettists are capable of transcending gender, ethnic and ensemble boundaries between diverse ensembles.

The musical exchange demonstrated by the clarinettists in the case studies was mirrored in Wellington's music venues, which facilitated cultural flows across 
performers and audiences. I observed that for a city of 195,500, Wellington offers its citizens regular access to a multitude of diverse cultural events which compares favourably with other cities in New Zealand, and even compared with its Australian cultural counterpart Melbourne, with its population of 3,900,000.

It is the process of musical exchange which makes the clarinet an exceptional and fascinating instrument which is capable of capturing the imagination of its players. Other instrumentalists such as violinists, oboe players, or trombonists tend to remain in one or two ensembles, whereas clarinettists are fortunate to have many stylistic opportunities open to them. In this process they meet and perform with a variety of musicians from different musical and cultural backgrounds, to a wide spectrum of audiences, acting as expressive conduits of musical styles in and between diverse ensembles. 


\section{CHAPTER FIVE: Conclusions}

As a clarinettist and a singer I was inspired to discover some new insights into this topic, because they might enhance the performance of clarinet repertoire in its diversity of musical styles, contribute to the understanding of the clarinet player's socio-musical role in an ensemble, and also encourage composers to write new 'vocal' works for the family of clarinets. Throughout this thesis I have given many examples of ways in which the clarinet acts as an extension of the voice and expressive conduit of musical styles in and between diverse ensembles. As individual cultural beliefs and attitudes reveal themselves immediately through the vocal music performed in a specific culture, singers have a special role to play in this process. Through exploring the links between singers and clarinettists, I discovered that clarinet players 'sing' the melodic line using their mouthpiece and reed, compared with singers who uses their larynxes to create vocal tone. It became apparent that the deeply vocal quality of the clarinet affords it many opportunities not only to extend, but to partner, imitate, amplify, mimic and replace the voice in many culturally diverse ensembles.

Research into the main theme of vocal-clarinet links, with the secondary themes of the clarinettist's musical identity within their own ensemble and between diverse ensembles provided the platform for my research, and I built on the work of several authors to provide further insight into these concepts. Kevin Dawe asserts that we have much to gain by studying the role of instruments as they help to shape societies and cultures, as he comments

I argue here that the study of musical instruments is as much about the study of ethnomusicology, anthropology, and cultural studies as it is about the study of physics, wood science, and biological systematics. It has to be, if we are to gain a better understanding of the affecting presence of musical instruments in human music making and of the ways in which they (and their makers and performers) help to shape societies and cultures, and vice versa (Dawe 2003:275). 
It became apparent through my ethnographic fieldwork with the four clarinettists in the case studies: Andrzej Nowicki in contemporary art music, Debbie Rawson in western art music, Greg Rogan in jazz, and Urs Signer in klezmer music, that several distinctive features were present in clarinet playing. Interestingly, in the interviews all the clarinettists in the case studies talked about how they 'sing' through their clarinets in their particular style of music. Due to the design of the instrument, the clarinet has an immediate connection with the sonority of the voice, and by changing the shape of the oral cavities, and the choice of mouthpiece and reed, its 'vocal' tone can become very flexible and expressive. The clarinet is capable of mirroring vocal qualities, such as singing melodic lines, (vowel sounds are cantabile, consonants are staccato), crying, growling, wailing, rolling an 'r', playing glissandi, rapid 'chattering' in fast passages, changing tone colour and performing vibrato. Due to the wide range and the heterogenous tonal quality in its three registers, the clarinet embodies both a 'male' voice and a 'female' voice, unlike other members of the woodwind family. With this in mind I found Elizabeth Wood's concept of 'the Sapphonic voice' (Wood 2002:83) intriguing, as she described the dramatic soprano in these mixed gender terms, which corresponded exactly to the tonal qualities of the clarinet. In my experience many similarities between singers and clarinettists are also present in bodymind integration, such as the importance of balanced posture and well supported abdominal breathing to produce a resonant tone.

Clarinettists Andrzej, Debbie, Greg and Urs each displayed their ability to either blend in with other instruments, or to be a soloist and play very fast technical passages. As a result of these 'blender-soloist' personality traits, they took a leadership role in their ensembles and often carried the melodic or improvised line to the audience, to extend, partner, imitate, amplify or replace the voice. Andrzej, Debbie, Greg and Urs 
also all took on a leadership role in their ensemble by initiating a vision for the group, and by providing repertoire and administration to support their vision.

It became apparent during the research that each clarinettist acted as an expressive conduit of either Polish, New Zealand, African American or Ashkenazic Jewish music in their particular ensemble, although they showed their diversity by being capable of performing in different styles in other ensembles. As an example of this diversity, a freelance clarinettist may play in a classical chamber music ensemble at a lunchtime concert, a klezmer ensemble at an afternoon wedding and a jazz ensemble for an evening concert. By comparison, the other members of those ensembles tend not to move so readily from their ensemble, such as string players in an orchestra or brass players in a jazz band. It seems to me that this flexibility in style switching, helps to shape the clarinettist's identity as an individual who is also flexible, and open to learning a wide variety of music, as well as meeting musicians from many different class and cultural backgrounds. In my experience, playing in a variety of ensembles allows clarinettists to transcend gender, ethnic, class and ensemble boundaries and to act as conduits of musical styles across ensembles. Jack Brymer illustrates how this is reflected in the professional demands of a clarinettist in his comment,

It is also important that at this stage the pupil should be introduced to the full range of possibilities a present-day job will offer and demand. He may have to play in a jazz style of one form or another; he may need to consider becoming something of a multi-instrumentalist by 'doubling' or even 'trebling' [on a variety of woodwind instruments]' (Brymer 1976: 192).

Due to their 'vocal' tone, versatility, small size, low cost and ready availability clarinets have been adopted by a variety of ensembles. Tuneful enough to be played solo, yet adding a rich sonority to ensembles of string, woodwind or brass instruments, the multifaceted character of the clarinet blends in to nearly every western musical 
ensemble, apart from the string quartet (and even then it can play as a soloist in works such as the Mozart Clarinet Quintet).

From an historical perspective, since its invention by Joseph Denner in 1700 composers have recognised that the clarinet offers opportunities for an extension of vocal expression. From the earliest baroque composers such as Vivaldi and Molter, to the classical composers Weber, Stamitz and Crusell, composers wrote lyrical melodic lines for the clarinet which often partnered or replaced the voice. Mozart also wrote exceptional 'vocal' lines for the clarinet in his Clarinet Concerto, Trio and Quintet, as well as in many symphonies and operas (Brymer 1976: 211-245). Ingrid Pearson comments that 'As Mozart's clarinet writing betrays, he did reserve a special fondness for the chalumeau register, and his use of the instrument in amorous contexts in Cosi fan tutte, and Don Giovanni and Le Nozze di Figaro has not gone unnoticed' (Pearson 1998:3). As a performer I have also experienced this 'vocal' approach to orchestral and chamber music composition for the clarinet in chamber music by Mozart, Brahms, Schubert and Schumann, and the twentieth century composers Milhaud, Stravinsky, Debussy, Poulenc and Gershwin (ibid.). Contemporary clarinet techniques used in western art music allow the performer to imitate many aspects of the voice and so convey deeply human emotions.

Examples of the vocal-clarinet links can be found in many countries in the world. Not only has the clarinet had a very interesting journey in the world of western classical art music, but its migration across territorial boundaries at the end of the nineteenth century meant that it often replaced the traditional wind instruments of the region. At the time of writing, ensembles in ethnically mixed regions such as Serbia, Romania, Bulgaria, Albania and Macedonia often feature the clarinet as the main melody instrument (Balkan Blues 1999). These clarinettists perform in songs and dance music 
from their culture and the partnering of the voice with the clarinet gives the music a deeper emotional signification, as it becomes a place to re-affirm their musical values.

Many interesting articles on clarinet performance in different countries are featured in The Clarinet, the Journal of the International Clarinet Association. These include articles on clarinettists in ensembles in South Africa, Senegal, Brazil, India, Spain, Russia, Mongolia, Moravia, the Andes, as well as the European countries, the United States, Australia, Canada and New Zealand. Further ethnographic research on a clarinettist in one of the ensembles in these countries would reveal more in-depth information about their specific role as an expressive extension of the voice and conduit of musical styles in diverse ensembles. Similarly research into the socio-musical context of instruments other than the clarinet would add significantly to the ways in which musical instruments contribute to the culture of a society. By necessity this thesis has focussed on the vocal-clarinet links at a physiological level to ascertain how they relate to the role of the clarinet in various ensembles, however further extensive research into the vocality of different cultures would also be a fascinating and worthwhile study.

My wish is that this research is of interest to scholars such as musicologists and anthropologists, and in particular to clarinettists, who may benefit by understanding the vocal links in their own performance, and how clarinettists function in a socio-musical context. Clarinet students may find the section on bodymind integration useful for their musicianship, their physical well-being and the reduction of repetitive strain injuries such as OOS. The section on clarinet design illustrates how different combinations of instruments and mouthpieces afford clarinettists the ability to individualise their tone qualities. An excellent outcome would be for composers to use the details of the voiceclarinet comparisons, to help inform new 'vocal' compositions for the instrument. The research shows that due to the versatility and flexibility of the instrument, clarinettists 
are accepted into a diversity of ensembles. This allows them to transcend gender, ethnic, and ensemble boundaries, to take on leadership roles and to act as expressive conduits of musical styles in and across diverse ensembles. The outcome of the research highlights the intersection between the physiological relationship between the voice and the clarinet and the scholarship on musical identity. 


\section{Appendix A}

\section{List of Participants}

Edwards Flora

2010 Interview, 7 September

Moscovitz Dave

2009 Interview, 20 April

Nowicki Andrzej

2009 Interview, 30 Sept

Email correspondence, 15 October

2010 Interview, 3 June

Interview, 26 June

Email correspondence, 24 October

Email correspondence, 25 October

Interview, 28 October

Rawson Deborah

2010 Interview, 4 August

Email correspondence, 4 September

Email correspondence, 10 September

Phone interview, 4 November

Email correspondence, 4 November

Email correspondence, 6 November

Rogan Greg

2009 Interview, 16 December

2010 Interview, 1 June

Email correspondence, 22 June

Email correspondence, 15 August

Email correspondence, 30 August

Interview, 25 October

Signer Urs

2009 Interview, 16 May

2010 Email correspondence, 22 July

Email correspondence, 3 August

Email correspondence, 20 August

Email correspondence, 20 September

Email correspondences, 9 November

Email correspondence, 10 November

Weinstein David

2009 Interview, 27 March 


\section{Appendix B}

\section{Questionnaire for Informants}

This questionnaire was given to the clarinettists in the case studies at our first meeting in order to discover important background information and to establish some parameters for further research in this area.

1. What do you enjoy about playing in this musical ensemble?

2. Do you think there are any links between vocal and clarinet tone production?

3. Do you think your cultural heritage influences your clarinet playing?

4. Which emotions or attitudes do you try to communicate to your audience?

5. Can you name your favourite performance in 2010 ? Why is that?

6. Which other musical styles do you play on the clarinet?

7. Which other instruments do you play?

8. Which clarinettists inspire you?

9. How is your ensemble organised and how do you find suitable repertoire?

10. Which music has recently been of interest to you as a clarinettist? 


\section{Appendix C}

Extract from music score of The Shepherd on the Rock (Der Hirt auf dem Felsen) by Schubert (Erato.uvt.nl 2010).

Der Hirt auf dem Felsen.

Nach Wilh. Müller's Gedicht „Der Berghirt”

Für eine Singstimme mit Begleitung von Clarinette und Pianoforte

Schubert's Werke.

\section{FRANZ SCHUBERT.}

Serie 20. No b61.

Für Frau Anna Milder-Hauptmann.

Erachionen sls Op.129.
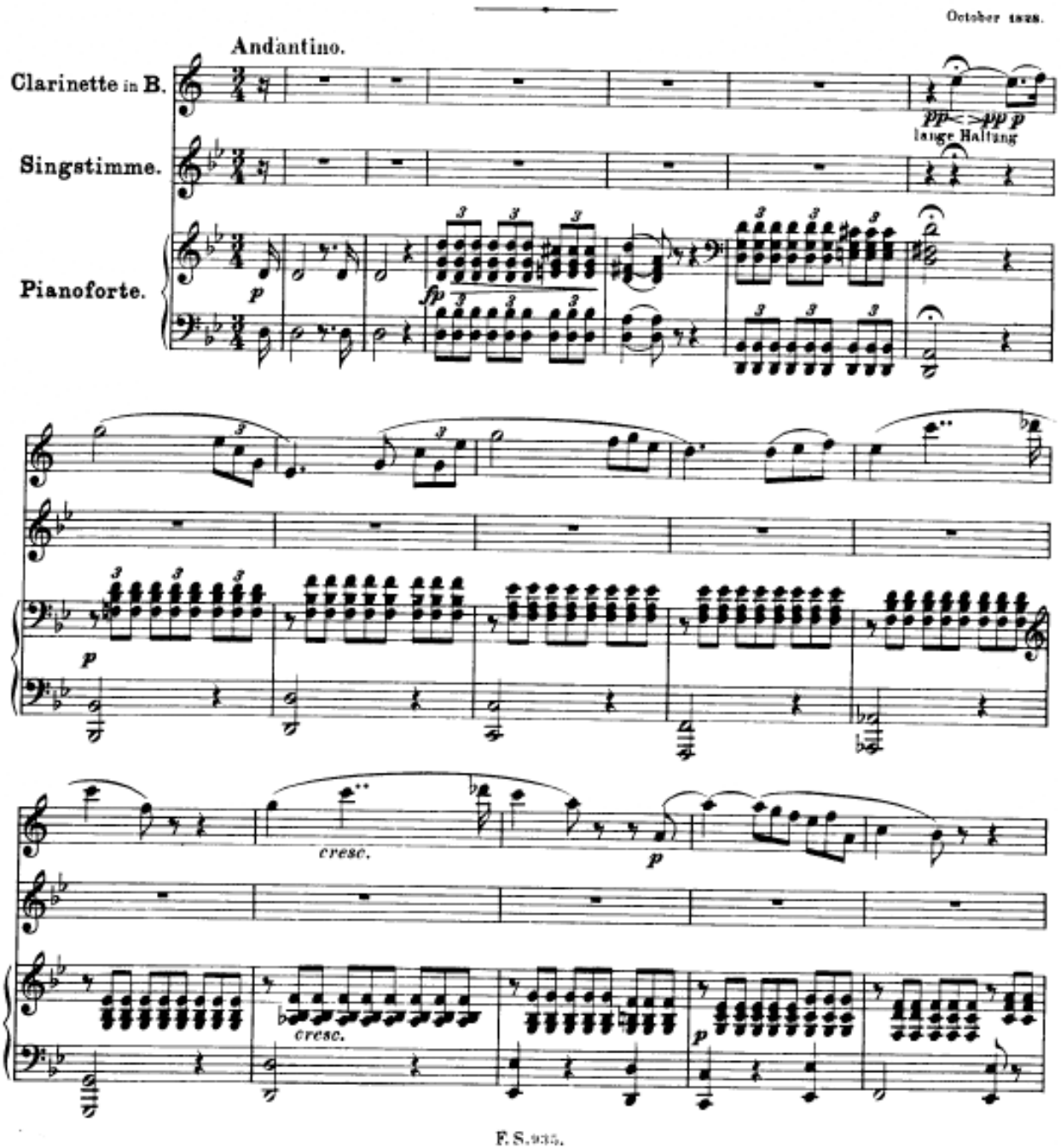

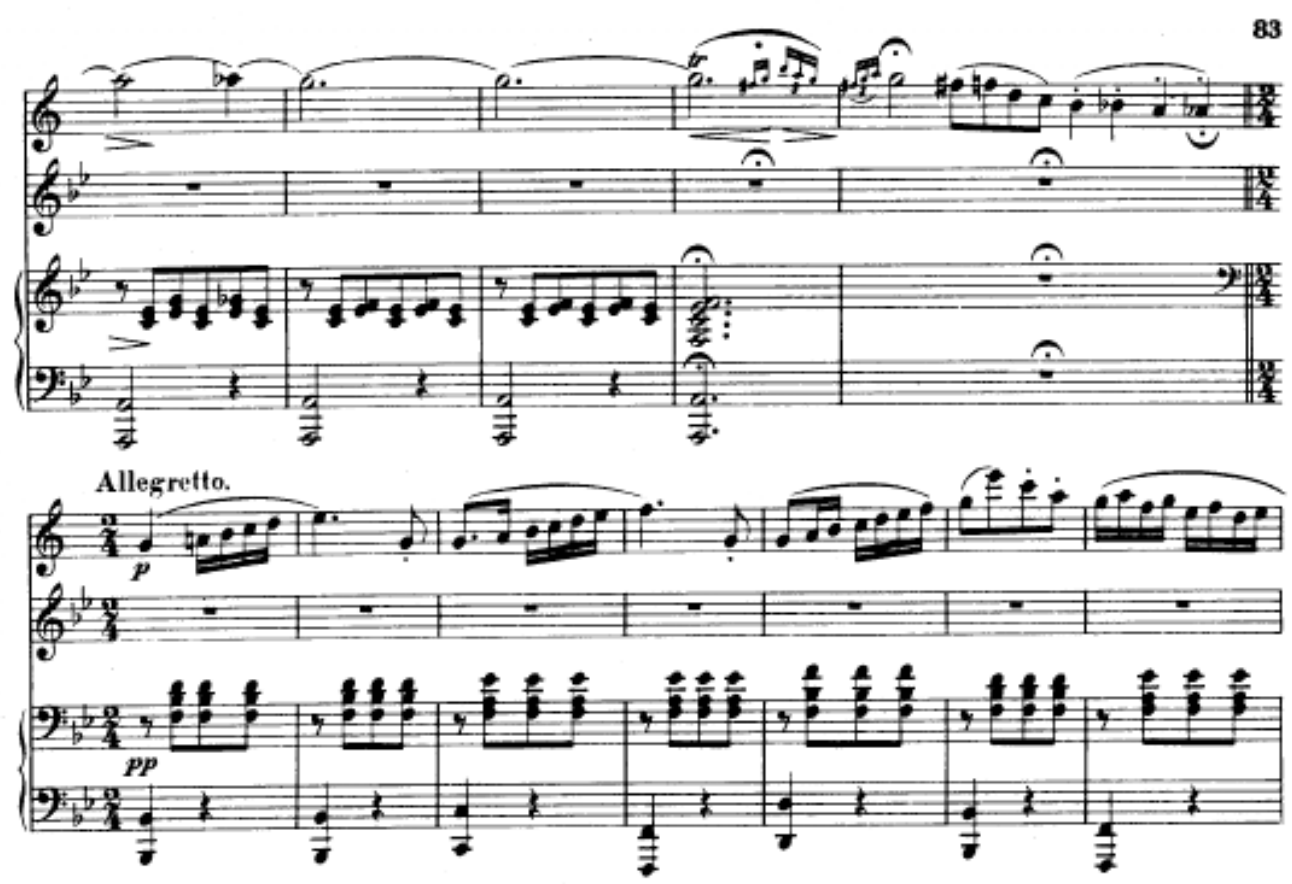

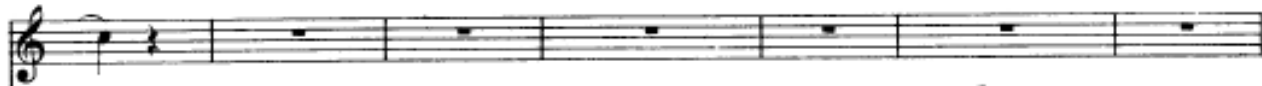

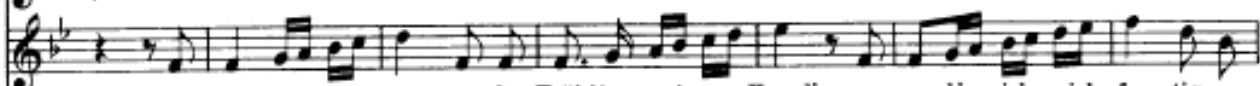
Der Früh.ling will kom_men,der Frühling, mei.ne Freud; nun mach_- ich mich fer - tigzum

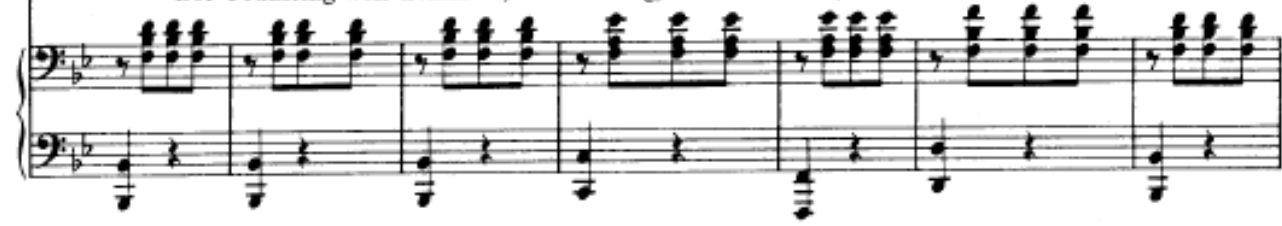
(a) 
$6+2=+1=$

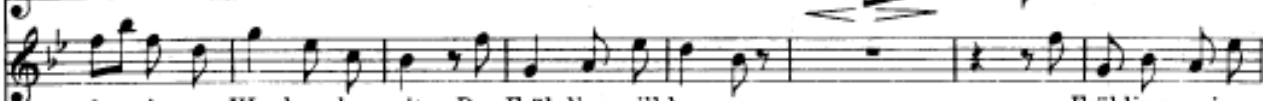
fer - tig zum Wandern be . reit. Dur Früh_ling will kommen, o Frühling, meine

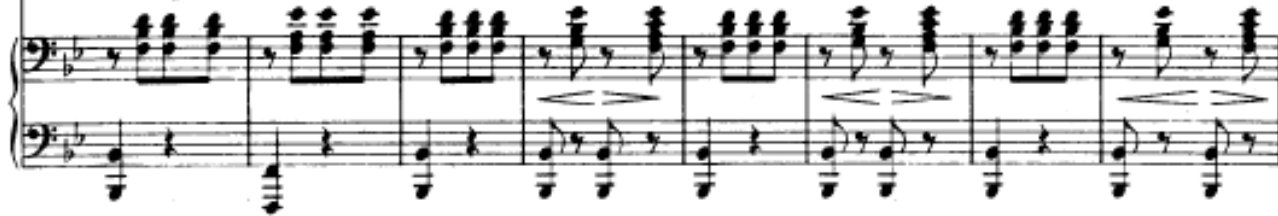

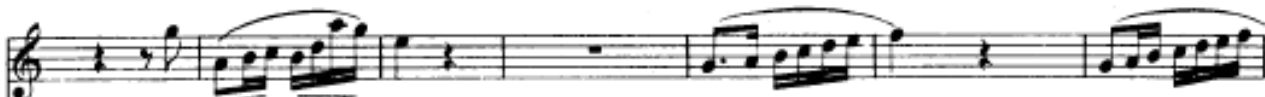

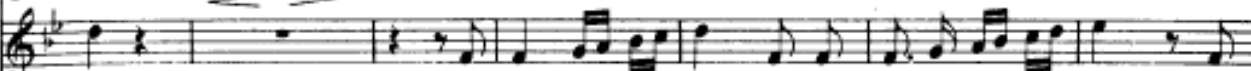
(2) $6: 1$ I

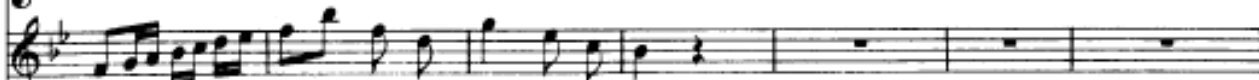

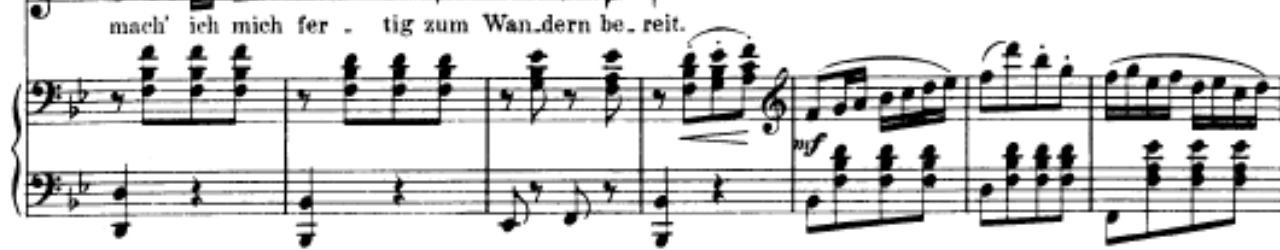
(2) F. S. 935 . 


\section{Bibliography}

Aitken, Paul and Malcolm Higgs

2010 Developing Change Leaders. Oxford: Elsevier Ltd.

Anatomy and Physiology of Voice Production

2004 www.voiceproblem.org/anatomy/index.asp (accessed 20 March 2010).

Auckland University Press

2010 http://web.auckland.ac.nz/uoa/aup/book/the-poems-of-lauris-edmond.cfm (accessed 28 August 2010).

Bohlman, Philip V

2004 The Music of European Nationalism. CD. Santa Barbara, California: ABC-CLIO.

Bouhuys, Arend

1969 Physiology and Musical Instruments. Nature 221: 1199-1204.

Brymer, Jack

1976 Clarinet. London: Macdonald and Jane's.

Burrows, David

1989 Singing and Saying. The Journal of Musicology 7 (3): 390-402.

Button, John

1986 Kodukotus. Debbie Rawson. CD.

The Roman Catholic Cathedral, Wellington, New Zealand.

Canning, Lisa

n.d. http://www.lisasclarinetshop.com/site/epage/74206_800.htm9

(accessed 16 August 2010).

Clayton, Michael and Terence O'Neill-Joyce

2006 Judy Bellingham, Terence Dennis, Debbie Rawson. CD.

Marama Hall, Dunedin.

Cottrell, Stephen and Evangelina Mantzourani

2006 "The Clarinet and Its Players in Eastern Europe and Greece." In The Versatile Clarinet. pp. 31-46. New York: Routledge.

Cox, Nicholas

1995 "The Professional Clarinettist." In The Cambridge Companion to the

Clarinet, edited by Colin Lawson, pp.150-162. Cambridge: Cambridge University Press.

Dawe, Kevin

2003 "The Cultural Study of Musical Instruments." In The Cultural Study of Music, edited by Martin Clayton, Trevor Herbert and Richard Middleton. pp. 274-283. New York and London: Routledge.

De Alcantara, Pedro

1997 Indirect Procedures: A Musician's Guide to the Alexander Technique.

Oxford: Clarendon Press.

Diction Domain

$2011 \mathrm{http} / /$ www.dictiondomain.com/cgibin/dd/dd_display.pl?action=show\&sp=ipa (accessed 5 Dec 2010).

Dychtwald, Ken

1978 Bodymind. London: Wildwood House Limited.

Edwards, Brent

2002 Louis Armstrong and the Syntax of Scat. Critical Inquiry 28 (3): 618-649. 
Emerson, June

2003 Jack Brymer. The Guardian Obituaries. Thursday 18 September.

Eventfinder

2010 http://www.eventfinder.co.nz/whatson/events/wellington (accessed 17 October 2010).

Feldenkrais

2007 http://www.feldenkrais.org.nz/Site/About_Feldenkrais/Default.aspx (accessed 6 April 2010).

Feldenkrais, Moshe

1949 Body and Mature Behaviour. Tel Aviv, Israel: ALEF Ltd.

Font, Oscar

n.d. http://usuarios.multimania.es/albertsystem (accessed 16 August 2010).

Foster, Roland

1935 Vocal Success. NSW, Australia: Chappell Music.

Fox, Christopher

2006 "The Extended Clarinet: Four Contemporary Approaches." In The

Versatile Clarinet, edited by Roger Heaton, pp.15-29. New York:

Routledge.

Fritz, Claudia and Joe Wolfe

2005 How Do Clarinet Players Adjust The Resonances of Their Vocal Tracts For Different Playing Effects? Acoustical Society of America 118 (5): 33063315.

Garnett, Liz

2005 Choral Singing as Bodily Regime. International Review of the Aesthetics and Sociology of Music 36 (2): 249-269.

Gibson, Chris

2007 Current Trends in Treating the Palatal Air Leak. The ClarinetFest Archive 30 (http://www.clarinet.org/clarinetFestArchive.asp?archive=30)

Gibson, O. Lee (accessed 10 April 2010).

1994 Clarinet Acoustics. Bloomington: Indiana University Press.

Gillespie, James

2008 The 2007 China International Clarinet And Saxophone Music Festival, Beijing, China. The Clarinet. 35 (2): 71-73.

Grafton-Green, Michael

1983 Romanza. Debbie Rawson. LP and Cassette Tape.

Radio NZ Studios, Wellington, New Zealand.

Grant-Williams, Renee

2002 Voice Power. New York: AMACOM American Management Association. Green, Lucy

2002 "On Musical Experience." In Music, Culture, and Society, edited by Derek

Harker, Brian

B. Scott, pp.158-159. Oxford: Oxford University Press.

2003 Louis Armstrong and the Clarinet. American Music 21 (2): 137-158.

Harris, Paul

1995 "Teaching The Clarinet." In The Cambridge Companion to the Clarinet, edited by Colin Lawson, pp.123-133. Cambridge: Cambridge University Press. 
Head and Neck Resonators and Articulators in Vocal Production

2010 www.websters-online-dictionary.org (accessed 20 March 2010).

Heaton, Chris

2006 "Jazz Clarinet Performance." In The Versatile Clarinet, edited by Roger Heaton, pp. 51-73. London: Routledge.

Heaton, Roger

1995 "The Contemporary Clarinet." In The Cambridge Companion To The Clarinet, edited by Colin Lawson, pp. 163-183. Cambridge: Cambridge University Press.

Heizmann, Klaus

2003 Vocal Warm-ups. Mainz, Germany: Schott.

Heman-Ackah, Yolanda

2005 Physiology of Voice Production: Considerations for the Vocal Performer. Journal of Singing 62 (2): 173-176.

Hoeprich, Eric

2008 The Clarinet. New Haven: Yale University Press.

Klezmer Music in a Few Words

2010 http://borzykowski.users.ch/EnglMCKlezmer.htm (accessed 22 July 2010).

Klezmer Rebs

2007 http://klezmer.co.nz/ (accessed 4 April 2009 and July 22 2010).

Lieberman Philip, Edmund Crelin and Dennis Klatt

1972 Phonetic Ability And Related Anatomy Of The Newborn And Adult Human, Neanderthal Man And The Chimpanzee. American Anthropologist New Series, 74(3): 287-307.

McLean, Gavin

2010 'Helen Clark', URL: http://www.nzhistory.net.nz/people/helen-clark, (Ministry for Culture and Heritage), updated 12-Jul-2010

Merriam, Alan (accessed 6 October 2010).

1964 The Anthropology of Music. Evanston, Illinois: Northwestern University Press.

Middleton, Richard

1990 Studying Popular Music. Milton Keynes: Open University Press.

Moore, John

1989 The Hieroglyphics of Love: The Torch Singers and Interpretation. Popular Music 8 (1):31-58.

Mukuna

2010 http://www.mukuna.co.nz/wellington/central/venues.htm (accessed 10 November 2010)

Nettl Bruno

1983 The Study of Ethnomusicology: Twenty-Nine Issues and Concepts. Chicago: University of Illinois Press.

2005 The Study of Ethnomusicology: Thirty-One Issues and Concepts. Second Edition. Chicago: University of Illinois Press.

New Zealand Clarinet Society

n.d. www.nzclarinetsociety.org.nz/scene/wellington/article_1.php (accessed 15 September 2010). 
New Zealand Search

2010 http://www.nzs.com/region/wellington/wellington-/entertainment/venues/ (accessed 10 November 2010).

Nowicki, Andrzej

2009 Podroze-Journeys by the SMP Ensemble. CD. Wellington, New Zealand.

Parr, Clayton

2006 Eight Simple Rules for Singing Multicultural Music

Music Educator's Journal 93 (1): 34-37

Pay, Anthony

1995 "The Mechanics of Playing the Clarinet." In The Cambridge Companion To The Clarinet, edited by Colin Lawson, pp. 107-122. Cambridge: Cambridge University Press.

Pearson, Ingrid

1998 Delicacy, Sentimentality and Intimacy: The Chalumeau as 'Signifier' International Clarinet Association Archives, 1-3. http://www.clarinet.org/fests/1998/pearson.asp (accessed 30 November 2010).

Perry, Timothy

1998 Clarinets in the Andes and Beyond. The Clarinet 25 (3): 66-68.

Pitfield, Spencer

1996 The Clarinet in Zimbabwe. The Clarinet 23 (3): 18-19.

Positively Wellington Tourism

2010 http://www.wellingtonnz.com/about_us/absolutely_positively_wellington (accessed 5 October 2010).

Radio New Zealand

2010 http://www.radionz.co.nz/concert/programmes/soundlounge/20100420 http://www.soundarchives.co.nz/ Peter Adams (accessed 12 September 2010).

Raval, Shanti

2005 The Clarinet in India: A Journey From the Village to the Concert Hall. The Clarinet 32 (4): 72-76.

Reeve, Matthew

2005 The Bernoulli Effect and Vocal Fold Vibration. Voicesource 151 (accessed 7 March 2010).

Rice, Albert

1992 The Baroque Clarinet. Oxford: Clarendon Press.

Rice, Timothy

2010 Disciplining Ethnomusicology: A Call for a New Approach. Ethnomusicology 54 (2): 322-323.

Rubin, John S., Lesley Mathieson and Ed Blake 2004 Journal of Singing 60 (3): 271-275.

Scholze, Christian, Christoph Herrmann, and Jean Trouillet 1998 Reve et Passion: The Soul of Klezmer. CD. Network Medien GmbH.

Scholzakis, Christos and Jean Trouillet 1999 Balkan Blues. CD. Network Medien GmbH.

Scoop Independent News

$2010 \mathrm{http} / /$ www.scoop.co.nz/multimedia/tv/entertainment/41405.html (accessed 17 Oct 2010).

Shepherd, John and Peter Wicke

1997 Musical and Cultural Theory. Cambridge: Polity Press. 
Shepherd on the Rock (Der Hirt Auf Dem Felsen)

2010 http://erato.uvt.nl/files/imgInks/usimg/f/f2/IMSLP05411-Schubert_DerHirt_Auf_Dem_Felsen_D965.pdf

Signer, Urs

2009 Songs of the Young Anarchist. CD. Wellington, New Zealand.

Slobin, Mark

1992 Micromusics of the West: A Comparative Approach. Ethnomusicology 36 (1): $1-87$.

Slobin, Mark

2000 Fiddler on the Move. Oxford: Oxford University Press.

SMP Ensemble

2009 http://www.smpensemble.com/pastconcerts. (accessed 7 June 2010).

Sounz

2010 http://sounz.org.nz/contributor/performer/1778

(accessed 12 September 2010).

Stein, Keith

1958 The Art Of Clarinet Playing. Illinois: Summy-Birchard Company.

Stier, Charles

n.d. http://wurlitzerclarinetsamerica.com (accessed 16 August 2010).

Stokes, Martin

1994 Ethnicity, Identity and Music. Oxford: Berg Publishers.

Sundberg, Johan

1987 The Science of The Singing Voice. Illinois: Northern Illinois University Press.

Theatre Review

2010 http://www.theatreview.org.nz/reviews/production.php?id=800

http://www.theatreview.org.nz/reviews/production.php?id=1660

http://www.theatreview.org.nz/reviews/production.php?id id=2015

(accessed 12 September 2010).

Trollinger, Valerie

2005 Performing Arts Medicine And Music Education: What Do We Really

Need To Know? Music Educators Journal 9 (2): 42-48.

Turley, Alan

1995 The Ecological and Social Determinants of the Production of Dixieland Jazz in New Orleans. International Review of the Aesthetics and Sociology of Music 26 (1): 107-121.

Urban, Greg

2002 Metasignaling and Language Origins in American Anthropologist 104 (1): 233-246.

Venuehire Wellington

2010 http://www.venuehire.co.nz/wellington-venues-1.htm (accessed 20 October 2010).

View Wellington

2010 http://www.viewwellington.co.nz/pubsandbars/live-music-bars-inwellington-recommended-wellington-395.html (accessed 20 October 2010).

Wade, Bonnie

2004 Thinking Musically:Experiencing Music Expressing Culture. Oxford:

Oxford University Press. 
Wade, Bonnie and Patricia Campbell

2009 Thinking Musically:Experiencing Music, Expressing Culture CDs 1 and 2.

Oxford: Oxford University Press.

Weinstein, David

2005 Klezmer Rebs Live at the Wellington Folk Festival. CD. Wellington, New Zealand.

2008 Klezmer Rebs, Just Add Schmaltz. CD. Porirua and Featherston, New Zealand.

Wellington Government

2010 http://www.wellington.govt.nz/services/history/mayors/1921.html (accessed 17 Oct 2010).

2010 http://wellington.govt.nz/about/overview/index.html (accessed 17 Oct 2010).

2010 http://www.wellington.govt.nz/services/events/index.html (accessed 17 Oct 2010).

2003 http://www.wellington.govt.nz/search/?cache\&url=www.wellington. govt.nz/plans/policies/events/pdfs/2003events.pdf (accessed 17 Oct 2010).

2010 http://www.wellington.govt.nz/plans/policies/events/index.html (accessed 17 Oct 2010).

2010 http://www.wellington.govt.nz/plans/index.html (accessed 17 Oct 2010).

2010 http://www.wellington.govt.nz/services/venues/index.html (accessed 17 October 2010).

White, Christopher and White Dona

2001 Commonsense Training For Changing Male Voices. Music Educators Journal 87(6): 39-43+53.

Wood, Elizabeth

2002 “On the Sapphonic Voice." In Music, Culture, and Society, edited by Derek B. Scott, pp. 84-87. Oxford: Oxford University Press.

Zakian, Lee

n.d. http://www.jlpublishing.com/ClarinetHistory.htm (accessed 16 August 2010). 